\title{
PHILOSOPHICAL EXPLORATIONS ON ENERGY TRANSITION
}

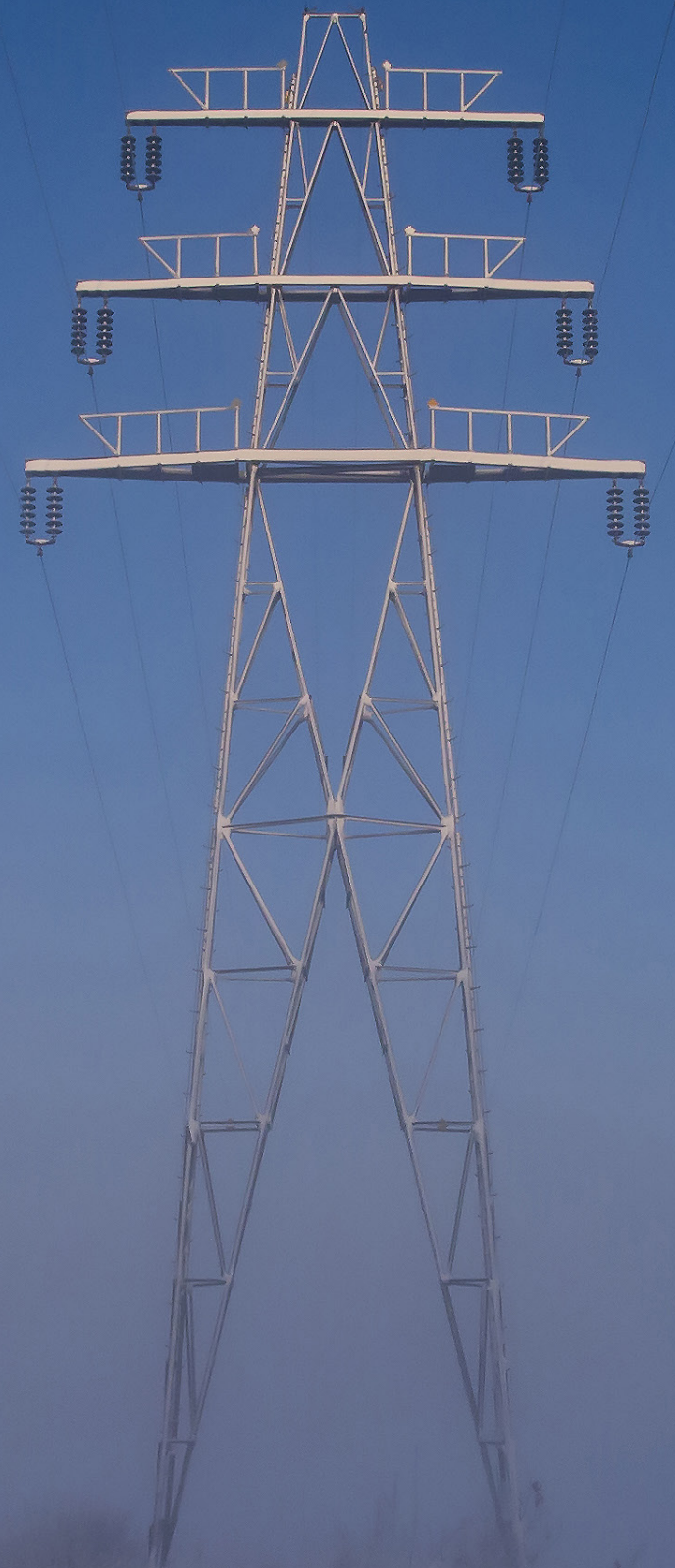

ROBERT-JAN GEERTS 

Philosophical explorations on energy transition

Robert-Jan Geerts 


\section{Thesis committee}

\section{Promotors}

Prof. Dr H.G.J. Gremmen

Personal chair, Philosophy Group

Wageningen University

Prof. Dr G.T.P. Ruivenkamp

Associate Professor, Rural Sociology Group

Wageningen University

Extra-ordinary professor of Humanization of Technology

University of Humanistic Studies, Utrecht

\section{Co-promotor}

Dr J.G.M. Jacobs

Assistant Professor, Philosophy Group

Wageningen University

\section{Other members}

Prof. Dr C. Leeuwis, Wageningen University

Prof. Dr C. Mitcham, Colorado School of Mines, Golden, USA

Prof. Dr S. Roeser, Delft University of Technology

Prof. Dr P.P.C.C. Verbeek, University of Twente, Enschede

This research was conducted under the auspices of the Wageningen School of Social Sciences (WASS). 


\title{
Philosophical explorations on energy transition
}

\author{
Robert-Jan Geerts
}

Thesis

submitted in fulfilment of the requirements for the degree of doctor at Wageningen University

by the authority of the Rector Magnificus

Prof. Dr A.P.J. Mol,

in the presence of the

Thesis Committee appointed by the Academic Board

to be defended in public

on Monday 23 January 2017

at $1: 30$ p.m. in the Aula. 


\section{Robert-Jan Geerts}

Philosophical explorations on energy transition, 172 pages

PhD thesis, Wageningen University, Wageningen, NL (2017)

With references, with summary in English

ISBN: 978-94-6343-048-7

DOI: $10.18174 / 400887$ 


\section{Table of contents}

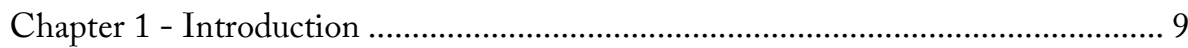

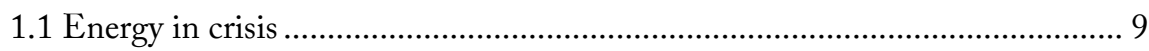

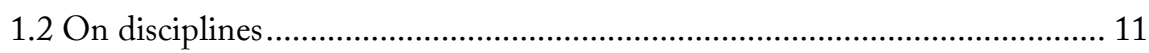

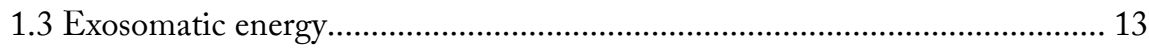

1.4 The impending energy transition ............................................................ 15

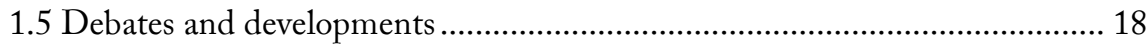

1.6 Research questions .................................................................................. 20

1.7 Methodology …………………………………………………………. 22

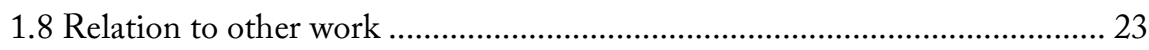

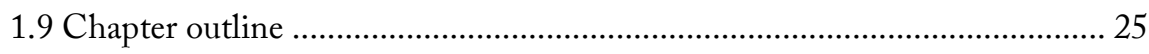

Chapter 2 - Towards a Philosophy of Energy ……………………………............. 31

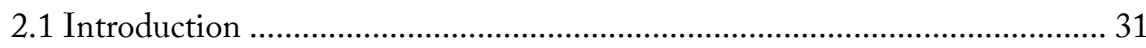

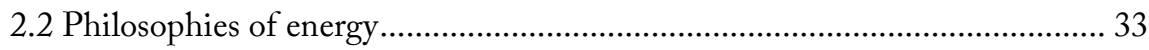

2.3 An empirical turn .................................................................................... 45

2.4 Flux and potentiality................................................................................ 47

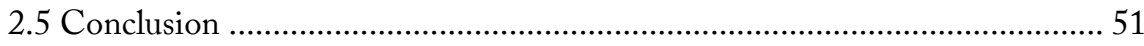

Chapter 3 - Self Practices and the Experiential Gap: An Analysis of Moral Behavior around Electricity Consumption......................................................................... 55

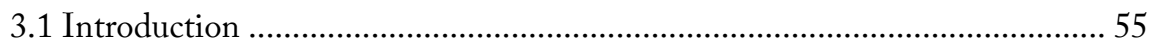

3.2 The Experiential Gap.......................................................................... 56

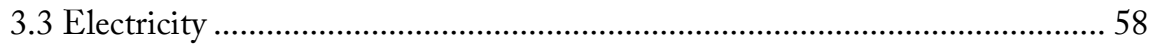

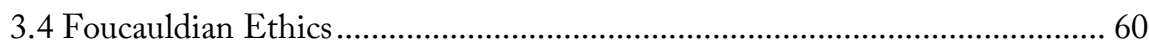

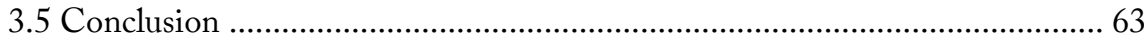




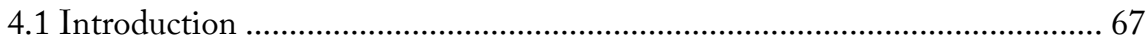

4.2 Discussions on possibility: boundless consumerism and eco-frugality .......... 68

4.3 The desirability of the possible: implicit understandings of a good energy

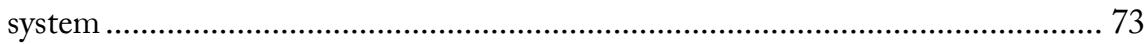

4.4 The rejection of the scarcity discourse by qualitative abundance ................. 81

4.5 New dimensions of discourse: prosperity and simplicity ........................... 84

Chapter 5 - Towards a Qualitative Assessment of Energy Practices: Illich and

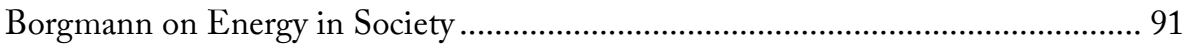

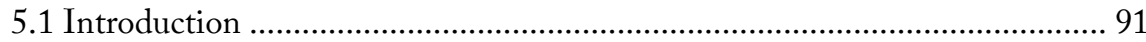

5.2 Illich and the issues of high-energy society .............................................. 94

5.3 Borgmann: beyond commodification and the device paradigm .................. 100

5.4 Synthesizing Illich and Borgmann for better energy practices ................... 105

5.5 A renewed look at energy transition...................................................... 109

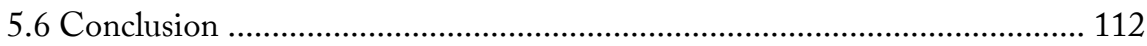

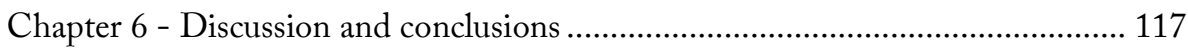

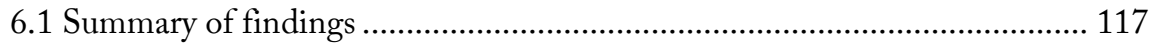

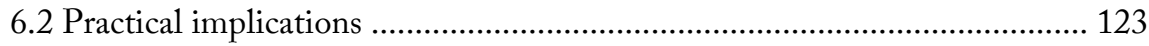

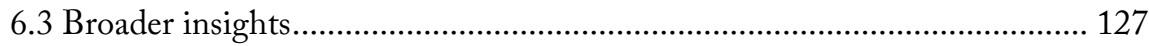

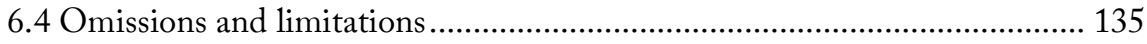

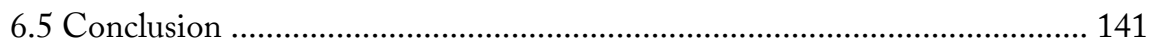

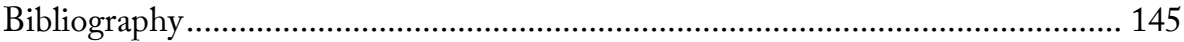

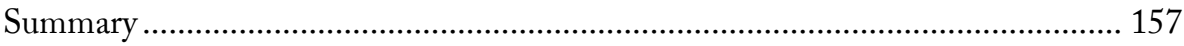

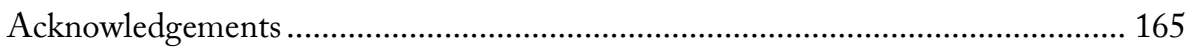

WASS completed training and supervision plan ............................................ 170

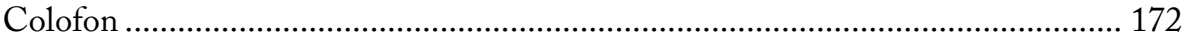


Chapter 1

Introduction 



\section{Chapter 1 - Introduction}

\subsection{Energy in crisis}

It has recently become fashionable to insist on an impending energy crisis

- Ivan Illich, Energy and Equity, 1974

Many things have changed since the 1970s, but we are once again in the midst of a debate on an impending energy crisis. This time it is not (just) about difficult relations with oil producing nations, but about globally dwindling reserves, increasing demand, and both global and local environmental concerns. Like in the 1970s, the crisis has sparked a plethora of expert forums, wide-spread media attention, diametrically opposed political positions, and actual impacts on our daily lives. Forty years ago car-free Sundays were organized; now we notice solar panels on our neighbors' roofs, we buy electric cars, and we protest against watercontaminating fracking sites as well as view-spoiling wind turbines. Energy, and the effort needed to provide us with it, is becoming increasingly visible again.

Illich did not believe in the energy crisis, at least not in the way it was perceived by most. Yes, there was something wrong with the way energy was used in society, but the problem was not that there was too little of it. The threat of an 'energy famine' sparked discussion and action, but, according to Illich, not enough reflection on how and why energy functioned in society. This line of questioning, I claim in this dissertation, is more relevant than ever. In order to solve the problems we now face with regards to the energy system, we must hold off attempting superficial 'technofixes', and first develop a deeper understanding of what is at stake.

This dissertation aims at arguing the importance of developing a deeper understanding, as well as making the first steps in its direction: it shows what kind of issues become visible with this approach, and starts to formulate a solution to some of these issues. Most generally, it puts forward the thesis that energy production and consumption is so deeply interwoven with society that the transition towards a sustainable alternative will involve more than simply implementing novel technologies. Fossil energy sources, a growth-based economy, and other particularities have resulted in very specific energy practices, and these will change in 


\section{Chapter 1}

the future. Only if we develop a better understanding of these practices, we can debate in which direction such change is acceptable and desirable. This dissertation initiates a reflection on these matters by articulating a number of pertinent problems with current energy practices that have thus far failed to receive appropriate attention in the debate on energy transition.

Energy transition is the shift from one energy system to another. Depending on what is at stake in a particular 'energy crisis', a transition involves particular elements of the system that are to change, while other elements may remain stable. Therefore, conceptions of an energy crisis are central to what people expect that energy transition to be like. This is salient because there is a lot of controversy about the current energy crisis. Is it about excessive $\mathrm{CO}_{2}$ emissions? Dependence on finite sources? Increasing negative side effects of energy technologies? Depending on one's outlook, expectations for transition vary wildly. In what follows, I will argue that what is at stake is much more than typically imagined: if we are concerned with the sustainability and functionality of our energy system, a transition involves not just our energy sources and technologies, but also our practices: the ways in which we use (that is: produce and consume) energy. Energy plays a vital role in shaping our lives, our conceptions of the good life, and our abilities to connect with our environment.

But what are practices anyway? Practices, in general, are the ways in which we do things. Energy practices are the ways in which we produce and consume energy in order to achieve particular goals. They are co-constituted, but not completely defined, by the technologies that are involved in them - individuals and societies can, within boundaries, choose to develop different energy practices while appropriating the same technologies. Practices can be explored with regards to their quality, quantity, and phenomenology. Quality refers to the kind of energy: electricity, liquid hydrocarbon fuels, natural gas, high or low quality heat, and energy embedded in consumer products and services are all different energy qualities. Quantity is the amount of energy used, and may be defined as Joules, barrels of oilequivalent, or perhaps the acreage needed to generate a unit of energy renewably. The phenomenology of energy practices may involve its visibility, accessibility, dependability, price, etc. Quality, quantity and phenomenology are highly interdependent.

A very rough sketch of current energy practices would mention the centrality of a few qualities of energy: liquid fuels for road transportation, natural gas for heating and cooking (at least in the Netherlands), and electricity for most other end-user consumption. A further move towards electricity is on the way in the shape of 
electric and plug-in hybrid cars, and heat pumps for indoor climate. Combined with electric cooking ranges, these developments make electricity to be the likely universal energy carrier of the near future. The phenomenology of electric energy consumption can most succinctly be described as clean and effortless. This convenience is an important factor in its success. Another important factor is the wide range of routes to create electricity. Whether from a coal-fired power plant, a hydroelectric dam, or a local wind turbine, the experience of consuming electricity remains the same. Electricity thus becomes the nexus between a range of primary energy sources and a range of consumption activities, effectively making sources and goals irrelevant to each other.

However, this apparent separation is not as perfect and unproblematic as it seems. To give an example, the current network that provides us with electricity closely follows demand over time. Power plants are ramped up and down to accommodate changes in the demand for electricity when factories are started up or lights switched off. Many renewable energy sources, like photovoltaics and wind turbines, are not so easily switched on and off: they generate electricity whenever the sun shines or the wind blows. Their dependability is different from traditional methods of generating electricity. Storing this energy on the scale necessary to power most of society with renewable electricity the way we use it now turns out to be a tremendous technical challenge (Barton \& Infield, 2004; Boyle, 2012; Mohd, Ortjohann, Schmelter, Hamsic, \& Morton, 2008). The intermittency of new sources may therefore challenge us to change our energy practices: rather than consume electricity when we like, effectively ignoring the system generating our electricity, we may move to a society in which we will consume it when it is available.

It is this kind of connection between technological system and societal practice that this dissertation is about. But before I go into further detail it is worthwhile to dwell a little on the fundaments of this perspective. In order to understand the complexly interwoven relation society has with its energy basis, I draw from insights in both philosophy and history of technology.

\subsection{On disciplines}

Philosophers of technology, or at least the ones most relevant to this dissertation, are interested in the relations between technology and humanity. They have introduced a great number of frameworks in order to answer this question in various ways. For Martin Heidegger modern technology constitutes a way of being (Heidegger, 1977); Jacques Ellul argues that technology turns everything into a bureaucracy, and leads 


\section{Chapter 1}

to a standardized culture (Ellul, 1964); Arnold Gehlen sees technology as ever more complex bodily extensions (Gehlen, 1980); Bernard Stiegler understands technology as a form of information and a third route for evolution (Stiegler, 1998); Gilbert Simondon holds that technologies develop according to the inherent logic of concretization (Simondon, 2012); Don Ihde claims that technologies mediate our perception of the world (Ihde, 1990); etc. This is not the place to discuss the merits and drawbacks of all these various approaches, but they at least have in common the notion that technology is a philosophically relevant category: it is worth exploring technology because it tells us something about (the predicaments in which we find) ourselves.

This also means that the focus is not only on technology for these thinkers: they are anthropologists, ethicists, and philosophers who realize that technology is part of the puzzle they are looking at, and may not even identify themselves as 'philosophers of technology'. There is no need to be territorial about it; at least if one is simply interested in improving our understanding of the world, philosophy of technology can and should always be inclusive and flexible in allowing insights from other fields of inquiry. In this dissertation at least, I understand philosophy of technology in such an inclusive way. A pluralist account of these approaches would then suggest that depending on the framework, different aspects of technology and humanity come to the fore. They are like contrast liquids that react to different ingredients in an emulsion. Depending on one's goals, some of these frameworks are more useful than others to get particular elements in focus.

However, none of these frameworks seem particularly well equipped to provide insights into energy practices. As we will see, energy practices are defined not just by specific artifacts that we surround ourselves with, but also (and in particular) by invisible and opaque networks of technologies, peculiarities of specific energy sources, and explicit and implicit perceptions of the functioning of energy in society. Therefore, although this dissertation is built firmly in the tradition of philosophy of technology in general, it cannot be placed in a particular line within it. Instead it draws from a variety of sources, exploring a new path that may, if it proves useful, be travelled more often and developed into a proper framework in the future.

This idea of exploring a new path is not to be understood as a claim that nobody ever thought before about energy as central to the relation between humanity and technology. Indeed, there are many implicit and explicit traces of energy and energy technology to be found in philosophy as well as in related fields such as sociology and history, and this dissertation draws from a number of them. Interestingly, many 
particularly illuminating thinkers are hard to pin down to one particular discipline: Lewis Mumford may be approached as a historian, philosopher, or sociologist; Vaclav Smil as a technologist or historian; Ivan Illich as a critical thinker, historian, or philosopher; but they all implicitly or explicitly centered (part of) their work on energy. It is quite possible that the particularities of energy force those who study it to approach it in a multidisciplinary fashion.

What these multidisciplinary thinkers have in common is at least a partly historical perspective. They tend to look at historical developments in order to say something about the present situation (of their day). Many of these accounts focus on the various stages of appropriation of fossil fuels; from the coal-powered steam engine to the ages of oil and electricity (e.g. Mitchell, 2013; Sieferle, 2010). Those transitions were most informative to understand the twentieth century societies on which these thinkers were reflecting, and there are important dissimilarities with the current situation. Still, those accounts can tell us many things about what tends to change in an energy transition, and about the situation before the transition we are now on the brink of. But the general take-home message of an historical perspective is that this is most certainly not the first moment in history in which energy practices changed considerably. To get a better understanding of the broader historical context, and to raise the stakes of energy transitions even further, we must go far back, to the appropriation of fire.

\subsection{Exosomatic energy}

A history of human energy consumption should probably start with the invention of cooking. For animals, the main source of energy is the digestion of food. Cooking is a range of practices that partially break down or digest food before consumption, which makes it easier for the body to take up nutrients. It has been argued that the human digestive system is extremely small for our bodily energy consumption thanks to the practice of cooking (Wrangham, 2010). Instead of burdening our bodies with the processing of raw foods, we use fire, boiling water, fermentation, and other methods to make all kinds of natural products fit for providing our bodies with energy.

The resources needed for making these fires and fermentation media (firewood, sugars) can be understood as exosomatic (outside of the body) food or energy. Using exosomatic energy achieves two things: first, as mentioned above, it disburdens the human digestive system as bottleneck for the amount of energy we can use to obtain our goals, and second, it expands the potential range of available energy: inedible 


\section{Chapter 1}

wood (cellulose) can be used to start the digestion process, other non-edible parts of plants can be made edible through cooking, and by warming our dwellings through fire we disburden our digestive system to stay warm. This way, important functions of bodies were partly externalized, which enabled population growth and dispersion of humanity to colder and less food-dense regions.

From the use of fire for heat and cooked food onwards, many (if not all) technological developments can be understood as new, different, or improved practices in exosomatic energy consumption. Sailing ships, trains, and automobiles disburden our legs for transportation by using wind, coal, and gasoline, respectively; industrial agriculture boosts food production by investing large amounts of fossil fuels in artificial fertilizers and mechanized tilling and harvesting; a variety of building materials (glass, aluminum, concrete) is available thanks to highly energy intensive procedures; our instant access to information is facilitated by the electricity-hungry world-wide network of computers called the internet; etc. People in the West now consume close to two orders of magnitude more exosomatic energy than endosomatic ('inside the body', i.e. food) energy ${ }^{1}$. In its focus on energy transition, this dissertation aims to provide some insight in exosomatic human energy consumption in all these aspects of daily life.

According to Lewis Mumford (2010), the history of energy use after the mastering of fire for heat and cooking can be divided very roughly into three epochs. The Eotechnic epoch revolved around wood, wind, and animal power. Next to cooking, people learned to use wind for sailing and providing rotary power which was used for irrigation and milling of grains, and animals for working the land and transportation. The Paleotechnic epoch was initiated by the industrial revolution. The usage of coal and steam engines opened up vastly larger energy resources than before, enabling higher production (factories) and more and faster transportation (steam ships, railways). The Neotechnic epoch, finally, that of oil, electricity, and nuclear power, involves both a further increase in available power and a more refined use of it: power sources become dispersed and better tailored to specific uses.

\footnotetext{
${ }^{1}$ According to the IEA (International Energy Agency, 2015), the US used 6.92 tonne of oil equivalent per capita in 2013. This translates to 290GJ per year. Assuming an average of $2500 \mathrm{kcal}$ of food consumption per day (translating to $3.8 \mathrm{GJ}$ ), the US exosomatic energy consumption is 76 times as large as the endosomatic energy consumption.
} 
These epochs are punctuated by revolutions, which we can understand as energy transitions. Mumford writes about these transitions because they have coincided with radical changes in society: the dynamics of an Eotechnic society are very different from those of a Paleotechnic society. Energy transition is therefore not just energy transition; it is also a moment of societal change. Such change can be researched in many different ways, each emphasizing different aspects of the complex connections between energy use and society. A thorough reflection on all societal changes coinciding with the current energy transition would be highly interesting, but too complex to do justice in a single dissertation. Instead of attempting to cover the full breadth of such connections and changes, the focus here remains on the direct relations between the shape of the energy system and the artifacts we engage with on the one hand, and the energy practices that we develop on the other.

Next to epochal revolutions, more modest energy transitions may be distinguished within epochs as well. For example, the common usage of heat pumps for air conditioning happened much later than the installation of electricity networks and therefore occurred within the Neotechnic epoch, but still resulted in different architectural designs and a narrowing of the range of temperatures their inhabitants tend to be comfortable with - it led to different energy practices in the area of indoor climate.

\subsection{The impending energy transition}

The transition that is the topic of this dissertation is, I claim, more significant than that of a new technology that changes a small part of daily life - it will not be contained to a few practices, but is likely to change much of the dynamics of society. Although this is rather speculative at this point, I suggest that the current energy transition may be understood as the next revolution in which the energy regime significantly changes (so, in Mumford's terms from the Neotechnic to the next): away from a finite/fossil supply and towards a sustainable one. What a 'sustainable' energy system exactly means is contested at this point, and the development of the contestations, discussions, subversions, and struggles surrounding the societal challenge of sustainability will influence the exact path of energy transition. In other words, energy transition is inevitable, but the outcome of energy transition is still unknown. The point here is that similar to earlier transitions, new 'sustainable' production practices will coincide with new consumption patterns and structures in society. 


\section{Chapter 1}

The claim that such a transition is taking place does not by itself mean that there is an objective need to discuss the practices that will be influenced: it will happen, and practices will be influenced, whether or not thought and deliberation is being put into the desirability of alternative pathways. It is very much possible, and indeed historically likely, that society will simply endeavor to change the machinery and change our practices along the way. This is how communication technology reshapes friendship (Briggle, 2008) and how obstetric ultrasound changes our perception of unborn children (Verbeek, 2008). We did not first discuss what we found important in friendships, proposed some changes, and designed a novel 'social media platform' to fit this new idea of friendship; it just happened and only in retrospect we reflect on it. In the case of energy practices it seems to be even more likely that we do not reflect on change in advance, because energy practices are very rarely made explicit in the first place: we are never using energy because of the energy - we use energy because of something else we want: travel, comfort, economic activity. Social networks on the other hand we use explicitly to stay in touch with our friends, so there is at least an opportunity for each user to realize how their friendships are changing because of it. Energy practices, implicit as they are, therefore appear to develop as an afterthought. We could simply change the energy system and our practices will reshape accordingly.

There are at least two reasons why this 'non-approach' of retrospective reflection is inferior to reflection before and alongside emerging transitions. The aim of this reflection is not so much to make sure a transition takes place, but to improve the odds that the transition will be towards a situation that is informed as much as possible by the values of both society in general and of specific individuals.

First, and this is the case for all non-reflective technological development, there is no reason to assume that a particular innovation that happens to appear on the market is the best version imaginable. Reflection during the design process may improve the odds here. An example of how such reflection takes place is the theory of value-sensitive design (Friedman, Kahn, \& Borning, 2002), which aims at expliciting designers' biases in order to come to more inclusive designs. However, in the case of energy systems, this method faces the additional difficulty that they are not explicitly shaped by a particular designer - they are the result of socio-technical processes that are much more complex and organic than the design of particular artifacts.

Second, for technologies that are to replace something else, there is the problem of path-dependence: what we expect from a new energy system is strongly dependent 
on what we are used to in the old one (cf. Unruh, 2000, 2002; Unruh \& CarrilloHermosilla, 2006). This shapes both the imaginations of designers and the (initial) acceptance of a new technology by society, which inhibits more creative, radical solutions. The first automobiles not only looked like carriages, they actually were carriages with an engine. We now see electric cars designed exactly like cars with internal combustion engines, right down to the charging cables that look like gas pump nozzles. Or on a more abstract level: travel in the era of sustainable energy is being imagined exactly like travel in the late fossil fuel era.

There are, of course, good reasons for this inertia. It is impossible to change the way in which we travel from one day to the next, so novel solutions need to be compatible with the current road network. Things have also developed in the direction that they have because there may be something good about them. We like the freedom and convenience cars give us, so we like the new thing to be a bit like cars. But this is not the whole story: the historical development of technology is messy and full of examples in which completely arbitrary reasons made something a success or a failure. Cars, and the particular cars that are currently available, are the direct descendants of historical developments influenced by cheap oil, tire lobbies, and highway systems built for military reasons. This means they inherited a number of features and limitations that may not be relevant anymore, or that may be detrimental to the goals these cars are supposed to achieve now and in the future.

Reflection on energy practices may uncover and distinguish between rudimentary and actually valuable aspects of a particular practice, and therefore the aspects of this practice that should be preserved in a substituting practice. But this is no easy task: there is no readily agreed upon framework against which one can assess the value of the things we do. Theories on the good life are contested (Crisp, 2016), and whether a certain practice adds to it (and why) is not easily determined. People may make decisions that appear to reduce their well-being because they do not realize there is an alternative, because they falsely believe in benefits of their choice, or because they truly prefer its outcome over other options. This dissertation does not pretend to provide any definite clarity on these matters, but it does argue that a more conscious dealing with these questions may be worthwhile. It shows that we can indeed make arguments for and against some practices, and that this has consequences for the kind of energy transition we should aim for. 


\section{Chapter 1}

\subsection{Debates and developments}

So far I have argued for attention to a specific issue around energy transition, and for a particular way of approaching this issue. This was, more or less implicitly, directed at other issues and approaches, which I deem problematic. It is good to make these 'other approaches' explicit before I flesh out exactly what I plan to do in this dissertation by stating the research questions. My interests, first and foremost, are in advancing energy transition in a particular direction: towards an energy system that is appropriate for its intended functioning in society. This actual change in the world should be distinguished from discussions on energy transition, which are merely a way (amongst other ways) of influencing the direction of energy transition. In this dissertation I contribute to these discussions both substantively, by describing in which direction energy transition should proceed, and procedurally, by pointing out how the current discussion fails to adequately deal with certain issues of energy transition.

So what do I mean when I speak about 'discussions' or 'debates' on energy transition? What are these discussions? These are difficult questions to answer, because there are many discussions on this topic, at many different levels, in many different geographic locations. I do not claim omniscience on this topic, and cannot give a detailed description that does justice to all of them. Still, in my experience there are some common denominators that seem to fit most current discussions, and that should sound familiar to anyone who has spent some time participating in such venues. Central to these discussions are following characteristics:

Urgency: Climate change is happening and we must hurry. The traditional energy system is falling apart, and change is unavoidable, but still there is work to be done to make it happen (Verbong \& Loorbach, 2012). There is no time to waste, which also implies that any action that seems to be in the right direction should be applauded. The time for contemplation is over, do something!

Scarcity: Energy is scarce and must be managed, either by reorganizing and increasing its supply or by reducing and better organizing its demand, but probably by a combination of both. Either way, a quantitative focus is essential to make the problem understandable and to compare alternatives (MacKay, 2009). This implies energy supply and demand is indeed measurable, and that using more energy in a more optimized way would make our lives better. 
Focus on technology: we have all the technology we need for a sustainable energy system; society simply needs to choose among the alternatives which we prefer. This implies an instrumentalist conception of technology: these are neutral tools we can choose to use or not, whatever we please. In some cases, the alternatives are actually described as a menu to choose from (Pacala \& Socolow, 2004). However, the more detailed plans that involve actual implementation of technology include either contestable assumptions or significant behavioral change (Lund \& Mathiesen, 2009; Richardson, 2013). Almost all the attention is focused on production (rather than consumption); if consumption is mentioned, it is about efficiency and conservation measures.

Us ws them (or levelling the playing field): the current rules of the game are in favor of the status quo, and that is not fair. Traditional multinational corporations too easily obstruct much-needed innovations of start-ups. We need better rules to beat the old regime and give these wonderful new technologies a fair chance. Whether this actually means that the new energy system should be largely de-centralized or not is contested (Lilliestam \& Hanger, 2016).

These discussions are important, but can be criticized. The urgency may be real, but this should not make us accept any plan, or the first plan that comes to our mind. Technologies may be available, but that does not make them neutral or unproblematic. Recognizing the need to develop better rules and regulations does not mean we already know what a level playing field would look like. This dissertation offers some additions and alternatives to these discussions in order to improve them.

Thus far, these discussions have been successful in igniting and sustaining a number of activities that aim at furthering energy transition. These activities range from research on photosynthesis (Reek, Hellingwerf, Klein Lankhorst, \& Harbinson, 2013) and electric grid management (Ipakchi \& Albuyeh, 2009), development of smart meters (al-sumaiti, Ahmed, \& Salama, 2014) and electric vehicles (Mwasilu, Justo, Kim, Do, \& Jung, 2014), government subsidies and other policies for sustainable energy projects (Jacobsson \& Lauber, 2006), and the setting up of local energy cooperatives (Viardot, 2013). These activities are significant and laudable, and certainly pass the mark of 'doing something'. My concern is that the set of activities is not complete: they are relevant efforts, but not all that is needed. By adding to the debates, this dissertation ultimately aims at realizing efforts that increase the chance of creating an energy system that caters successfully to human needs while remaining within the planetary boundaries. 
Chapter 1

\subsection{Research questions}

This brings us to my research questions. Most generally, I am interested in the question:

\section{How can philosophy of technology guide the emerging energy transition?}

I aim at answering this question by demonstration: this is how philosophy of technology can do that. It should be noted that 'philosophy of technology' is understood in the broad sense here: philosophical approaches that somehow relate to technology and society. The sub-questions are such that they build towards a specific answer to the main question, while keeping an openness to other concerns and approaches. They are as follows:

1) What philosophical basis allows for constructive thinking about energy transition?

2) How do contemporary energy systems discourage reflection on energy practices by users?

3) In what way does the centrality of scarcity in discussions on energy transition obscure alternative approaches?

4) How can we construct critiques on specific energy practices and guide improvement?

How can philosophy of technology guide the emerging energy transition? This is my most general guiding question. The aim is not so much to uncover a true or definite description of energy practices, but to develop perspectives that inspire reflection, discussion, and critique. Such perspectives are valuable if they provide insight in this more or less virgin research area. The only way to answer this question is by doing: by simply writing philosophically on energy practices. It should be emphasized that my aims are explorative, and therefore more constructive than critical. Although certainly not uncritical, my approach is relatively charitable towards the work of philosophers I build upon, because I am primarily interested in the insight it may provide into the question of energy transition.

The task of answering these research questions is approached in three phases. Subquestion 1 is answered first in this introduction and chapter 2, where the problem and a number of traditional philosophical perspectives are introduced to get a general sense of the issues at hand and the state of available knowledge. The end of chapter 2 and chapter 3 deal with sub-question 2, and describe two specific issues from the production and consumption sides, demonstrating how philosophy can 
create novel insights in such particular cases. Sub-question 3 and 4, finally, are answered in chapters 4 and 5 respectively. They work together toward a broader, more general contribution to the debate on energy transition by questioning the focus on scarcity and growth, two central and as yet unexamined concepts that turn out to be rather problematic.

After the general introduction, this dissertation thus builds from the particular to the general, and in the same movement from descriptive to (more) normative. The latter shift is a result of the nature of the problem: by zooming out it becomes clear that a great extent of energy practices of individuals is shaped by coincidence, contingencies, and decisions made elsewhere. It thus becomes impossible to ignore the ethical question what a good energy practice would be like while dealing with the energy system at large: whereas a focus on particular artifacts can at least sidestep normative issues by providing 'alternative options', a broader perspective needs to come to terms with complex interactions and the impossibility of a neutral system. Without claiming to have a definite answer, it is emphasized that this is a critical question to concern ourselves with while we are shaping the energy system for generations to come.

My aim of 'guiding' energy transition suggests an instrumental understanding of philosophy of technology, and it is indeed the case that I am interested in furthering this field of knowledge for the benefit of society. When discussing the work of others, the focus is always on the insights they can bring to the table for this particular issue, rather than a more general critique or appraisal of these works. There is, of course, also an intrinsic value to knowledge, but this is not the main driver for this project. However, this instrumental approach to philosophy does not imply an instrumental understanding of technology. This dissertation does not defend the position that technology is a neutral tool that humans may choose to use for good or evil. Neither does it defend a determinist position that claims that the development of (energy) technologies directly leads to a particular societal structure, culture, or (energy) practice. Instead, it builds upon the assumption that technology and practice are co-created, both at the level of the individual shaping their own life, and at the level of (global) society with its inequality, political structures, and culturally specific virtues. It is exactly because of this co-creation that a closer look at energy practices is so valuable.

The focus throughout this exploration is primarily on energy transition in the Western world, roughly European and North-American energy systems. Although general insights are useful in a broader context, this focus allows me to draw more 


\section{Chapter 1}

authoritatively from my own experience, and enables me to encourage the (presumably Western) reader to join me in exploring the personal experience of energy practice. Less opportunistically, it can be argued that energy transition in the affluent West is absolutely essential to counter climate change, simply because this is the region with the largest greenhouse gas emissions.

\subsection{Methodology}

But how does one go about such an exploration? Writing philosophically about realworld problems that are not yet framed in effective philosophical structures means drawing from many different sources: philosophical as well as technical literature, societal debate as well as personal experience. It is impossible to do such exploration objectively; the author will be recognizable in the outcome ${ }^{2}$. It is important to note in this context that my aim is not so much to uncover a true or definite description of energy practices, but to craft perspectives that inspire reflection, discussion, and critique. They may be incomplete, imbalanced, emphasizing apparently arbitrarily. There may be other ways to do this, perhaps even more effectively, but that would not disprove the value of this particular account.

It may appear that by adding such a disclaimer, I exempt myself from critique, as I readily admit that I am not aiming for any neutral and objective description that can be tested to be true or false. However, this must not be understood as an easy way out, on the contrary: as my interests lie not in truth but in providing insight, the real test of this work lies in the question whether I add anything significant to the debate on energy transition. The difficulty of this goal is not to be underestimated.

Why do I think that philosophy is the right tool to provide insights in energy transition? Why not ask energy experts? I do not dispute their expertise when it comes to their respective specialties, and gratefully make use of their insights, but the problem of energy transition, I claim, is larger than any one expertise. Philosophy, broadly understood, is particularly well-equipped to sketch the broader situation and explicate underlying concepts and relations. This is especially the case when a variety of philosophical methods are combined, as is the case in this dissertation: comparative literature study, (post-)phenomenology, Foucauldian ethics, conceptual clarification, philosophical anthropology, and virtue ethics are all woven together in this exploration.

\footnotetext{
${ }^{2}$ Although I claim that this cannot be done objectively, I do not make any claims here that all knowledge is necessarily subjective or perspectivist.
} 
It should be noted that I do not intend to develop a rigorous study of the concept of energy. Although valuable for its own sake, I do not have the impression that such a study would provide any guidance on how to discuss energy transition and what to aim for. Nor do I aim for a clear definition of energy that could settle any possible dispute and to steer further development of energy technologies, because it is impossible to do so with an issue as complex as energy transition. Instead, my pluralistic approach aims at developing a number of perspectives that allow one to see and recognize more of the disputes and issues underlying current developments, and some tools that enable discussions on which way to guide our energy practices from now on.

This approach is related to the recently proposed 'Constructive philosophy of technology' that aims not only to study and describe the functioning of technology in society (like philosophy of technology both before and after the 'empirical turn'), but importantly to guide and change it (Brey, 2016). Brey proposes a range of strategies to guide the development, governance, and use of specific technologies and technological developments in the light of reflection on the functioning of technology in society. What makes this dissertation different from these proposals is a peculiarity of the problem at hand: energy transition is not so much about novel technological developments, but about an emerging issue with an existing sociotechnical system. Properly understanding this existing system (that is: the ways in which the energy system provides society with its needs) necessarily precedes the possibility of 'guiding' technological developments, or even recognizing which developments need 'guidance' in the first place. This dissertation may thus be understood as the foundational work for constructive philosophy of technology in the field of energy transition.

\subsection{Relation to other work}

This project can be related to at least these three fields of knowledge: research in energy technology, transition studies, and contemporary philosophy of technology.

Research in energy technology, extending from photovoltaics to 'smart' grids, always departs from some technical list of design criteria. It presupposes a more-or-less agreed upon problem definition and issue demarcation: energy transition is about replacing fossil fueled power plants with renewable sources that fit in the current consumption patterns, for example. The BioSolarCells research program that funded this project fits this description: it is aimed at understanding and improving upon photosynthesis in order to power and feed the 'bio-economy' (Reek et al., 2013). 


\section{Chapter 1}

Philosophical insight in energy practices allows a critique of the design criteria that follow from such a conceptualization: which are problematic, kept implicit, overlooked? Which should be rephrased to expand the possible solution space? On a broader level, a better understanding of energy practices may lead to the insight that some problems cannot be solved with novel technology. Rather than directly reflecting upon particular research in energy technology or rejecting its value altogether, this project is situated alongside it, reflecting on the broader context in which research in energy technology is situated.

Transition studies are about moving from one regime to another, in general. There is a particular interest in the field of transition studies for sustainable development (Grin, Rotmans, \& Schot, 2010). Energy transition fits within this specific interest in sustainability, and is prominently visible in the literature (Bergh \& Bruinsma, 2008; Rotmans, 2012). Many of the insights of transition theory are valuable for energy transition, but the focus in transition studies is understandably on the transition part of the issue rather than the energy part, thus failing to appreciate the specificities of energy practices. Transition theory tells us, for example, that in the start-up phase many different initiatives are introduced and tested, many of which will fail. For the transition to succeed, the important thing is that the effective, successful initiatives are able to outgrow their niche and shape the new regime. Such insight is certainly valuable for e.g. an agency tasked with subsidizing technological start-ups. But it does not say anything about which aspects of the old regime are likely or necessary to change in order for a new regime to fulfil its promises. In other words: transition theory is about the how, but not about the what of the transition. This dissertation explores the what.

As already mentioned above, philosophers of technology have argued for decades that technological artifacts are morally, politically, and anthropologically relevant. Technology inspires us to do certain things and to abstain from others, helps create a certain societal structure, and changes the way we experience and act in the world. The field of philosophy of technology has in recent years focused on the role of specific artifacts that are most near us and that demand our attention, but the peculiar thing with energy practices is that a large part of them happens unconsciously, invisibly, and unintentionally. Looking at a socket in the wall does not tell us much about electricity and where it comes from. Part of the challenge to reflect on energy is therefore how to fruitfully approach such an amorphous structure or system. Like philosophy of technology in general, a philosophy of energy would draw from a variety of philosophical traditions. Insights in how to do this may be transferable to the study of similar technological systems (e.g. information systems). 


\subsection{Chapter outline}

After this introduction, in which the problem has been defined and situated, the next four chapters are written as stand-alone research papers, (to be) published in academic journals. This means they are all readable on their own and in any order, but they are also stepping stones that lead in a particular direction in the order they are presented here.

Chapter 2 introduces the reader to twentieth century philosophical perspectives on energy by Lewis Mumford, Georges Bataille, and Martin Heidegger. They suggest that energy is not the unproblematic concept that is often assumed in discussions on energy transition. Energy can be interpreted in a number of ways, and these interpretations allow us to see different issues when used to describe energy transition. An empirically informed philosophical perspective can offer clarity regarding particular problems in energy transition. As an example, the chapter discusses the problem of intermittency in the electric network. Via the work of Heidegger it is proposed that energy is currently conceptualized both as flux and as potentiality, and that there is a tension between the two. Energy is 'flux' when it is flowing, doing work, being used, effecting change. It is 'potentiality' when it is stored, waiting to be used, available. The problem of intermittency occurs because wind and solar power emerge as flux, unlike fossil fuels which emerge as potentiality. It is argued that Mumford's theory of four stages in energy use opens up a solution space for intermittency beyond the currently popular and technically complex attempts at energy storage.

Whereas the example in chapter 2 focuses on production, chapter 3 raises questions in the context of energy consumption. Specifically, it explores the phenomenology of electricity consumption in relation to the ability of the consumer to develop an ethical position on the matter. Via the concept of the 'experiential gap', the invisibility of a large part of the electric system comes to the fore. This is salient in the light of Foucault's work on self practices, in which it is argued that ethical behavior can only be built from the relation with a morally relevant environment. The complex and opaque electrical network thus makes 'ethical consumption' particularly difficult. Simpler and more transparent energy systems could enable ethical engagement, but at the cost of decreased usability: ethical behavior demands that the problem 'gets in the way', but when using technology the user needs the medium to dissolve in the practice. 
Chapter 1

After the focus on the two poles of energy practices, chapter 4 revolves around debates on energy transition. It suggests that two dominant positions in these debates can be distinguished: the 'boundless consumerism' approach which argues that growth will remain possible via efficiency improvements and novel energy technologies, and the 'eco-frugality' approach which argues that instead, consumption should decrease radically by making energy conservation a central aspect of our lives. This chapter problematizes both routes via their implicit understanding of the good life, and proposes a third route. Not only is society interested in a sustainable energy system, but it should also (and perhaps primarily) cater to society's needs and enable people to flourish as human beings. Neither side in the current debate seems to have this worked out very well. Boundless consumerism has already proven to be ineffective: over the last half century, growing energy consumption has not led to greater subjective well-being in the western world. Eco-frugality meanwhile focuses our attention on everything we cannot do: a protestant ethic without the appeal of a good afterlife. Through the introduction of a third position, 'qualitative abundance' (centered on the question how energy contributes to well-being), discussions on energy transition are expanded to include concerns of prosperity and simplicity, next to the traditional concern of scarcity. This expansion of the debate opens up a space in which it becomes possible to discuss ways to reduce energy consumption by improving well-being.

In chapter 5, this idea of low-energy good living is developed further: why does increased energy consumption fail to improve well-being, and what kind of energy practice would increase quality of life? The chapter explores and combines the work of Ivan Illich and Albert Borgmann, both of whom have been critical of the effectiveness of industrial society to provide for human needs, but from very different starting points. Illich looks at society in general and provides a compelling narrative how a narrow focus on efficiency becomes counterproductive. For example, beyond a certain threshold faster transportation ends up leading to more rather than less time spent on transport. If many of our practices have reached such a threshold, increasing energy consumption is detrimental to society's goals. Borgmann starts with the individual, and argues that embodied engagement with our environment is crucial for our well-being. Borgmann's analysis is here extended with the insight that such embodied engagement is always low-energy: we experience the world through our body, and not through our 'extended body' of machinery. This leads to the position that energy consuming technology can only be used to support the good life, and not be central to it. With Illich' cautionary remarks in mind, this support can only have a limited intensity. 
The discussion and conclusion takes stock of the insights gained. Answers to the research questions are summarized, and it is argued that this philosophical exploration on energy transition provides new perspectives to look at energy in society, provides concepts that enable a better understanding of particular issues in energy transition, clarifies misconceptions about energy consumption, and provides a more nuanced understanding of the relationship between energy consumption and the good life. Combined, these insights enable a much broader discussion and 'solution space' for energy practices to develop. It enables energy research programs to take into consideration consumption practices when making design choices around energy production, and offers individuals reflecting on energy practices a much broader vocabulary for reflection.

These points are placed in the broader context of both energy transition and the related research fields of philosophy of technology, research in energy technology, and transition studies. Finally, some limitations are discussed, leading to suggestions for further research. 



\section{Chapter 2}

\section{Towards a Philosophy of Energy}

Published as: Geerts, R. J., Gremmen, B., Jacobs, J., Ruivenkamp, R. (2014)

"Towards a philosophy of energy" Scientiae Studia 12(spe): 105-27.

(invited for special issue)

Co-authors: Bart Gremmen, Josette Jacobs, Guido Ruivenkamp 


\begin{abstract}
Transition to a sustainable energy regime is one of the key global societal challenges for the coming decades. Many technological innovations are in the pipeline, but an uncritical appraisal of anything and everything called green innovation lacks methods for testing both the necessity and the sufficiency of these developments. We propose to develop a philosophy of energy to fill this lacuna. Its task is to explore and clarify the space in which the so-called energy transition is taking place. This chapter sketches the fundaments of such a philosophy and suggests how it might be built upon the work of twentieth century critics of the functioning of energy in society, including Mumford, Bataille, and Heidegger; but not without empirical analysis of contemporary energy systems. Via the example of flux and potentiality - two apparently opposing conceptions of energy - we propose that a philosophy of energy allows for a broader perspective on specific problems in energy transition, and illuminates implicit and problematic assumptions behind these problems.
\end{abstract}

Keywords: Philosophy of energy. Energy transition. Sustainability. Renewable energy. Mumford. Bataille. Heidegger. 


\section{Chapter 2 - Towards a Philosophy of Energy}

\subsection{Introduction}

The functioning of Western society is currently vitally dependent on the combustion of fossil fuels for energy. This energy is used for transportation, heating, the production of food and consumption articles, and a myriad of other things. Two developments threaten this dependence: anthropogenic climate change and the depletion of easily accessible fossil fuel stocks. In recent years, these twin problems have sparked an enormous array of innovations: from energy efficiency improvements to renewable electricity sources, and from biofuels to cycling infrastructure. These innovations do not all represent solutions to the same problem, but are generally assumed to work towards the common goal of a sustainable energy regime. Developments towards this novel situation collectively make up an energy transition (Kern and Smith, 2008).

The fact that people are working on so many different solutions to so many different problems relating to energy transition typically gets positively perceived. With our dependence on (fossil) energy so all-encompassing, relying on a single "silver bullet" technology would be both naïe and risky (cf. MacKay, 2009). Instead, it would seem better to spread our chances and develop a range of technologies that cumulatively and sufficiently reduce our dependence on fossil fuels and also reduce $\mathrm{CO}_{2}$ emissions. This line of reasoning has resulted in a situation in which "green" innovations crop up everywhere: from new types of photovoltaic cells to airlines bragging about running their ground vehicles on biofuels. However, an uncritical appraisal of anything and everything called green innovation lacks methods for testing both the necessity and the sufficiency of these developments. We may currently outline two lines of critique against green developments.

The first might be described as the "greenwashing police" - contesters of specific innovations, who critically assess the quality of the "green" claims made by developers. Are they actually true? Do they deal with the most pressing problems? In the case of the airline ground vehicles for example, one could claim that the focus on renewable energy for ground vehicles serves only to deflect attention from the much 
larger energy consumption of the airplanes that these companies operate. This strategy is limited in scope: whilst raising questions on what we understand as proper green technologies, the approach does not prove appropriate to answering those questions. It sticks to the hard facts, and works in the language of the technologists. This means that although able to engage in actual debate with the developers of novel technologies, this also means that the perspective sticks with the technologist framework: it will contest a misleading representation of vehicle mileage but leave car culture as it is.

The second line of critique works through social science and emphasizes "soft" impacts of energy technologies. Anthropological accounts, for example, describe how electrification shapes life in remote villages, sociology and science and technology in society (STS hereafter) scholars research how the location of wind farms is negotiated among stakeholders, thereby pointing to novel dimensions to the energy transition problem. This approach tends to focus on all that is left out of the technologist cost- benefit analysis. Social scientists therefore use a language that is fundamentally different from that of technologists; this leads to technologists freezing up when societal aspects of the implementation of their plans come into play. Claims such as "we just provide the options, society decides which ones it will accept" are commonplace. Similarly, social scientists refrain from taking a position on any technical issue: for them, the whole exercise is one of social capital, actors and networks, and so forth. For example, when talking about the development of wind farms in Wyoming, Strauss and Reeser (2013) remain silent on differences between coal mining and wind farming. These technologies remain black-boxed in their analysis.

Neither of the problems with the two aforementioned lines of critique proves serious as long as we have a clear image of the problem, and we assume independent development of society and technology. However, in practice, this is hard to accept: energy transition represents a messy project with a broad variety of goals and, within STS research; that there is at least some kind of co-development of technology and society no longer gets contested. Furthermore, in the case of energy this becomes particularly obvious: industrial society with all its benefits would never have been possible without ample and inexpensive energy sources (cf. Sieferle, 2010; Wrigley, 2010).

From a theoretical standpoint, we might now suggest that the two current approaches to critiquing the energy transition project seem to leave a gap in their strategies. If goals are not clear and there is a co-development of technology and 
society, then there might be an area of critique running deeper than the mere critique of particular technologies, remaining closer to the intricate connections between technology and society, and therefore more reflective than technological approaches and more technical than current social science approaches. We believe this area belongs to the philosophy of energy.

This claim immediately raises two questions: why philosophy, and why a specific and new branch of philosophy? We hold that philosophy's conceptual analysis, critical reflection on argumentation, and its ability to raise the level of abstraction, provide exactly the clarity that is currently lacking in the debate. In addition, by drawing from a broad range of sources, more-or-less continental approaches to philosophy can introduce new concepts and perspectives to the debate in order to open up the playing field. This constitutes the kind of creative philosophy that we seek. Furthermore, the specificities of energy and energy technologies are central to the current lack of clarity, so any philosophical insight must be firmly grounded in a proper understanding of energy. Without this, it will be impossible to create relevance for actual energy-related problems, and to appeal to the engineers and policymakers who are shaping the energy transition. This chapter represents an attempt to establish this field, locating it amongst its theoretical neighbors and identifying its roots and ancestors. We compare and contrast the philosophy of energy to these fields, and defend the position that this indeed entails a distinct niche that comes with its own specific perspective that is not, and cannot be, adequately addressed by any other field. The chapter concludes with an example of the kind of issue susceptible to better understanding via our approach.

\subsection{Philosophies of energy}

This is not the first attempt at philosophizing about energy. Indeed, there are at least three lines of thought to be found in history dealing to a greater or lesser extent with aspects of energy:

(1) the inquiry into the natural phenomenon of energy;

(2) the critique of the functioning of energy in society;

(3) the philosophy of technology.

All three lines of thought contribute essential ingredients to a fully-fledged philosophy of energy: the first two can be seen as attempts to develop philosophies of energy in their own right, whereas the third guides us towards a more fruitful level of analysis for issues relating to the current energy transition. In this section, we 
introduce the first two of these lines, but would first emphasize that we take some liberties in our reading of these thinkers in order to build upon them and, as we are specifically looking for philosophies of energy, we do not approach these texts neutrally.

\section{Inquiry into the natural phenomenon of energy}

Inquiry into the natural phenomenon of energy stretches back to Heraclitus (c.535 c.475 BC) and Aristotle (384-322 BC). Whereas the former allegedly argued that everything changes, the latter noticed that this was not exactly true: although change happens, a lot of things also stay the same. The energy historian R. Bruce Lindsay suggests that, from Aristotle onwards, an unbroken line of inquiry into the concept of energy can be drawn all the way to Einstein, with as common denominator the assumption that "the root of the concept is the notion of invariance or constancy in the midst of change" (Lindsay, 1971, p. 383). The domain of these inquiries steadily expanded from mechanical questions on the functioning of levers and pulleys through to thermodynamic phenomena such as combustion, electromagnetism, and the discovery of mass-energy equivalence in the early twentieth century.

We do not need to reiterate this history in any detail here; what is important here involves realizing the exceptional breadth of phenomena that are fruitfully connected with the concept of energy. Over time, these insights have led to increasingly complex technologies for converting one kind of energy into another. windmills convert the linear movement of air into a rotating movement, steam engines convert chemical energy into a rotating movement via heat and pressure, solar panels convert the energy in sunlight into electricity, and, in our homes, our appliances convert electricity back into movement, light, heat, and sound. Arguably, all our activities are understandable simply in terms of converting one kind of energy into another.

The universality of the energy concept does not merely extend to a number of fields in science; it also provides a running thread in the production of other resources. The scarcity of food, drinking water, minerals, transportation capacity, and all kinds of produced goods are all to a greater or lesser extent bound up with the price or availability of energy. There are ways to produce or access more of these goods, but this would involve higher energy expenditure. This is why technologists get so excited when new and apparently infinite energy sources are introduced. In the heyday of nuclear energy, Weinberg (2006), for example, suggested that desalination of sea water would make arid areas all over the world productive, whilst nuclearpowered air traffic would make flight accessible to all. We now know things 
developed otherwise, but the appeal and importance of developments in energy remain as strong as ever. ${ }^{1}$

There is a specific understanding of energy underpinning all these developments: a quantitative, abstract concept of "the ability to do work" that mutually interconnects a broad range of physical phenomena. This is the first philosophy of energy that we encounter, and most present-day natural scientists subscribe to some similar form of understanding energy. Although the unification of physical phenomena via the concept of energy has been exceptionally successful, conflicting conceptions of energy do exist. These conceptions are also the result of inquiry into the natural phenomenon of energy, but, rather than relating to the scientific, quantitative paradigm, they appeal to qualitative approaches. As Hein van Dongen (2013) notes, the exploration of the natural scientists obscures the non-exact phenomenon of "life energy", related to the oriental idea of qi: the immanent energy in social relations. This is what Stephanie Rupp (2013) found when interviewed New York City citizens came up with phrases like "the energy of the city", and what Van Dongen noticed when a team of exhausted soccer players could be re-energized by a sudden goal late in the game (cf. Van Dongen, 2013, p. 37). Although on a biochemical level these experiences may share a unified physical theory with a power plant, understanding them in these terms does not prove very helpful.

Thus, there would be great relevance in ascertaining whether an overarching philosophy of energy would enable the reconnection of these two apparently disjoined conceptions of energy. At the very least, the qualitative conception of life energy hints at what the scientific understanding of energy could do for humanity: it reminds us of the reasons why we are interested in harnessing energy in nature: to work towards achieving our goals and expanding our abilities.

The scientific understanding of energy has enabled society to plug into ever increasing amounts of energy in various forms, but it fails to say much about the effects of these developments on society. After all, the physical understanding is distinctly lab based - only looking at the phenomenon of energy in isolation. We would note that it understands energy as a purely natural phenomenon, external to the level of society's control over it. This leads to a static conception of energy over time: we might improve our understanding of it, but energy itself remains the same no matter what we do with it. Something similar holds for inquiries into life energy:

\footnotetext{
${ }^{1}$ We now see a similar hype around bio fuels, whilst hovering in the background there is the expectation of nuclear fusion as the unproblematic energy source in the distant future.
} 
Chapter 2

they are silent on energy external to the body. However, while this is not problematic in itself, should we seek to gauge what is changing in energy transition, a static understanding of energy falls short of the mark.

As changes in energy practices became increasingly visible and influential in industrial societies, in the late nineteenth century, an interest in energy emerged in the area that can broadly be described as social critique. In the twentieth century, this was picked up by a few great thinkers, and here we do find some ideas on how society relates to energy, and how this relationship developed throughout history. The following sub-section touches on three of these thinkers: Lewis Mumford, Georges Bataille, and Martin Heidegger.

\section{Critique of energy in society}

In his ground-breaking book Technics and civilization, Lewis Mumford (2010 [1934]) places energy usage squarely in the middle of his analysis of society. From his perspective, there are four steps in the functioning of energy in society: conversion, production, consumption, and creation. All energy we know originates from the sun $^{2}$, and solar energy is converted into food and fuels via photosynthesis. "This seizure of energy is the original source of all our gains: on a purely energetic interpretation of the process, all that happens after this is a dissipation of energy" ( $p$. 375). Next to organic conversion, Mumford mentions mechanical conversion: water-wheels, steam engines, and so forth. These technologies opened up new sources of energy and allowed for "the gigantic scale [the apparatus of production and transport] attained in the nineteenth century" (p. 376). Production, then, involves the usage of converted energy to gather, transport, and shape raw materials into products, which are subsequently consumed by society. The final step - that of creation - is what everything really revolves around for Mumford.

Not until the economic process reaches the stage of creation - not until it supplies the human animal with more energy than he needs to maintain his physical existence, and not until still other energies are transformed into the more durable media of art and science and philosophy, of books, buildings and symbols - is there anything that can be called, even within a limited span of time, a gain (p. 376).

\footnotetext{
${ }^{2}$ This was before nuclear energy and geo-thermal energy became well-known.
} 
Simply sustaining society is not enough. The goal of all our efforts must be to develop into something better, to create a lasting heritage of worthy cultural products such as art and science. This leads Mumford to a critique of capitalism. According to his position, the surplus energy that could be used for creation instead gets deployed for re-investment to increase production, which leads to the overexpansion of production facilities and correspondingly to efforts put into marketing and promotion in order to be able to sell all these superfluously produced goods. The reason behind this, as Mumford proposes: "there is no capitalist theory of non-profit-making enterprises and non-consumable goods" (p. 377). The few bits of "creation" that do occur, do so accidentally: there is no place for them within the system.

This disquiets Mumford, due to his belief that a society able to harness increasing amounts of energy should also be able to devote an increasing share of this to the things that actually matter. ${ }^{3}$ One does not have to share Mumford's position on capitalism to appreciate his more general insight as to how the availability of more energy does not automatically lead to either a better society or better lives lived within this society. Mumford drives this point home as follows:

The real significance of the machine, socially speaking, does not consist either in the multiplication of goods or the multiplication of wants, real or illusory. Its significance lies in the gains of energy through increased conversion, through efficient production, through balanced consumption, and through socialized creation. The test of economic success does not, therefore, lie in the industrial process alone, and it cannot be measured by the amount of horsepower converted or by the amount commanded by an individual user: for the important factors here are not quantities but ratios: ratios of mechanical effort to social and cultural results. A society in which production and consumption completely cancelled out the gains of conversion - in which people worked to live and lived to work - would remain socially inefficient, even if the entire population were constantly employed, and adequately fed, clothed, and sheltered. The ultimate test of an efficient industry is the ratio between productive means and the achieved ends (Mumford, 2010 [1934], p. 378-9).

\footnotetext{
${ }^{3}$ Smil (2007) contests this. He maintains that more energy production leads to greater carrying capacity, but at the cost of a larger effort for its inhabitants: intensification of agriculture leads to declining energy return on energy investment (EROEI). The upshot of this is that intensification is ultimately self-defeating: it leads to higher energy levels, but less free energy (Smil, 2007, p. 148-9).
} 
In Technics and civilization, Mumford implicitly develops a philosophy of energy. He seems to subscribe to an instrumental position. Energy is a resource we can consume however we please, but we are not currently doing so in the best way imaginable. This position makes possible, and perhaps even requires, the additional development of an ethics of energy: if it is essentially a neutral instrument, there are better and worse ways of dealing with energy. It is clear that, for Mumford, the main target for an ethics of energy is to steer as much as possible towards creation.

The creation stage is still notably absent in current debates on energy transition. Implicitly it is assumed that whatever energy we can get hold of will be put to good use. In a recent article, Carl Mitcham and Jessica Smith Rolston (2013) problematized this assumption. They argue for an energy ethic that does not equate more energy with better lives, by pointing to historical data that show little growth in quality of life in the US in the second half of the twentieth century, even though energy consumption increased significantly. Although Mitcham and Rolston do not go into it, their approach raises questions regarding "good" energy consumption: is there really a ceiling to it? Is there a maximum creation-to-conversion ratio? Are there different levels of energy consumption at which we attain the same quality of life, by organizing society differently?

However, before plunging into such questions, we take a step back and move onto the work of Georges Bataille, who contests the instrumental conception of energy proposed by Mumford. In The accursed share, Bataille (Bataille, 1988 [1949]) suggests that our energy practices are not instrumental to satisfying our needs, but rather it is the other way around; satisfying our needs is a way of dealing with the excessive emission of energy by the sun. This reversal may strike the reader as farfetched, but does contain some insights, as well as a number of striking parallels between Bataille's and Mumford's position and some statements in renewable energy projects.

Life, argues Bataille, has always been about abundance rather than scarcity. The surplus of abundant solar energy makes life possible and, over the course of evolution, life has found ways to consume increasing amounts of this energy. Every organism has, after using energy for its sustenance, access to a certain surplus, which is used either for growth or reproduction (which represents growth on the population level), leading to an accumulation of biomass. However, this process cannot proceed indefinitely; at some point, carrying capacity is reached, and it becomes impossible for a certain organism to continue accumulating. "[T]his movement of growth runs up against limits at every stage of life. It is continuously 
stopped and forced to wait for a change in the conditions of life before resuming" ( $\mathrm{p}$. 180). Two examples of such changes in the conditions of life referred to by Bataille are the development of trees (the tendency of plants to grow skywards to increase their photosynthetic surface) and the emergence of carnivores. The former is a way of life to increase accumulation potential, the latter is a means of burning off useless excess. Death is not strictly necessary for life, as infinitely dividing bacteria prove, but it is a way for life to burn off excess energy that cannot be used in a productive manner.

According to Bataille, the development of technologies by humanity must be understood in this light.

And similarly, once domination of the available space is ensured at the
expense of animals, men have their wars and their thousand forms of useless
consumption. Mankind is at the same time - through industry, which uses
energy for the development of the forces of production-a manifold opening
of the possibilities of growth and an infinite capacity for wasteful
consumption (Bataille, 1988 [1949], p. 181).

Our growing energy production and consumption simply represent an extension of this natural tendency of life to look for ever increasing accumulation and niches to fill, and to burn off the excess when accumulation is not possible. As the reference to war in this quote suggests, this dynamic comes with a certain danger. The burn-off of excess often happens in violent ways, and, with our increasing capabilities to accumulate large amounts of energy, the burn-off events display an increasing intensity. Wars in the twentieth century were far more deadly and devastating than their predecessors in earlier centuries.

This problem only gets exacerbated by the capitalist ethic, which, as we have already noted, always aims to re-invest any surplus available, rather than expending it on lavish consumption. This has created a society with relatively few pressure valves in place for shedding accumulated excesses. As Bataille maintains that it is only a matter of time before our accumulative practices reach their limits, he believes we can only ever be heading towards another and even more violent war. Only understanding an economy from the general perspective of the cosmos - rather than that of particular players in that economy - can render this problem visible.

Rather than understanding energy as a resource to help society advance, Bataille perceives society as the result of an energy surplus, and a surplus that is explosive and 
impossible to fully control. Whereas Mumford believes that we might deploy energy in better or worse ways to improve our lives, Bataille suggests that the ways in which we deal with energy might not only be simply unproductive, but downright destructive. If his analysis holds any merit, this considerably increases the stakes for a philosophy of energy.

In addition to the significance of energy practices at the global level, Bataille details the implications of his perspective for individuals.

The beings that we are are not given once and for all; they appear designed for an increase of their energy resources. They generally make this increase, beyond mere subsistence, their goal and their reason for being. But with this subordination to increase, the being in question loses its autonomy; it subordinates itself to what it will be in the future, owing to the increase of its resources. In reality, the increase should be situated in relation to the moment in which it will resolve into a pure expenditure. But this is precisely the difficult transition. In fact, it goes against consciousness in the sense that the latter tries to grasp some object of acquisition, something, not the nothing of pure expenditure. It is a question of arriving at the moment when consciousness will cease to be a consciousness of something; in other words, of becoming conscious of the decisive meaning of an instance in which increase (the acquisition of something) will resolve into expenditure; and this will be precisely self-consciousness, that is, a consciousness that henceforth has nothing at its object. (Bataille, 1988 [1949], p. 190).

Bataille here suggests that while efforts towards increasing our energy utilization capacities come naturally, concluding that we should therefore embrace this tendency would be a naturalistic fallacy. Instead, Bataille argues that we should attempt to embrace ourselves as we currently are, with the energy-using capabilities we currently have, and focus on the ways and means of burning off the excesses now available to us. It is precisely in useless expenditure that we find our true selves.

One might conclude that Bataille's sketch of the history of energy consumption bears little resemblance with the present situation. After all, we are not currently trying to expand the energy base of society but rather trying to rid ourselves of the fossil fuel-based portion of it, and thereby shrinking it. Our problem is not that we do not know how to expend uselessly, but that we need to find less polluting resources to do so. When Bataille wrote The accursed share, the finitude of fossil fuels did not seem to be on his radar, let alone the effects of their combustion on the 
Earth's climate. Arguably, moving away from fossil fuels serves to extend the time before society reaches any limitations as to its capacity for accumulation.

In Bataille's peak, Alan Stoekl (2007) suggests that we should not disregard Bataille so quickly. Even though Bataille did not foresee the current energy crisis, his perspective remains valuable to elucidate why neither proceeding on the path of ruthless fossil fuel exploitation nor the green perspective of sober frugality provide proper answers to the current situation. The former leads to a problematic build-up of explosive potential that will sooner or later become destructive; the latter does not do justice to our nature (aiming for growth) or our Bataille stipulated potential (aiming for self-consciousness through useless expenditure).

Meanwhile, spokespersons for green technology appeal neither to paths of ruthless fossil fuel exploitation nor to sober frugality. Instead, they tend to sketch Bataillean visions of abundance: "the Earth receives more energy from the Sun each hour than humans use in a year", implying that we simply need to better harness this energy and thereby avoid any such thing as an energy crisis. Bataille's paragraph on the perspective of the individual cited above appears to hold direct relevance to such bold statements. Why exactly would our lives become better should we command an even greater amount of energy?

Both Mumford and Bataille develop critiques against the energy practices of their day agreeing on how energy is not guided towards its proper purpose while disagreeing sharply on just what would constitute that proper usage. Mumford would like to see long-lasting cultural projects (art, architecture) developed and Bataille would like us to simply embrace the burn-off of surplus energy that makes our existence possible. Any attempt at applying the available energy to alternative ends would fail to appreciate the dynamic in which we currently find ourselves.

One other twentieth-century thinker needs addressing in this context. In a quote above, Bataille appeals to our existence as individuals with access to a certain amount of energy. This represents a rather specific perspective on just what forms the human existence, with a similar perspective playing a key role in the writing of Martin Heidegger, for whom human existence changed radically with the advent of modern technology. Heidegger argues that, in modern times, the only way of understanding the world and ourselves is as a "standing-reserve" that is ready to be put to use. Stored energy proves the purest form of this standing-reserve. 
Heidegger reaches this insight in his essay "The question concerning technology" (1977 [1954]), in which he searches for the essence of technology. This essence can be found, he holds, in the way that that which is comes into being. In ancient Greece, the process of coming into being was called poiesis, a bringing-forth. This concept served both for that which emerged of its own accord (like a flower) and whatever had a specific creator (a poem, or a tool). Bringing-forth thus represented a particular form of "unconcealing" that which was previously concealed, one in which Aristotle's four causes have play. The general process of shifting from concealed to unconcealed was called revealing, from aletheia, veritas in Latin, and now usually translated as truth.

The word technology comes from techne, which is a form of bringing-forth and therefore a way of revealing, and is correspondingly located in the realm of truth. Technology thus reaches beyond a simple means we use to become a fundamental way through which the world emerges before us. One should therefore be able to recognize the four causes in the things that have been brought-forth by technology. However, Heidegger holds that it is impossible to distinguish these causes in the case of modern technology, because technology uses a different form of revealing than bringing-forth.

What is modern technology? It too is a revealing. Only when we allow our attention to rest on this fundamental characteristic does that which is new in modern technology show itself to us (...). The revealing that rules in modern technology is a challenging [Herausfordern], which puts to nature the unreasonable demand that it supply energy that can be extracted and stored as such (Heidegger, 1977 [1954], p. 14).

The tendency of modern technology to store and extract energy on demand features here as a crucial moment in history. It is the central characteristic of a new way of revealing.

Whatever is ordered about in this way has its own standing. We call it the standing-reserve [Bestand]. The word expresses here something more, and something more essential, than mere "stock". The name "standing-reserve" assumes the rank of an inclusive rubric. It designates nothing less than the way in which everything presences that is wrought upon by the challenging revealing. Whatever stands by in the sense of standing-reserve no longer stands over against us as an object (Heidegger, 1977 [1954], p. 17). 
From this moment onwards, we cannot but understand a forest as a place that produces wood, a river as hydropower potential, a mountain as a container for ore, and a natural area "as an object on call for inspection by a tour group ordered there by the vacation industry" (p. 16). The very way the world presents itself to us has been changed by this new way of revealing, which Heidegger proceeds to call enframing [Ge-stell $]$.

But how does humanity relate to this enframing? Because modern technology remains a human invention, one might assume we control it or can at least remain outside of its scope, but this does not prove the case. Although we might have put it in place, we have no control over the way of revealing.

Enframing is the gathering together that belongs to that setting-upon which sets upon man and puts bim in position to reveal the real, in the mode of ordering, as standing-reserve. As the one who is challenged forth in this way, man stands within the essential realm of enframing (Heidegger, 1977 [1954], p. 24).

This makes enframing not simply a new form of revealing, but the only form of it available to us while simultaneously threatening to strip us of our humanity as we learn to see one another and ourselves as standing-reserves rather than subjects as well (terms like buman resource management spring to mind). Modern technology therefore poses the ultimate danger. The way out and forward into a new form of revealing is unclear, but Heidegger suggests the answer might be found in poetry, which was one and the same as technology to the Greeks: techne.

There is no coincidence behind Heidegger introducing his gloomy vision of modern technology through recourse to energy technologies. As mentioned above, energy is an exceptionally powerful concept for connecting and equating a variety of forms of potential with each other with this potential serving numerous ends. Energy is indeed the perfect standing-reserve. From this perspective, one must conclude that our efforts to move from one energy system to another are hardly significant: these simply represent different ways in which enframing reveals the world to us. Energy, to Heidegger, is no mere means, but also not akin to Bataille's cause of life. Instead, it proves the form through which modern times reveal the world.

We make no claim to be exhaustive as regards these three positions, but merely demonstrate the kinds of perspective that is available once one moves beyond purely utilitarian technological debates. Furthermore, we believe these three thinkers 
collectively sketch a rudimentary philosophy of energy. ${ }^{4}$

What exactly is the value of these perspectives to our project? There are numerous problematic aspects to all of them, and any assessment of their factual correctness (should this prove at all possible) remains beyond the scope of this chapter. Instead of questioning the correctness of their examples or their historical analyses, we suggest approaching these works as attempts to signify the functioning of energy in society, and therefore, either implicitly or explicitly, sketching a philosophy of energy. In these attempts, we encounter a number of insights with previously hidden aspects of energy practices uncovered or highlighted. How the spectrum of energy technologies available to us expands and might be understood as the extension of evolutionary phenomena, how we increasingly understand everything in terms of stackable resources in our energy-rich society, and so forth.

Beyond these insights however, the differences between these approaches raise more fundamental questions. In the first place, at just what level should we understand the relationship between energy and society? Does this relationship change over time and, if so, does the current energy transition entail such a shift?

The inquiry into the natural phenomenon of energy and the critique of energy in society both point to the universal applicability of the concept. Whether from a dammed-up river or a coal bed, energy, its usability, and its functioning in society are understood as one and the same. As seen, this viewpoint leads to insights into energy in general, but it is not very helpful when we look into the dynamics of the current energy transition: if it is all the same, why would new technologies result in a new situation? By focusing on the shared qualities of energy technologies, and talking about the distilled effects of energy in general, these perspectives fail to be sensitive to the peculiarities of specific energy technologies and practices. If our aim is to develop a philosophy of energy that does justice to its complicated workings in our society, as suggested above, we must move away from the general and towards the particular.

This does not mean to say that the general perspective holds no value; rather, we must instead find ways to relate these general insights to distinct practices: to what extent are these practices understood through a general understanding of energy, and to what extent do they distinguish themselves from one another?

${ }^{4}$ One particular omission we would like to mention is Ivan Illich, who problematizes expanding energy use in relation to equity in society (cf. Illich, 1974). We hope to return to Illich in later work. 


\subsection{An empirical turn}

A similar problem was recognized in the philosophy of technology in the late twentieth century. Novel technologies like cellular telephones, microbially produced insulin, and communication satellites changed people's lives in very distinct ways, but the classical approaches of Mumford and Heidegger, among others, with their critique of "Technology" with a capital "T", proved of no meaningful assistance. As Verbeek sums it up:

During recent decades, philosophy of technology has increasingly paid attention to the impact of technological artifacts on the liferworld of human beings (...). As opposed to classical approaches, which were mainly focused on understanding the conditions of "Technology" taken as a monolithic phenomenon, the philosophy of technology has started to approach technology in terms of the actual material objects that help to shape human actions and experiences (Verbeek, 2011, p. 6).

This shift has now been understood as an empirical turn in the philosophy of technology (cf. Brey, 2010). From grand critiques on technology in general, attention has shifted towards the ways in which particular technologies - say, prenatal ultrasound or Skype - lead to new moral problems, or new conceptions of proximity.

This focus on artifacts has proved very useful in providing clarification and guidance in an increasingly complicated technological lifeworld. However, in relation to energy technologies, this approach proves less insightful. One reason, as one of us has argued elsewhere (Geerts, 2012), stems from the way the energy aspects of our daily practices tend to get hidden from sight by the artifacts we adopt and use. The computer on which this chapter has been written is powered by a vast network of natural gas production sites, pipelines, power plants, wind turbines, power lines, load management control rooms, and so forth; but one does not need to know or think about any of this to operate the computer. Precisely because users are not constantly reminded of this complexity, they are able to focus on the task at hand. A philosophical focus on artifacts serves to teach us how little of modern energy practices comes to the surface of daily life, but it is not helpful to get a better perspective on energy technologies.

If artifacts do not constitute the appropriate level of analysis for a philosophy of energy, then just what is? We propose a systems perspective because only at the 
systemic level can we fruitfully distinguish between different energy practices. Take, for example, two systems for domestic electricity consumption: the standard (inter)national grid, and an off-the-grid solar/battery system. The former is convenient for the user, optimized for efficiency, and opaque, whereas the latter is more cumbersome, possibly less energy efficient, and more transparent. If we simply assume a fixed energy requirement for consumers, the national grid would probably provide the better tool for the job. If, however, we entertain the possibility that these different systems induce different practices, different attitudes towards energy consumption, then the off-the-grid system might be preferable to a national grid in some aspects: it might induce a conscious reduction in consumption, or a rhythm of consumption more closely following the rhythm of the day and the seasons. Furthermore, connecting to the critical perspectives above, a less efficient or more transparent energy system might enable us to look beyond standing-reserves or infinite re-investment.

We are neither making any claim here that this is actually the case, nor taking any position on whether our energy future lies in national or micro grids. To make such claims, a more thorough analysis of these systems and people's attitudes towards them would be necessary. We are merely suggesting that the system level is the appropriate level for performing such analyses. Artifacts obviously play a role in these systems, but by looking at them individually and specifically, we miss the fact they can function differently in different systems. A solar panel can be used both locally (off the grid) and in a large-scale system, but this leads to different practices: off the grid, its power will need to be stored somehow in order to use it when the sun goes down; but, within the larger grid, solar panels can be used to a certain degree to decrease the daytime peak load of traditional power plants. Simultaneously, any higher level of analysis, of energy in general, for example, would miss out on the nuances and particularities of specific technologies.

The example above highlights three dimensions to energy systems: convenience, efficiency, and transparency. Many further dimensions can be envisaged: geographic size and shape, load-balancing abilities over time and space, cost per unit of energy, user-reparability, reliance on finite resources, pollution, and so forth. Some dimensions are likely to prove more salient than others. It is the task of a philosophy of energy to compare and contrast different energy systems along those dimensions that allow for the most insightful perspectives.

The focus on systems in this philosophy of energy renders it unmistakably a specific incarnation of a philosophy of technology. Attention goes towards the kind of 
energy that occupies our technologies, as well as the technologies making this possible. Technologies here must be understood in the broad sense: not simply artifacts, but also societal organizations, "energy culture" and, most centrally, the systems combining all of these factors. How would such an approach work in practice? What kind of insights could it offer? In the final section, we briefly introduce one dimension to energy systems that we would claim generates valuable insights into energy transition developments: the dimension of flux and potentiality.

\subsection{Flux and potentiality}

We have thus far described how a philosophy of energy might help tackle issues in energy transition via conceptual analysis, critical reflection on argumentation, and raising the level of abstraction, while also broadening the playing field by drawing from a range of sources. Although it is difficult to illustrate all these claims within a single example, especially when there is little space to convey its subtleties and nuances, this section aims at taking some preliminary steps in that direction. It problematizes the concept of energy neutrality as the ultimate target for energy transition by emphasizing the importance of temporality in our energy systems.

To introduce this example, we return to the work of Heidegger. In the introduction to Heidegger's work on energy above, we saw that "the revealing that rules in modern technology is a challenging [Herausfordern], putting to nature the unreasonable demand that it supply energy that can be extracted and stored as such" (Heidegger, 1977 [1954], p. 14). The fact that energy is understood as something storable proves essential here. Energy is here patiently waiting; this represents what we propose calling potentiality, something static that can be put to use at the flick of a switch. It is, for example, the stock of coal next to a power plant, or the reservoir created by a hydropower dam.

Heidegger notes how this is a new phenomenon; it is the merit of modern technology to have access to energy in the form of potentiality: "[b]ut does this not hold true for the old windmill as well? No. Its sails do indeed turn in the wind; they are left entirely to the wind's blowing. But the windmill does not unlock energy from the air currents in order to store it" (p. 14). Energy as conveyed in the example

\footnotetext{
${ }^{5}$ The suggestion that energy as potentiality emerged with modern technology is historically problematic. Peat, stacks of fire wood, and other forms of stored energy (i.e. potentiality) date back much longer, whereas recent technologies like photovoltaic cells and wave power stations must be understood in terms of energy as flux. Additionally, with Mumford, one can say that,
} 
of the traditional windmill, we propose calling flux. This is energy that cannot be extracted and stored as such; thus something elusive, uncontrollable, and flowing.

The crucial difference between flux and potentiality therefore revolves around whether or not humanity controls it. Both a waterwheel placed in a river, and a hydropower dam blocking that river, make use of the potential energy of water flowing to a lower point. However, whereas the waterwheel can only influence the amount of energy taken out of the stream - the river flows whether or not there is a waterwheel placed in it -, the dam enables humanity to let the river flow only when we want to use its energy. In both cases, the river provides flux; but only in the latter case does the river turn into a provider of potentiality. The upshot of this form of control is an increased independence from temporal fluctuations in the energy source: a dam can store water for the dry season whereas the waterwheel becomes useless just as soon as the river stops flowing.

This distinction does not hold only for the primary energy source stage, but rather for every stage in an energy system. Take, for example, an electricity network fed by a coal-fired power plant. The stack of coal next to the power plant is a potentiality, a standing-reserve of chemical energy awaiting combustion in the power plant. When this finally occurs, it becomes flux: first in the form of heat, then as steam pressure, turbine rotation, and electric power. Some forms of flux can be stored and converted into a potentiality again: pressure stored in pressure vessels, electricity in batteries. At every stage in the process, energy is either stored (potentiality) or flowing (flux), but never both. Although flux within the power plant is initiated by human acting, we do not control the flow as such. A certain drop in turbine pressure results in a flow of gas, regardless of whether we are interested in this flow. In order to keep these flows stable and constant, great effort is put into managing pressure drops in the steam cycle and voltage levels in the electricity network: at every moment in time, the energy input has to match the energy output.

Armed with the twin concepts of flux and potentiality, we turn to the practice of green electricity. This is a product offered by power companies, enabling consumers to purchase electricity produced by wind turbines, photovoltaic cells, hydropower dams, or biomass combustion. Switching from grey to green power is as easy as ticking a box or making a single phone call to the utility company. Because green electricity is not (or hardly) more expensive than traditional electricity and there

although a windmill does not capture energy to store it as such, it does store it as produced flour, ready for consumption by society. 
appear to be no further drawbacks, it seems to be a pain-free solution to becoming part of the solution rather than part of the problem.

How might it be that changing the very source of one's electricity does not seem to involve any physical change but just a simple administrative procedure? This happens because the actual service the utility company provides does not change. It simply continues powering our houses, but now promises to generate as much renewable energy annually as it sells to consumers who have opted for green power. There is no guarantee that the actual electricity one uses is generated renewably; as it is still produced by a continually changing combination of sources to the grid. This scheme allows for the delivery of "green power" even when renewable sources are temporarily unavailable (say, on a windless night), as long as this is made up for at another point in time.

The implicit assumption here is that all electricity is generated equally. It does not matter exactly when or where a $\mathrm{kWh}$ is produced, as its function in the network is not related to its source. Electricity is treated as potentiality: stored energy directed to wherever and whenever needed. The electricity meter in our home patiently accumulates our consumption until periodically getting read and we pay the bill. Although electricity in the network actually is flux, because it needs to be in balance at all times and cannot be stored as such, this misconception might be fine as long as its ultimate source is an easily controlled form of potentiality: measuring electricity as just a proxy for the amount of fossil fuels being burnt to make it. ${ }^{6}$ However, when fluctuating sources become significant, this becomes problematic. Presently, German renewable electricity is already dumped on neighboring markets on sunny, windy days, because there is no place for it in the national network (Postma, 2012). As we do not control the availability of solar and wind power, there are periods of surplus as well as periods of shortage. Approaching electricity solely as potentiality becomes untenable.

How can society approach electricity as potentiality rather than as flux? We suggest that there are two core reasons. First, the fossil fuels around which our electricity systems are designed are indeed near-perfect forms of energy understood as potentiality. Although there are examples when the flow of fuel stocks (potentiality) was interrupted, leading to temporary energy "famines", the flux component of the

${ }^{6}$ This approach is not limited to our treatment of electricity. More generally, the concept of energy neutrality reflects the same focus on potentiality: something is energy neutral when, over its lifetime, it produces as much energy as it consumes. Within, for example, green architecture, it appears to be the pinnacle of developments (cf. Meijer et al., 2011). 
global fossil energy system has been relatively unproblematic in the last century or so. Second, the flux-related issues that did occur were always dealt with through technological innovation, hidden away from consumers. In the 1920s, pumpedstorage hydropower facilities were already being used to aid coal-fired power plants provide power during peak hours and correspondingly absorbing excess energy when the load on the network was low (cf. Hughes, 1993). Current efforts towards, for example, automatically load-balancing smart grids (cf. Clastres, 2011), or the envisioning of electric cars as distributed storage opportunities (cf. Kempton and Tomić, 2005), continue to distance flux-related energy problems from a broader audience.

For a number of reasons, we do believe that this purely technological approach to dealing with flux in our energy systems becomes problematic. First, and most fundamentally, we would note that the very nature of our primary energy sources is supposed to be changing through energy transition. Whereas fossil fuels function very successfully as potentiality, wind and solar power are forms of flux, fluctuating with daylight, weather patterns, and seasons. Should these sources become the basis of our energy system, load balancing needs to happen on a much larger scale than we currently achieve. That we are already touching on the boundaries becomes clear in the example of the German dumping of excess renewable energy on neighboring markets, and, for example, when technologists assume significant flexibility on the demand side of the energy system when calculating the feasibility of large-scale renewable energy systems (cf. Lund and Mathiesen, 2009).

This assumed flexibility on the demand side hints at the second problem we raise: this suggests that technological solutions can go a long way, but still need some help from consumers. However, because these consumers have been largely cut off from any appreciation of flux in the energy system, requesting they play their part is no trivial issue. They must first be made aware of this dimension before in any way being expected to act on it. After all, for the consumer, electricity emerges as if a form of potentiality; only when we plug in our appliances does the electricity meter star clocking up consumption. Meanwhile, the proposed technological solutions do little to change this - smart grids act behind their users' backs and give only the impression that fancy software on its own solves the problem.

Finally, the technologist pleas for consumer cooperation also suggests that the actual problem might be solved via different solutions. The issue is not necessarily a technical problem of load balancing within the network; rather, it is a question of the compatibility between energy usage by society and the sources and the system 
providing this energy. The two sides of this system co-evolved to their present situation, and trying to change the production side to accommodate renewable sources while leaving consumption as it is may not just prove extremely difficult, but may also be a solution for a misconceived problem. Another form of energy supply, perhaps one more sensitive to daily and seasonal rhythms, will induce different energy consumption practices. The task for engineers and policymakers is not necessarily to fit renewable sources into the current energy system, but rather to come up with a system that is both sustainable and caters to human needs.

At this point, we have begun questioning the exact nature of the energy transition that was briefly and uncritically introduced at the very beginning of this chapter. It has become clear that the transition cannot be merely a change of energy inputs, as those inputs have helped shape current energy practices. Which aspects of these practices do we deem most valuable? Only after gaining a better understanding of its functioning can we embark on a properly informed redesign of our energy system. More fundamental questions emerge: can ever-expanding energy consumption be sustainable? To what extent is current consumption merely a result of the structure of energy supply rather than the fulfillment of human needs or wants? What exactly are these human needs for which the energy system should provide? As already noted in the works of Mumford, Bataille, and Heidegger, these questions have no easy answer, but it is equally obvious that they need considering should energy transition prove able to provide us with energy for generations to come.

\subsection{Conclusion}

In this chapter, we argue in favor of establishing a philosophy of energy to deal with developments in what is known broadly as the energy transition. A philosophy of energy would be able to explore and clarify the space in which the so-called energy transition is taking place. It can be built upon the work of twentieth century critics of the functioning of energy in society such as Mumford, Bataille, and Heidegger, but not without an empirical turn towards actual energy systems.

We suggest this philosophy of energy would help in tackling issues inherent in energy transition via conceptual analysis, critical reflection on argumentation, and raising the level of abstraction, whilst simultaneously broadening the playing field by drawing on a range of sources. Let us briefly reflect on the treatment of our example in section 3 to illustrate these claims. From one of the twentieth century critics of energy in society, we developed two conceptions of energy that allow us to gain insights into the transition in electricity systems. The formerly unproblematic 
misconception of electricity as potentiality becomes an issue when intermittent renewable sources become more significant in the energy mix. The contrast that the two opposite conceptions provides also shines light on the logic underlying the solutions proposed: as long as users perceive electricity as potentiality, they cannot be expected to change their behavior in order to cope with flux. These are fundamental problems in the current debate that emerge through philosophical analysis. Finally, this approach enables a somewhat wider perspective on the actual problem: what is it that the electricity system is supposed to do anyway?

The example of flux and potentiality demonstrates how a brief philosophical exploration of a rather specific issue to energy transition quickly leads onto fundamental questions regarding the functioning of energy in society. Simply dismissing this result as a case of philosophers problematizing everything would be too easy. These weightier issues were already there but either ignored or answered specifically and implicitly in the current debates and proposed solutions. A philosophy of energy does not complicate the problems needing to be addressed on the path to a renewable energy regime; rather, such a philosophy provides clarifying concepts for tackling some issues while shedding light on problems hitherto hidden as well as the most appropriate paths to the solutions. It is high time to start fleshing it out. 


\section{Chapter 3}

\section{Self Practices and the Experiential Gap: An Analysis of Moral Behavior around Electricity Consumption}

Published as: Geerts, R. J. (2012) "Self Practices and the Experiential Gap: An Analysis of Moral Behavior around Electricity Consumption."

Techné: Research in Pbilosophy and Technology, 16(2): 94-104. ${ }^{1}$

${ }^{1}$ No co-authors. 


\begin{abstract}
As a way to mitigate climate change, ways to reduce electricity consumption are being explored. I claim Briggle and Mitcham's experiential gap offers a useful framework to understand the workings of our environment regarding this consumption. Via Foucauldian ethics, which holds people need to relate to their environment through 'self practices' in order to make moral choices, I argue that the complex and opaque electrical network makes it particularly difficult to consciously curb consumption. Efforts to make the network simpler and more transparent could enable engagement and 'ethical consumption,' but at the cost of decreased usability.
\end{abstract}

Key words: energy, electricity, consumption, Foucauldian ethics, experiential gap 


\section{Chapter 3 - Self Practices and the Experiential Gap: An Analysis of Moral Behavior around Electricity Consumption}

\subsection{Introduction}

One of the great global problems of our time revolves around energy. A century of increasing wealth for an increasing amount of world citizens has resulted in an enormous demand for fossil fuel (e.g., Raupach et al., 2007). Next to the fact that easily accessible supplies are running low, the main problem with the consumption of fossil fuels is the influence the emission of greenhouse gases have on the composition of the atmosphere. Low supplies result in political instability when countries start fighting for the last bits (Correljé and van der Linde, 2006), and resort to ever dirtier and less efficient ways of producing useful fuels. ${ }^{1}$ Global climate change threatens agriculture, ecosystems, and communities around the world with changing weather patterns and precipitation distribution, and more frequent extreme weather events (Barker et al., 2009).

To deal with these issues, a large variety of solutions have been proposed, one of which being the reduction of our energy consumption. But this is said more easily than done (Jaffe et al., 1999). Although many of us know we should reduce our consumption, progress is made slowly, if it is made at all. One of the ways in which we use energy is by consuming electricity. Since electricity comes from a variety of sources (coal, natural gas, wind, nuclear, etc.) and has many uses (lighting, cooking, all sorts of electronic appliances, etc.), measuring electricity (rather than the amount of light emitted in a house) is a useful way of measuring a large chunk of someone's energy consumption.

To reduce electricity consumption, two strategies are typically embraced: technological innovation, and the appeal to 'ethical consumption.' Technological innovation revolves around efficiency improvements and other energy saving

\footnotetext{
${ }^{1} \mathrm{~A}$ hundred years ago, one could practically pinch a hole in the ground in Texas, and oil would flow out instantly. Efficiencies of 100:1 (energy output : energy input) were not uncommon. To produce crude oil from Canadian tar sands, large amounts of fresh water and natural gas are needed, and efficiencies have dropped to around 9:1 (Shah, 2006).
} 


\section{Chapter 3}

measures, like the automatic shutdown of an electrical appliance after a period of non-use. To change consumption patterns, appliances are labeled according to their efficiency, and our morals are addressed via public service announcements. But despite significant technological improvements and an increased 'environmental consciousness,' electricity consumption per capita is not declining (De Decker, 2011; Steg, 1999). What is holding us back? Why do our attempts at reducing electricity consumption fail to be effective?

If we accept that the emission of greenhouse gases via domestic electricity usage is a case of pollution due to the practice of many independent consumers, we see that the twin strategies of efficiency improvements and ethical consumption are aimed at both ends of this problem: attempting to make practices less harmful, and attempting to alter the practices themselves. But these routes take for granted the center of the issue: the electrical system and the context in which consumption takes place. Could there be something about the electrical system that makes it particularly difficult to reduce its usage?

This chapter explores the idea that this is indeed the case. My aim is to describe the way we experience electricity, and to find out why this experience inhibits our making ethical choices about our consumption of electricity. In order to do this, I will use the concept of 'the experiential gap' as a way to understand why we are not actively involved with our electricity, and deal with a few technologies that aim to close or narrow the experiential gap, either by increasing the visibility of consumption, or by forming a much smaller network to produce electricity. Then, I will use Foucauldian ethics to understand why we need an active relation with our electrical system, concluding that the experiential gap inhibits the 'self practices' one needs to become an ethical subject.

\subsection{The Experiential Gap}

In "Embedding and Networking: Conceptualizing Experience in a Technosociety" (Briggle and Mitcham, 2009), Adam Briggle and Carl Mitcham claim that it is useful to understand modern society as a networked society, rather than an embedded one. In an embedded society, parts are subordinate to the whole, and the parts have a strong relation with the whole. Disembedding occurs when these strong partwhole relations get dissolved, resulting in an 'autonomization' of the parts. These autonomous 'ex-parts' can become nodes in networks, where networks are understood as systems of relations or links between nodes. These relations are much 
weaker and more susceptible to change than the ones that form an embedded society.

To make this a little less abstract, we can imagine a self-sustaining community on an island without contact with the rest of the world. People living here are embedded in their society, and probably have a fixed task or role in this society. The local economy is tied to social relations, culture, schooling, etc. Then, on the mainland, it is decided to initiate a ferry service with the island. Suddenly, there is an influx of foreign people and artifacts on the island, and perhaps some of the islanders' products are valuable elsewhere. The local economy gets disembedded and forms a node in the network of global economy, resulting in disrupted social relations, culture, and schooling as well.

Briggle and Mitcham describe five types of disembedding, the most interesting of which for us (and them) is 'experiential disembedding.' This entails the phenomenon that in increasingly complex networks, the experience of the effects of an action at a node becomes more distinct from the actual effects this action has on the network as a whole. The authors refer to this as the 'experiential gap.' To stay in the network idiom: "when individuals 'ping' the world with their actions, the return signals they receive are often distorted or muted" (Briggle and Mitcham, 2009, p. 11). An example of this effect is described by Garret Hardin in "The Tragedy of the Commons" (Hardin, 1968). If a pasture is shared by several shepherds, and these shepherds intend to maximize their income, the rational action for them is to add more sheep, even if this results in overgrazing and eventual exhaustion of the grounds. After all, the short-term benefit of adding another sheep-more wool and meat for this specific shepherd-is obvious, while the long-term harm-a little increased grass consumption per added sheep-much less so. (To make it even worse, it works the other way around as well: a single 'environmentally conscious' shepherd will not have much influence on the overgrazing problem, while their income does decrease significantly if they decide to tend a smaller herd.) While all shepherds closely monitor the apparent effects of the size of their herds, they cannot but increase them. Yet, on the scale of the pasture (or the network), their actions are devastating.

Although disembedding and networking are characteristics of all societies, they occur in an unprecedented intensity in the modernizing development of the western world. Means and ends become separated in what Albert Borgmann calls the 'device paradigm' (Borgmann, 1987): people only connect with commodities, while the machinery that produces them remains in the background. Modern production 


\section{Chapter 3}

systems are only possible through a disembedded understanding of the world: resources are 'decontextualized' and reduced to their technical functionality, stripped from everything that could remind us of their origin. ${ }^{2}$ The experiential gap is both a cause and an effect of increasingly large networks: the sense of autonomy and insignificance of one's choices makes it easy to take whatever one likes, and this taking enrolls a complex system of people and technology that makes sure you can get it.

It must be noted that Briggle and Mitcham offer a bit of a one-sided story. Technologies do not always have disembedding effects, and modernization does not always result in larger networks and increased experiential gaps. When inhabitants of a small town in the Chilean desert switched from delivery of fresh water by truck to a fog catching system, the network for providing them with fresh water shrunk considerably (Anonymous, 1998). A technology like the skateboard can have an embedding effect among its users in a city: skateboarders become part of the whole of the skateboarding subculture and connect to their streets in new ways. Still, the concept is a powerful tool to recognize certain techno-social developments. As we shall notice shortly, it helps to form important insights in the way we consume energy, and this alone should prove its merits.

\subsection{Electricity}

The electrical system fits the description of disembedding and networking extremely well. Electrical power enters my house silently and odorless. The only thing I need to know about electricity, is how to hook up appliances to the network to make them work. I do not need to know that electricity is generated somewhere from primary energy sources, and that these primary sources and the process of generating electricity are sometimes very dirty and destructive to the environment. Since my energy bill is debited automatically, I do not even need to know that getting the electricity to my house costs anything. But if I do notice it is not for free, I notice it is not very expensive, either. When I am writing this chapter late at night, I am not experiencing any fossil fuel being burnt or squeezed out of Canadian tar sands, even though my slightly humming computer, the light in my room, and the refrigerator in the kitchen are quietly fed by this enormous network that provides us with

\footnotetext{
${ }^{2}$ The food industry is a good example here. Most meat products available in supermarkets do not resemble the animal that they once were part of at all. A lot of people love those anonymous slabs of meat, while they have problems eating food that 'looks like animals.'
} 
electricity. Compared to medieval monks writing on locally produced parchment by candle light, my writing activity is highly disembedded (as I do not know where the things I am using come from) and networked (as I am having effects in far-away places like Canada or Nigeria, as opposed to the local parchmenter and chandler).

There are ways to (partially) close the experiential gap of electricity consumption, a few of which I will mention here. A 'kill-a-watt', a little apparatus that measures the energy consumption of the appliance it is connected to, makes one aware of the 'silent and odorless' flow I mentioned earlier. But the numbers visible on the display still do not say anything about the impact of the consumption. It is at most a reminder that there is indeed a network that feeds my fridge. In network terms, the kill-a-watt shows the download rate, but not the downloaded content, nor the nodes where the content comes from. More sophisticated devices like 'smart energy meters' work on the household scale and make users aware of their consumption patterns during the day. They allow people to connect a peak in their consumption with the moment they come home from work, or the consumption during the night with the 'background noise' of appliances on stand-by. Still, they offer the same kind of information as the kill-a-watt. Electricity suppliers might inform their customers about the origin of their electricity: 10 percent wind energy, 60 percent from suchand-such coal-powered generation plant, 10 percent imported from a neighboring country, etc. This way, a part of the network is being revealed, but it remains incomplete. The sheer size and complexity of the network makes it practically impossible to understand all of the effects of electricity consumption. ${ }^{3}$

Another way of closing the experiential gap is to make the network smaller. One could opt out of the electrical network and use their own off-grid micro generation system, for instance with a small wind turbine or solar panel. Being dependent on the local weather conditions (and the natural day), results in a less convenient, but more embedded experience. The user might have to save energy for a few days in order to run a washing machine, or call it a day because the batteries of the computer run out. Whether this is an acceptable sacrifice is a complex matter I will touch on in the final section of this chapter, but, for example, Jesse Tatum (1994) has shown that it is indeed possible to live and function off the electrical grid in western

\footnotetext{
${ }^{3}$ To make matters worse, even if one puts a lot of effort into understanding where their electricity comes from, it is but one of the many networks in which they are partially embedded. What are the effects of our food, or the clothing we buy? Our world is so complex that we will never understand our impact completely.
} 


\section{Chapter 3}

society. ${ }^{4} \mathrm{~A}$ self-supporting electrical system is surveyable for the user, or at least considerably more so than the worldwide energy network. Actions (turning on a light) return much clearer signals from other nodes in the network (drainage of the battery).

But why do we need to know our impact before we act accordingly? We have been told we should conserve energy whenever we can, so why do we fail to behave properly? Why is it the case that an experiential gap results in poor decisions, even if we do know that somewhere in the network, resources are being depleted and greenhouse gases are being emitted? In the next section, I will use Foucauldian ethics to understand the importance of strong relations with one's surroundings in order to make ethical choices.

\subsection{Foucauldian Ethics}

In "Obstetric Ultrasound and the Technological Mediation of Morality: A Postphenomenological Analysis” (Verbeek, 2008), Peter-Paul Verbeek describes Michel Foucault's work on ethics in the second and third volumes of Histoire de la sexualité (Foucault, 1984a, 1984b). "For Foucault, ethics is not primarily about the question which imperatives we need to follow, but about the ways in which human beings constitute themselves as 'subjects' of a moral code" (Verbeek, 2008, p.19). So rather than developing a new moral code, Foucault investigates what the underlying framework is that enables people to become ethical subjects. The key term here is 'subject.' Usually, the word is used as a noun, as more or less the opposite of 'object': something active or autonomous, opposed to a world of passive objects surrounding it. But 'to subject' is also a verb, and the action of subjecting oneself to a moral code is the action in which Foucault locates ethics.

The act of subjection to a moral code forms the basis of every ethical framework. Living according to Christian morality implies subjection to the Christian god, utilitarians have subjected themselves to the rule that the action with the most favorable outcome is the ethically just one, and deontologists have subjected themselves to the categorical imperative. Subjection often happens implicitly, but according to Foucault, it was a rather explicit endeavor for the ancient Greeks. For them, "ethics was not about showing morally right behavior, but about living a good

\footnotetext{
${ }^{4}$ Since 1994, solar cells and batteries have come a long way, so one can imagine that living off the grid is more feasible now than when Tatum did his survey.
} 
life" (Verbeek, 2008, p. 20), so to become a moral subject was to practice and stylize one's behavior explicitly. This happened through a variety of ascetic and aesthetic practices, where 'asceticism' does not necessarily mean to abstain from all sorts of pleasures, but rather to consciously form a relation with urges and pleasures. Whether someone lives a good life, is defined by the relations this person has formed with their surroundings.

It is interesting to note that this is quite different from the idea of the autonomous subject, which is that subjects are to be rational beings, free from influences from the outside. "Freedom here is not the absence of factors that steer and shape the subject, but the very relation to these factors" (Verbeek, 2008, p. 22). This is where, for Verbeek, technology comes in. Since technologies shape our choices- if only because of the possibilities they create-we cannot be understood as autonomous subjects, so in our technologically mediated society 'traditional' ethics is of limited use. Since Foucault allows for external influences, his framework shows insight on how technologies can be understood as 'factors that steer and shape the subject,' and how to form a relation to these factors.

In accordance with Aristotle's four causes, Foucault discerns four aspects of moral self-constitution: the ethical substance (causa materialis), the mode of subjection (causa formalis), self practices (causa efficiens), and the teleology of these practices (causa finalis). The ethical substance is where people understand their 'ethical self to be, for instance in their intentions or passions. This 'material' takes shape by finding ways to deal with the outside world. The mode of subjection is the form which people use to develop their moral self, for instance a divine law, cosmic order, or rational rule. Self practices are 'self-forming activities' in which one takes some distance from what determines them, in order to form more of an explicit relation with it. Teleology, finally, concerns what the goal of the ethical subject is. Does one want to become free, immortal, pure?

How does this work with the electrical system? Our choices do not have much to do with the ethical substance in this case. The mode of subjection could be a rational rule, for instance a utilitarian one: "I should only use so much electricity that the added happiness for me is larger than the diminished happiness of others." Depending on how broad the group of 'others' is defined (other people, future generations, non-human animals, ecosystems), one could possibly come up with some amount of electricity to be used. So far so good, but it is the self practices where the story gets troubling, as the design of the electrical system makes it difficult to explicitly engage with it. Its convenience makes it easily sink into the background, 


\section{Chapter 3}

and its complexity makes it hard to see through. To take some distance and form an explicit relation with the electrical system, is therefore a difficult task. Finally, the teleology of the ethical practice remains open here, but is an important issue to understand what we really should do.

The experiential gap thus inhibits people from enrolling in self practices regarding the consumption of electricity. As a result, they are unable to properly 'stylize' their use of electricity according to their moral beliefs, and are led in their decisions by a system that they are unable to take a distance from. Technologies that close or narrow the experiential gap, like the kill-a-watt or a self-powering electrical system, do allow one to take more of an explicit stance towards their use of electricity. But this stance is no guarantee that you will make the 'right' decisions, it is rather a minimal requirement. Neither Foucault nor Briggle and Mitcham offer a conclusive argument that one should indeed switch to energy saving light bulbs. What they do offer is a way to make sure that people are in a position to make informed choices about the matter.

This analysis shows that often claimed drawbacks of environmentally conscious alternatives for polluting technologies, like being cumbersome or less pragmatic, are no mere side-effects that need to be overcome by smarter designs, but are rather essential to their functioning. It is exactly the attention of the user that these technologies demand, that makes them work. There are no shortcuts or easy ways out; to become an ethical subject, one must invest time and effort into forming healthy relations with the proper technologies around them.

This has significant implications for the expectations regarding strategies to reduce electricity consumption. Public service advertisements drawing on a moral duty to 'save the planet' by reducing electricity consumption are unlikely to succeed as long as the complex and opaque electrical system remains in place. I do not claim that ethical behavior is necessary to reduce electricity consumption, or ultimately to overcome difficulties of resource depletion or global climate change. There might be other ways to pursue these goals. Perhaps proper laws or tax incentives can persuade people into using less electricity, or renewable energy generation could turn the whole thing into a non-issue. Yet, if our hope is on moral choices of citizens, the technologies with which they interact need to be taken into consideration.

Regardless of the environmental issues that come with energy consumption, the above analysis brings to the fore how our behavior is strongly influenced by the technological systems surrounding us. If we accept that Foucauldian self practices 
are essential to develop moral behavior, it can be argued that technologies inhibiting these practices are inhibiting our moral development. Therefore, closing the experiential gap and thus enabling or even encouraging self practices can be understood as a moral goal for designers and users of technologies.

However, this is not as straight forward as it might appear. We use the electrical system exactly because it gets out of the way, so we can focus on the task at hand. A system more tailored towards moral behavior will inevitably be less user friendly, which makes this alternative less appealing when people are looking for a technology that fits their purposes. Only if prospective users recognize the moral issues inherent in modern technological networks, they might accept the reduced usability of systems that narrow or close the experiential gap; but the recognition of these issues is unlikely because of their hidden character. We thus find ourselves in a deadlock when it comes to asking users to switch to a system that allows self practices: they need to understand the moral issues to start using an alternative system, but the issues become apparent only after making the switch.

If this analysis is adequate, it becomes clear that the opaque electrical network impedes the development of the 'ethical consumption' of electricity. Making the network smaller or more transparent will improve the abilities of people to develop self practices, which improves their moral competence and could lead to more sustainable practices, but at the cost of reduced convenience. Whether or not that price is justified, the fact that it comes at a cost does reduce the likeliness of a widespread shift in this direction.

An alternative route revolves around making the network less polluting, e.g., by using renewable energy sources or deploying energy saving measures. This would not reduce the convenience of the system, but also would not allow for self practices by the user. This latter point is problematic if self practices are appreciated as an end in themselves, and if the 'greening' of the network is expected to come partly from consumers (e.g., when purchasing appliances or choosing their energy supplier), as this again presupposes a certain engagement with the system, which is exactly what is lacking in the conventional system.

\subsection{Conclusion}

Our electrical system invites easy and latent consumption of energy through its clean and silent design, while making it difficult to appreciate all the effects that come with using electricity. This is due to the networked nature of the system: 


\section{Chapter 3}

technologies like the electrical system separate means (generating electricity somewhere far away) from ends (refrigerating beverages), resulting in large networks which cannot be overseen by a consumer. There is a discrepancy between the experience of a consumer of electricity, and the effects of this consumption on the rest of the network. This is the experiential gap. Technologies like the kill- a-watt aim to decrease energy use in closing the experiential gap by increasing visibility; micro generation does this by radically decreasing the network size.

Closing the experiential gap is important because to become an ethical subject and make ethical choices, one needs to develop a relation with one's surroundings. This is what Foucault calls 'self practices': to gain some distance and form an active stance towards your environment. Complex networks with large experiential gaps do not allow relations to be formed with them, so people are unable to behave as ethical subjects when they deal with such networks. However, redesigning these networks to encourage self practices is problematic because this would reduce the convenience of their use. This entails an additional difficulty to the development of morally sound behavior of consumers. If we want people to develop themselves as ethical subjects, we should not just aim for moral education, but also for technologies that allow the forming of relations with them. Failing to do so will lead to a society in which people might be willing, but are not able to reduce their energy consumption. 


\title{
Chapter 4
}

\section{Beyond Scarcity: Perspectives on Energy Transition}

\author{
Submitted for publication ${ }^{1}$
}

${ }^{1}$ No co-authors. 


\begin{abstract}
Two dominant lines of reasoning in the philosophical debate on energy transition can be described as boundless consumerism (we should find ways to keep growing) and eco-frugality (we should reduce our impact as much as possible). This chapter problematizes both approaches via their implicit understanding of the good life, and proposes a third alternative: qualitative abundance. Society is not interested in any sustainable energy system, but in one that caters to our needs and enables us to flourish as human beings. Because the dominant lines in the current debate share a concern for scarcity, they fail to raise the question of a good energy system. Qualitative abundance initiates discourse around prosperity (with boundless consumerism) and simplicity (with eco-frugality), thus expanding and enriching the understanding of issues at stake in energy transition.
\end{abstract}




\section{Chapter 4 - Beyond Scarcity: Perspectives on Energy Transition}

\subsection{Introduction}

Energy transition, understood as the shift from a finite, polluting, climate changeinducing, fossil energy regime towards a sustainable, clean, climate neutral, renewable one, is a large, complex, and poorly delineated socio-technological project. It is large because the energy basis of society is enormous - about one sixth of all economic activity revolves around energy (Shah, 2006). Its complexity derives from multiple problems needing resolution: anthropogenic climate change, peak oil, local environmental issues, national energy security, etc. Additionally, the energy system is intertwined with almost every aspect of modern life. National economies function in relation to energy production and use. The shape of cities is influenced by the amount and kinds of energy available to their inhabitants. Individuals make energy consumption choices on the basis of cost and availability. Finally, the energy transition is poorly delineated because different routes imply different boundaries. An engineer working on solar fuels may think the thing to change is the production and refining of primary sources, whereas the sociologist studying relations between energy consumption and culture imagines an emergence of new practices and traditions. The problem, and thus the solution, is different and much narrower for the engineer than for the sociologist.

It should not come as a surprise then, that the debate around the energy transition has so far been a complicated one. But this is not to say that no structure or clear contrasts can be recognized. This chapter aims to sketch one such contrast around the issue of scarcity, and problematizes the implicit understanding of aims of energy transition on both sides of this discourse. An alternative position is proposed that rejects scarcity, and that leads to the creation of two other discourses, on prosperity and simplicity.

It should be noted up front that the 'positions' and their resulting lines of reasoning described here are not necessarily actual positions that are held by participants in the debate. Rather, they are starting points: philosophical positions on the functioning of energy in society which underlie discussions on energy technologies, systems, 


\section{Chapter 4}

policies, and practices. Argumentative routes originate at such starting points, and also have a direction: they are aimed at contesting arguments from other starting points. In extreme cases, in which a debater exclusively employs one of these routes to define their position, it may be said that they identify with that starting point, but I do not make any claims here that such people exist ${ }^{1}$. Instead, argumentation from various starting points may be mixed and weighted through some kind of balancing mechanism.

Such balancing mechanisms may lead to nuanced positions, arguing for example that both sides have their merits and that truth must be somewhere in the middle. In such cases the distinction between various lines of reasoning is useful to get more grip on how exactly this middle would be conceptualized: can we speak of a continuum, or is it actually not an opposition after all? In other cases, people may argue from a variety of positions to make a claim, but those arguments may be inconsistent. In such cases, describing the opposition in clear terms helps to understand exactly why such positions are inconsistent.

The chapter is structured as follows: section 4.2 outlines two positions or 'camps' in the current debate, boundless consumerism and eco-frugality, and briefly discusses their merits and demerits. This is followed by an exploration of the notions of the good life implicit in these positions, and their shared perspective on energy and scarcity in section 4.3. Section 4.4 introduces another perspective, called qualitative abundance, and explores its roots and characteristics. Section 4.5, finally, relates qualitative abundance with the other two perspectives, and briefly sketches the resulting discourses between them in terms of prosperity and simplicity.

\subsection{Discussions on possibility: boundless consumerism and eco-frugality}

A good amount of discussion on energy transition revolves around concerns of possibility: what kind of energy system is available, considering problems such as climate change and dependence on finite sources? What are the design options, which boundaries do we have to consider? Within this discussion on possibility, which is a sub-section of the discussion on energy transition in general, a general distinction can be discerned between those embracing growth of some sort, and

\footnotetext{
${ }^{1}$ Indeed, when I give examples of 'boundless consumerist thinkers' later on in this chapter, I do not expect that those thinkers would self-identify with my proposed concept. What I claim is that their in their work, lines of reasoning are present that strongly align with my concept of boundless consumerism.
} 
those who reject it. These positions I name boundless consumerism and eco-frugality respectively. By distinguishing and characterizing these lines of reasoning, we gain insight in what is and is not discussed between them.

The boundless consumerism line of argument embraces high-energy practices that developed in the fossil-fuel era, and aims at finding sustainable sources and efficiency improvements to continue to power them. Simply put, it holds that smart management and novel technologies are all we need to plug into abundant sustainable energy sources that can keep powering our ever-increasing demands. Adherents to this position argue for 'green growth': the idea that economies can keep growing if only we made some changes in the direction of development. Examples are Julian Simon (1981) and more recently the 'Ecomodernist' movement spearheaded by The Breakthrough Institute (Asafu-Adjaye et al., 2015).

Belief in the viability of this route can be based on a variety of arguments, which can be categorized as ecological, technological, and economical optimism. Ecological optimism holds that the (fossil or renewable) energy supply on which society is based is practically unlimited, for example by appealing to the earth's enormous solar income compared to society's total energy consumption: "Within 6 hours the world's deserts receive more energy from the sun than humankind consumes within a year. This means that sufficient clean power can be generated from the world's deserts to supply mankind with enough electricity on a sustainable basis." (Anonymous) This is ecological optimism because it argues that the ecological basis of society is not as limited as is often argued.

Arguments based on ecological optimism are often combined with those based on technological optimism, which holds that technological developments will outpace depletion of the energy sources we are currently using. For example, we would be able to produce unconventional oil and gas at a pace fast enough to compensate for declining conventional oil production; carbon capture and storage will solve the problem of $\mathrm{CO}_{2}$ emissions while continuing fossil fuel use; or photovoltaics will become so cheap that within a few decades we can fill deserts with them to actually employ the abundant solar income. These expectations are typically backed up by historic data of depletion and replacement rates of various resources (Simon, 1981). The optimism in this argument revolves around the assumption that historic technological breakthroughs will be replicated in the future, even though this is not necessarily the case. Battery technology for example, which is essential for wide-scale use of intermittent energy sources in the current electricity system, has proven to be notoriously resistant against real breakthroughs in capacity. 


\section{Chapter 4}

Economical optimism, finally, holds that the economy can keep growing on a declining energy footprint. This idea is based on the fact that when economies develop, they tend to grow faster (in terms of GDP) than their energy basis does; for example because it shifts from industry to less energy intensive services. Although this effect thus far has been mostly relative rather than absolute (energy consumption grows more slowly than GDP but it still grows, at least when imports are taken into consideration (Barrett et al., 2013), absolute reductions of energy consumption are possible at least in principle. These arguments are optimistic because as yet there is little proof that the energy footprint of our economy can shrink quickly enough whilst not significantly reducing economic growth.

Decoupling comes in various forms. Efficiency improvements may make a unit of travel less energy intensive, so even with a limited ${ }^{2}$ flow of available energy we can keep increasing our mobility demands. We may move on to different, less energy intensive forms of consumption: from purchasing physical media on CD/DVDs to streaming services, for example ${ }^{3}$. Finally, inflation may mean that although GDP grows, actual physical consumption drops. After all, monetary value is a construct that has no strict relation to the physical world.

Note that although these positions are grouped under the banner of boundless consumerism, they do not necessarily argue for growth of consumption at any cost they may accept a slower pace of growth in order for this growth to be sustainable. Also, they do not necessarily always agree with each other; there is plenty of debate between proponents of different technologies regarding how exactly to produce unlimited energy. Although such debates are worthy of study as well, these are bracketed here because diving into the various provinces of boundless consumerism would reduce the clarity of the concept at the general level needed for the present purposes.

The central point shared by all these positions is that there is no absolute limit in sight: the energy basis (or technological development, or economic activity) is boundless. This means that an energy transition needs to ameliorate current problems of the depletion of specific resources, or specific forms of pollution (e.g. smog or

\footnotetext{
2 'Limits' come in two forms: limited income (such as solar energy, monthly salary, or interest) and limited stock (such as fossil fuels or savings in a bank account). In this case limited income is meant. I only explicate which kind of limit is meant when it is not obvious from the context.

${ }^{3}$ This is contested, see for example De Decker (2008) who argues that this is only less energy intensive when we do not stream the same material too often.
} 
$\mathrm{CO}_{2}$ ), but not much more than that. It is therefore a rather modest project, that may be solvable by a dedicated group of technologists or technocrats, out of the way of the consumer, who can keep expanding their consumptive interests. This is exactly what eco-frugality problematizes.

Eco-frugality can be described as being concerned that one or more of the optimisms described above is not warranted by our present situation: resources are limited; alternatives are not being developed quickly enough, and/or (fossil) energy is too central in our economic system to be drastically rejected without giving up growth. It may be argued, then, that eco-frugality is based on one or more pessimisms that mirror the optimisms described above.

Such pessimisms are not new. One early version of them can be found in Malthus' (1999) population dynamics: he argued that a society cannot continue growing indefinitely because of a limited carrying capacity of the soil. In the 1970s the industrial version of this argument was put forward by the Club of Rome in their seminal report entitled Limits to Growth (1972). More recently, peak oil and climate change have spawned a myriad of pessimist commentators. See, for example, the work of Heinberg (2004) and Greer (n.d.) on peak oil, and the Stern review (Stern, 2007) and This Changes Everything by Naomi Klein (2014) on climate change. These authors typically debunk one or more of the optimisms mentioned above with a number of empirical claims, after which a proposal is made on what to do to avert the crisis.

The eco-frugalist conclusion is that boundless consumerism is impossible, and that therefore we must minimize our energy consumption whenever we see the opportunity. This is no trivial task, as energy consumption is not usually on our minds. This means we need to be constantly reminded of the efficiency of our cars, to turn off the lights when we leave a room, and to simply stop doing whatever can be understood as wasteful expenditure of energy. Eco-frugality is a conscious reduction of energy consumption: we need to be aware of what we are doing in order to change our routines, and (the abstention from) energy consumption must be on our minds at all times. It is a negative message: although we may want to indulge in certain polluting or depleting activities, we are not allowed to, because it would lead to negative consequences.

Although some eco-frugal efforts may appear to be very similar to the ones which improve efficiency in order to allow continued economic growth, the aim is rather different. In the case of eco-frugality, a car displaying its current fuel consumption in 


\section{Chapter 4}

order to inspire more efficient driving is aimed at reducing the energy expenditure of a specific trip, whereas the same car would allow more and longer trips to boundless consumers.

Discussions between boundless consumerism and eco-frugality thus revolve around competing and incommensurable empirical claims about e.g. the amount of available fossil resources (and therefore the time available for a transition), and competing theories with regards to technological development, economic principles, climate science, etc. These issues are complex and not likely to be solved any time soon. It has been shown that the typical approach of 'further research' does not do away with controversies, but rather allows for further reasons to disagree with one another (Sarewitz, 2004; Thompson, 2007).

One example of controversy between these two positions revolves around 'Jevons' Paradox'; the insight that with increasing efficiency in steam engines, demand for coal increased rather than decreased in mid-19th century England (Jevons, 2013). Generalized, it argues that efficiency improvements do not lead to conservation of resources. The reason for this effect is that energy becomes relatively cheaper to use when it is being used more efficiently, so its demand increases. The general form is known as the rebound effect, and appears to be a rather robust economic law (Saunders, 1992), although controversy still remains regarding the magnitude of the effect. At the micro-scale, studies reveal rebound effects of a fraction of the efficiency improvements (Greening et al., 2000), indicating a smaller but still existing conservation through efficiency improvements. This is also reflected in the fact that energy consumption in several developed nations has declined over the last decades. For example, UK primary energy consumption decreased between 1990 and $2009^{4}$. However, part of this decline is caused not by efficiency improvements, but by off-shoring energy intensive industries to developing nations (Peters et al., 2011; Wiedmann et al., 2015). Taking greenhouse gas emissions as a proxy for energy consumption, Barrett et al. (2013) show that while territorial emissions dropped similarly to primary energy consumption in the UK between 1990 and 2009, emissions caused by UK consumption (including imports) showed a net increase. This suggests that despite two decades of efficiency improvements, no actual reduction of energy consumption seems to have occurred at the nation level.

\footnotetext{
${ }^{4}$ From $9.4 \times 10^{18} \mathrm{~J} /$ year in 1990 to $6.9 \times 10^{18} \mathrm{~J} /$ year in 2009 , a drop of $26 \%$, according to the
} EIA (accessed through Wolfram Alpha) 
Although the empirical data is still inconclusive, the upshot here is that an economy imagined by boundless consumerism may be unable by itself to reduce its energy footprint - it may be that as long as the market does its job, energy consumption will not decrease. Still, adherents to boundless consumerism would have a variety of arguments at their disposal to defend their approach: they may dispute the data, argue that increased energy consumption is no problem as long as it is clean and sustainably produced, or they may suggest a tax on energy use which creams off efficiency gains. However, this final route seems to be a hard sell to a public that has been taught that growth is the source of all that is good in life, and it would still not result in an absolutely declining energy footprint while GDP increases.

At first sight, eco-frugality seems to be threatened even more by rebound effects: penny-pinching leads to savings which at some point will have to be spent on something else. But this assumes market mechanisms, while eco-frugality attempts to override the market with morality: it side-steps Jevons' Paradox by not relying on market effects to reduce consumption, but on moral limits society sets for itself. If our energy consumption has increased steadily because technology made our consumption mostly invisible and therefore impossible to relate to morally (Chapter 3), eco-frugality would promote more transparent energy technologies, so that a moral appeal for restraint can be made on consumers.

Discussions such as these clarify and sharpen argumentation from both lines of reasoning and help explore and explicate potential issues, thus furthering the debate. Although certainly important, these debates fail to reflect on the playing field, the (implicit) rules of engagement, shared fundaments, and blind spots. Indeed, sometimes the lack of attention to an issue is more telling than the discussion itself. In the next section I propose to raise the level of comparison to such an issue: the conceptions of the good life implicit in the proposed futures. It turns out these are poorly developed, and it is suggested that this is due to the centrality of scarcity in the discourse between these two positions. This insights allows me to introduce an alternative perspective that enables a richer discussion.

\subsection{The desirability of the possible: implicit understandings of a good energy system}

Before we dive into the substantive conceptions of the good life implicit in discussions on energy transition, it must be argued why such a shift in the discussion is permissible. The central point here is that the reason society pays so much 


\section{Chapter 4}

attention to energy systems at all is that these are supposed to provide for our wellbeing. Not only are we interested in a sustainable energy system, but it should also (and perhaps primarily) cater to our needs and enable us to flourish as human beings. One may then argue that the task of the energy system is to silently provide for our needs and to let the shaping of our lives be solved by every individual personally. However, that is not how it works.

The influence of our technological systems on the lives we live has been a central thread in philosophy of technology since the early 1900s. Martin Heidegger, for example, argued that modern technology has radically changed the way human beings are in the world (Heidegger, 1977), Bruno Latour holds that technological artifacts lead a life of their own and should be understood as actants much like ourselves (Latour, 1992), and post-phenomenological scholars like Don Ihde (1990) and Peter-Paul Verbeek (2005) have explored the various ways in which technologies change the way we perceive and act in the world, which has consequences for the ways in which we should think about morality (Verbeek, 2011).

But for the current argument it is enough to subscribe to a rather minimal understanding of the influence of technology on our lives, for example the one subscribed to by Thaler and Sunstein. In Nudge (2008), they argue that our physical environment may be understood as a choice context: any choice we make will be more or less influenced by the way in which the choice is presented. There is no such thing as a neutral choice context: there must be a default option, a way to organize the options, the exclusion of some options, etc. One of their most famous examples is the ordering of food in a cafeteria. People are known to be more likely to purchase the food that they see first. Should the cafeteria manager therefore put the healthy food up front in order to inspire healthier diets? Or, armed with this knowledge, are they still justified to organize the food in any manner that maximizes their profits? In the light of this chapter, Thaler and Sunstein's point is not so much that there needs to be one best way to arrange things, but that the arrangement of things matters, and therefore provides us with some knotty problems to think about when we design the environment in which we live.

Considering the enormous magnitude and pervasive nature of the energy system, it is quite obvious that it influences many choice contexts. The easy availability of gasoline makes the automobile a viable option for transportation, while the ubiquity of cars in the streets makes cycling or walking less appealing. Central heating makes every room in our houses comfortable, and so discourages a family to gather to share 
warmth. Simply put, the kind of energy system we design will have a big influence on the lives we will be living. Energy transition is therefore an opportunity to reflect on the current system, conserve the good parts, and improve the rest so it caters better to diverse human needs while being sustainable.

This shift in the discussion means broadening it from the possible to the desirable. Although it is tempting to try and keep the debate on energy transition 'factual' and leave the morality to individual users, that simply is not possible - societal choices will constrain individual choices, the shape of the energy system we share constrains the options that individuals have to design their own environment. The energy system is morally relevant, so its transition is as well. A discussion on energy transition can either engage with or ignore the moral issues, but it cannot circumvent them.

There are many ethical issues related to the energy system, such as concerns of justice (what is a fair distribution of energy in society?), risk (what kind of risks can the energy system acceptably cause?), and the environment (what burden can we place on the non-human environment?). Although these all warrant attention, they do not really provide an alternative perspective on energy transition. Rather, they provide (negative) boundary conditions: the energy system should not be unjust, it should not involve risks greater than this-or-that, and should not burden the environment excessively. Focusing on the good life, on the other hand, offers an alternative perspective on what the energy system should do. This makes it a suitable angle to lift the discussion on energy transition from the possible to the desirable.

Boundless consumerism revolves around the idea that consuming goods and services importantly constitutes the good life. Individuals, or perhaps more accurately consumers, ideally find themselves in a free market, and are expected to make consumption choices that ultimately add up to a good life as conceived by this consumer: they are expected to 'design their own lives'. As long as the free market is plentiful and consumers are wealthy enough to pursue their goals, this will automatically result in people living the best lives they can. The goal of energy transition must therefore be nothing else than ensuring there is no lack that inhibits anyone to pursue their goals. Allan Stoekl describes the resulting stance of the consumer as "I spend, or waste, so that I will ultimately be saved" (Stoekl, 2007, p. xv) - the religion of the credit card. This approach to the good life is based upon a crude economism: any good that is available in the market comes at a certain price, and the individual consumer is to make the assessment whether the purchasing of a specific good would be worth the price, or indeed the best way to spend their limited 
amount of funds. Growth, then, is always good, as it increases the amount of purchases we can make.

There are several ways to critique this approach. I will here briefly discuss two main routes: the mismatch between the need for infinite growth on a finite planet, and the failure of the means of consumption to lead to the end of the good life.

The first route to problematize boundless consumerism is to claim that it may be a dead end. Even if this route would provide for the best possible lives in theory, it will not work on a finite planet. This is an argument made by Richard Heinberg (Heinberg, 2004), and reflects the eco-frugalist stance at a higher level of abstraction. Striving for infinite growth of a finite planet is bound to lead to resource wars, many losers, and disillusionment: the outcomes will not reflect the utopian vision we set out to reach. The weakness of this critique is that it is partly based on empirical claims that counter one or more of the optimisms mentioned above. As long as there is controversy about these empirical claims, this argument is not likely to win many sceptics over. ${ }^{5}$

The second route problematizing boundless consumerism is to argue that it does not seem to work. Above a certain threshold, there is little to no correlation between (energy) consumption and happiness: in the United States between 1950 and 2005 per capita GDP tripled, but the percentage of people considering themselves 'very happy' has remained largely stable (Speth, 2009, p.132). Tim Jackson for example therefore argues for a new economic approach in Prosperity Without Growth (Jackson, 2011): we can improve our quality of life without relying on growth. While the first route uses an argument external to the boundless consumerist understanding of the good life, the second route comes closer to the core. Arguing that it is not a wise project, like Heinberg does, does not question the goals of boundless consumerism, were it possible to pull it off. Jackson, on the other hand, raises the question whether the project of consumption growth would even in theory be the proper means to get to the end of the good life: he suggests this route is fruitless in principle as much as it is in practice.

This route is still susceptible to discussions on the empirical basis of this claim. Is it really the case that consumption and happiness are not related above certain threshold, or have other causes (e.g. environmental, social, or geo-political concerns)

\footnotetext{
${ }^{5}$ Whether such a controversy is actual or staged does not matter much for people to feel reassured in their position, as becomes clear by how little climate change deniers give in to the scientific evidence stacking up against their position. (Klein, 2014)
} 
offset the benefits of consumption? By comparing across nations Jackson makes his thesis at least plausible, but another level of conceptual critique would add to the strength of the argument.

Such conceptual critique can be found in the work of Albert Borgmann, who has argued that when modern technology commodifies elements of our lives, it silently reduces their quality (Borgmann, 1987). According to Borgmann this is because the practices we consider valuable always get changed when they are commodified, and often the aspects of these practices that felt cumbersome turn out to be essential to their contribution to the good life. For example, a central heating system commodifies warmth in a household, making the whole of the house comfortable to be in. At first sight a great gain, but it discourages the members of the household to convene around the hearth, which did not just provide heat, but also an opportunity for sharing good stories and a sense of community. If consumption expands boundlessly, it commodifies more and more elements of our lives, and thus could leave us impoverished rather than enriched.

A further and much more diverse critique of industrial society can be found in the work of Ivan Illich $(1973,1974)$. Perhaps most central to his work is the idea that narrow goals end up counterproductive if given enough time. Illich identifies two watersheds through which every modern institution will pass: the first when this institution becomes more efficient than the practices it replaces, the second when increasing development only increases the effort needed to support the institution. Motorized transport, for example, already passed both watersheds: the first when railways made travel faster than what used to be possible on foot, and the second more recently when automobile culture became dominant. The automobile may have a higher top speed than the bicycle, but at the cost of spending a substantial amount of our income on the car itself, its maintenance, fuel, road tax, etc., and at the cost of spending more time waiting in traffic, looking for parking spots, and going to the gym to get exercise. All in all, Illich calculated, the net velocity of the average car in 1970 in the US was close to $5 \mathrm{mph}$.

Such counter-productivities are hard to break through because of the development of radical monopolies: monopolies of one kind of means to reach certain ends. The automobile has a certain degree of radical monopoly for transportation in some geographical areas, for example through the (re)design of cities with shopping malls away from the city center (accessible only through freeways), sprawling suburbs, and underdeveloped public transport options. By tailoring the transportation system to favor automobiles, walking, cycling, and mass transit are discouraged or impossible. 


\section{Chapter 4}

This means that although we as consumers find ourselves in a 'free market' with plenty of options regarding which car to purchase, but all of these choices are within a narrow spectrum ${ }^{6}$, meaning that the system is characterized by a combination of affluent choices on commodities and very limited choices on different societal trajectories.

The general point to take away from this is that we may be consuming ourselves into a corner: we work more and more to achieve something that becomes increasingly hard to reach, while obstructing the possibility of alternatives. Illich therefore suggests we should be wary of such developments, and refrain from 'optimizing' our institutions beyond the second watershed. In other words, we need to keep checking whether we consume to satisfy our needs and wants, or whether we consume to be able to consume more.

Whereas boundless consumerism is built around a problematic understanding of well-being, eco-frugality is concerned even less with a developed understanding of the good life. It is based on a negative message: yes, we may like the lives we are currently living, but if we do not stop doing these things we like, we will suffer the consequences. We do not really want frugality, but it is our only option: we have to give up part of our freedom (wealth, purchasing power) in order to prolong life (society, the earth). The eco-frugalist conception of the good life is therefore not central to its argument: instead of thinking about how to live a good life, we should be concerned with living life at all. But this does not mean that there is no reason to assess the kind of life being envisioned by eco-frugalists. Is the price to be paid worth it? Are there perhaps positive aspects to life as promised by eco-frugality? Is it at all desirable?

A good place to start is Allan Stoekl's assessment:

An ecoreligion, one that would defy the 'comfortable' or 'free' (and nonnegotiable) lifestyle of consumerist humanism ... through a religiously inspired cult of austerity, simplicity, and personal virtue. Such a cult refuses certain basic human urges to consume or destroy, and in the process involves

\footnotetext{
${ }^{6}$ Illich argues that radical monopolies may be situated at an even higher level: not just automobiles, but mechanized transportation in general, including e.g. motorcycles and public transport such as trains and buses. This would still be a 'narrow spectrum' for Illich, because self-powered mobility is made all but impossible. In practice, the absence of public transport options in a significant part of the developed world further narrows the options for the individual.
} 
the affirmation of yet another humanism (the self as virtuous in its austerity) and, after consumer profligacy, yet another model of nature as a standing reserve to be protected largely for its value to Man. (Stoekl, 2007, p. XV).

The core of the good life according to eco-frugality is 'virtue in austerity': the satisfaction that is found in making do, doing without. However, Stoekl is very critical of its appeal. Historically, virtue in austerity has been strongly promoted by Protestantism, but unlike Protestantism, eco-frugality does not offer the promise of an afterlife in abundance - just the grey life on earth. Stoekl simply cannot believe that austerity has any appeal beyond a small minority which gets their satisfaction mostly from feeling smug about being more sustainable than the majority.

One may wonder whether Stoekl is fair in his assessment. Perhaps describing ecofrugality as promoting a bland life of being cold and eating potatoes into eternity is erecting a strawperson only to then knock it down. There is more to it than just feeling smug about an austere lifestyle. One may feel independent and selfsustaining when repairing ones clothes or bicycle, and there is a certain satisfaction to being able to cook a great tasting meal from humble ingredients. Being successful in decreasing one's own energy footprint by ten percent every year gives a feeling of accomplishment perhaps not unlike that of a manager who has reduced the operating costs of a company by the same. Being able to competently deal with limits promotes a general feeling of competence, and a sense of adulthood, as compared to being a big baby who always wants and needs "more".

But at least when eco-frugality is taken seriously, its negative message is not so easily bent around into a positive can-do atmosphere. When it comes to depletable resources like fossil energy or rare earth metals (rather than income-limited resources like solar energy), no reduction in use is strict enough for the true eco-frugalist, because any further reduction would still extend the date of depletion. This means any activity that is not essential to life is problematic: if we get rid of those frivolous spices in our food, it would be cheaper still. Ten percent energy reduction is nice, but why not twenty? Any success can be put into perspective by the daunting scale of the real goal of sustainability. Pushed to its limit, even life itself becomes questionable: if the aim is to sustain life on earth, do we really need so many people to do this? When the only goal is to reduce our footprint by as much as possible, 


\section{Chapter 4}

suicide reaches that goal 100 percent $^{7}$. The aspects of eco-frugal practices that add to our perceived quality of life (feeling independent, the satisfaction that comes with creation, etc.) may be real, but they do not come from the gospel of eco-frugality itself; they are additional benefits that are not central to the aims of eco-frugality. Indeed, these 'side-effects' cannot be properly defended from the perspective of ecofrugality itself, such appeals must come from elsewhere - we will get to their source in the next section.

Although boundless consumerism and eco-frugality appear to be each other's opposites, they do share an important notion of how to understand the relation between energy and society. Stoekl (2007) emphasizes that they are both based on efficiency improvements and the organization of 'measurable' energy; they both affirm the importance of energy (or resources in general) to the good life; they share the idea that the ultimate question is how to deal with scarcity. Boundless consumerism embraces the ceaseless production and squandering of these resources for hedonistic enjoyment; eco-frugality intends to hoard them in order for them to last forever. In this, they both understand our environment as the 'standing reserve' central in Martin Heidegger's understanding of modern technology (Heidegger, 1977): we cannot see our environment other than as a stock of consumable resources, and through this, ourselves as both the managers of this stock, and as a stock (of human resources) in ourselves ${ }^{8}$.

This shared focus on the question of scarcity allows boundless consumerism and eco-frugality to develop their disagreements: they both see the problem of energy transition as an issue of allocating scarce resources, but disagree on the ways to do this. However, a focus on scarcity is not unproblematic - it leaves out a number of other concerns, such as questions regarding the best use of these resources, whether scarce or not.

\footnotetext{
7 This sounds harsh, but there are people who make similar claims for the sake of sustainability. Dutch environmental blogger 'Green Evelien' at one point states that "the most ecological is not living, but that may be exaggerating it" (Matthijssen, 2014). On a more positive note, people can also have positive impact, for example by restoring forests, so at least in theory there are better choices than the 'zero-option' of suicide.

${ }^{8}$ Many advocates for eco-frugality may dismiss this analysis, because they consider themselves to have a more appreciative view of the world and humanity. My claim is that such views are not (purely) eco-frugalist, but would include another perspective; the one I develop in the final part of this chapter.
} 
In his later work, Ivan Illich recognized the problem of the centrality of scarcity, and argued that the eco-frugalist side of it is the most problematic. "We are straight on our way towards an energy-obsessed low energy society in a world that worships work but has nothing for people to do" (Illich, 2013, p. 118). In our attempt to manage energy (and thus the ecosystem and the biosphere), we move from a technocracy to an 'ecocracy', in the sense that life itself becomes managed by the system. Eco-cracy is described by Henryk Skolimowski (2005) as "recognizing the power of nature and of life itself, mean[ing] observing the limits of nature, designing with nature, not against it, creating ecologically sustainable systems, reverence for the planet- not its continuous plundering”. In the perspective of the eco-frugalist, this 'reverence' can be understood as little different from the reverence the first industrialists may have felt for the steam engine: observing the limits of nature in order not to overload or exhaust it, but instead making sure the 'factory of life' keeps outputting the things we need. Whilst the boundless consumerists end up deploying technologies that are counter-effective in their own aims and destructive to freedom via radical monopoly, eco-frugality reduces life itself to a process that needs to be optimized regarding its (energy) efficiency. "[The ecocrat] replaces the technocrat whose authority was at least limited to the management of people and social machines. The ecocrat's aims transcend these institutions; his management tools fit nature into their domain." (Illich, 2013, p. 120). Moreso than boundless consumerism, which at least let everyone 'design their own life', eco-frugality represents one step further towards the submission of everything to the goal of efficiency, which, as we know by now, is an empty goal in itself. Ecocracy is in this sense not a reversal of technocracy, but a more refined version of it, taking into account the ecological basis in which technocracy functions.

Understood this way, the concerns around the negative message of eco-frugality are very serious indeed. In its attempt to extend life, it inadvertently reduces it to another $\operatorname{cog}$ in the machine. If we want to save ourselves from this dystopia, we must move beyond the scarcity perspective.

\subsection{The rejection of the scarcity discourse by qualitative abundance}

If one would have to choose between mindless consumption in a world that is falling apart and a lifeless life of austerity, there is little appeal to either option. But in some discussions on energy transitions, a much more positive note can be detected, for example when people speak of the feeling of empowerment after placing PV-panels on their roofs, or when the commute becomes something to look forward to when it 


\section{Chapter 4}

is done by bicycle instead of automobile. Such positive aspects of energy transition may be noticed and mentioned, but in a debate revolving around scarcity, there is no place to integrate such notions. To stick with the example of the commute by bicycle, a boundless consumerist may respond that everybody is free to ride their bicycles, but the fact that most people commute by car shows that there is an obvious need for automobiles, so we need to work on ways to continue fueling them. An eco-frugalist may respond to the bicycle commuter by emphasizing the amount of energy saved by cycling instead of driving. But the idea that there may be something good about riding a bicycle remains unchallenged, and therefore undeveloped. It remains a personal preference, a side-note, whereas it needs to become truly part of the debate. What is needed is a line of argumentation that challenges the dominance of scarcity.

A seed for this can be found in the work of Illich when he suggests that "we cannot break out as long as our principles are the laws of thermodynamics" (Illich, 2013, p. 118). Illich realized that life (or at least the good life) should not be understood in terms of efficiency and scarcity, so his earlier arguments for the bicycle as a more efficient mode of transport than the automobile were misconceived, and indeed counterproductive: they reinforced the notion that efficiency is what matters. But the most important vice of the automobile is not its failure to deliver the promised speed, but rather its way of transforming distance. Whereas the self-propelled traditional modes of travel should be understood as transit, the automobile, as well as other modern, 'fast' modes of travel are forms of transport. Transit is an intrinsically human mode of moving around, one that makes people connect with each other, makes them appreciate the route itself. Transport on the other hand obliterates distance, sucks people up at one point to emit them at another, and makes the distance invisible and un-transitable. This makes transport qualitatively different from transit and therefore incomparable to it quantitatively.

For the later Illich, the efficiency of the bicycle is thus beside the point when we are interested in a mode of travel that is compatible with a good life: it is a good mode of travel because it agrees with human nature, it is egalitarian, accessible, safe, and gentle on the earth. And because of these features it also happens to be efficient and sustainable. It is sustainable because it agrees with the good life, not the other way around. This effect is not unique to the bicycle. Other examples are shopping for food at a farmers market in order to know where your food comes from and to celebrate the seasons (whilst also reducing the carbon footprint of your food), and building a house that lets in lots of sunshine for a more pleasant living environment (whilst reducing the cost of heating). Although these ideas and examples remain 
short of a robust law that connects a certain understanding of the good life with a sustainable society, they at least offer some theoretical scaffolding that enable discussion, and a first indication that there is a valuable connection to be explored further. I propose to name this line of reasoning qualitative abundance, referring to the shift in focus from the quantitative, measurable scarcity that underlies the discussion between the two positions mentioned above.

Qualitative abundance thus starts not with the availability of energy, but with its uses: the question for energy transition is not how much there is or can be in the future, but how much and what kind of energy is needed for humans to flourish. It sets out to understand how energy consumption contributes to well-being, and how to improve upon energy consumption practices. By making the good life the central issue, it does not just go beyond the more-is-better rhetoric that is often central to quantitative discussions, but also beyond concerns of quantity in general - there does not necessarily have to be an 'optimum' quantity either, as this may be strongly related to the ways in which energy is produced and consumed, and to the particular ideas of the good life that one may ascribe to.

Much like the other two lines of reasoning described above, qualitative abundance may also come in different forms. One way to distinguish between various forms is through their underlying theories of the good life. Hedonists would be interested in an energy system that provides them with the greatest amount of pleasure. Desire satisfactionists would strive for an energy system that would satisfy their desires, and objective lists theorists would want an energy system that enables the achievement of a particular list of goods. Although any theory of the good life is compatible with questioning the kind of energy consumption to achieve its goals, the outcomes would be different. For example, moving from utility grid-delivered electricity to a cooperatively owned micro-grid increases independence and sense of community, but decreases convenience and possibly security of delivery. How to balance these effects on well-being? Such questions are under-explored and would benefit from systematic treatment. But even in its current underdeveloped state, the notion of qualitative abundance can guide to break the dominance of scarcity discourse by engaging with either of the other two starting points. In the next section, I will sketch the discourses that could emerge and develop in this way. 


\subsection{New dimensions of discourse: prosperity and simplicity}

If the discussion between boundless consumerism and eco-frugality is characterized by their shared concern and different understanding of scarcity, the discussions between qualitative abundance and boundless consumerism and between qualitative abundance and eco-frugality may be characterized in a similar way. I will suggest that the central issues these discussions revolve around are prosperity and simplicity respectively. A schematic rendition of the resulting lines of discourse can be found in figure 1. The three original positions are found in the corners, and between each combination of them, the central issue of discussion is mentioned. Finally, between the positions and central issues, one can find the opposing understandings of the central issue at hand.

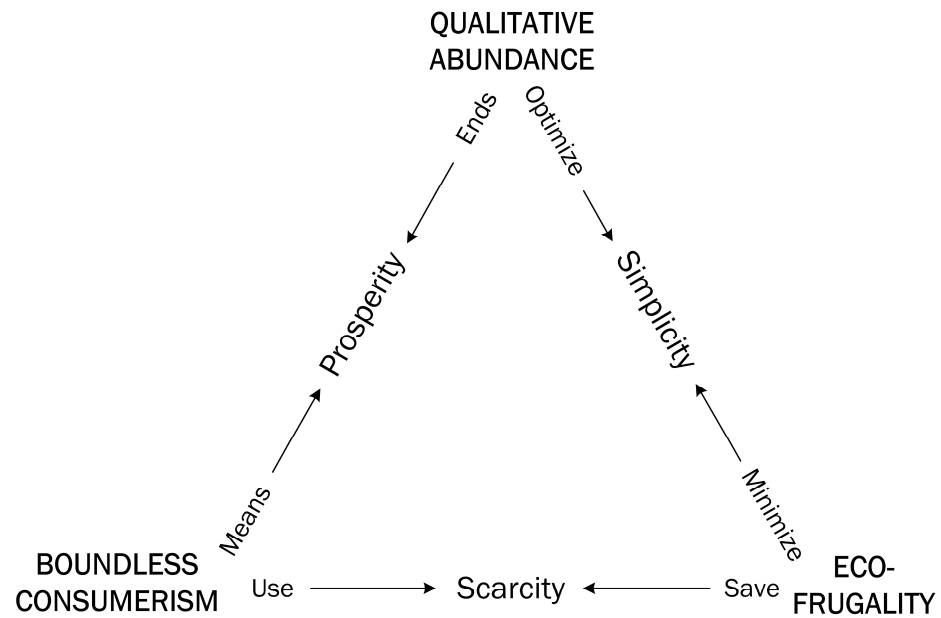

Figure 1: Lines of discourse on energy transition

Boundless consumerism and qualitative abundance are both concerned with means and ends. The former aims at supplying a maximum amount of the means of energy in order for society to consume it - for whatever ends it can imagine. The latter, on the other hand, aims at maximizing the ends (what is the very best way we can consume energy?), to then look for the energy means that best fit those ends. They are both concerned with prosperity through the expenditure of energy, but approach it from diametrically opposed directions. 
Proper discussions on prosperity could further the debate on energy transition significantly, because it will improve the modes of comparison between various means. For example, when dealing with the transportation system, the boundless consumerist perspective may suggest that comparisons between modes of travel should be done in terms of energy costs per passenger kilometer. Prosperity would be the ability to travel far and often. But we are not necessarily interested in passenger kilometers, but rather in visiting friends and places of interest, getting to work, or the feeling of being on the move. The amount of passenger kilometers needed for this are dependent on the geographical dispersal of one's social network, the richness of one's (nearby) surroundings, the distance to work, and the modes of transportation chosen. All of these are more or less interrelated: someone living and working in the same city is more likely to have friends in that same city than someone who commutes from a sleeper town, for example. A better mode of comparison between modes of transportation would revolve not around passenger kilometers, but around people's ability to go 'get around': prosperity lies in going where and how one pleases. This can be achieved not only by making passenger kilometers more affordable, but also by making people interested in local destinations. In more general terms, discussions on prosperity in relation to energy transition raise questions on the proper ends for which means are expended.

Eco-frugality and qualitative abundance both tend towards being critical of overconsumption of commodities: qualitative abundance raises the question whether they are truly the proper means towards an end, and eco-frugality wonders whether we can really afford them, or whether there are better ways to spend those resources. In short, then, they are both interested in simplicity, in the general sense of the word: in having fewer things and complications around. They differ on the proper aim of simplicity: eco-frugality aims at doing with as little as possible, whereas qualitative abundance suggests there is an optimal amount of simplicity (or complexity) that we should strive for.

Simplicity is not a new topic when it comes to discussions on consumption. The voluntary simplicity movement, which can be traced back to the mid-nineteenth century with the work of Thoreau, was described by Elgin and Mitchell (1977) as follows: "The essence of voluntary simplicity is living in a way what is outwardly simple and inwardly rich. This way of life embraces frugality of consumption, a strong sense of environmental urgency, a desire to return to living and working environments which are of a more human scale, and an intention to realize our higher human potential - both psychological and spiritual - in community with others" (Elgin \& Mitchell, 1977, p. 2). This description clearly contains elements of 


\section{Chapter 4}

eco-frugality (frugality of consumption, environmental urgency) as well as qualitative abundance (human scale, higher human potential, community with others), but puts little effort into distinguishing between them and recognizing their different roots.

The tension between the two approaches is clearly noticeable in the concept of alternative hedonism, coined by Kate Soper (2008). Its argument is again made along two lines: the first, eco-frugalist line that the affluent lifestyle of consumerism is beginning to show its polluting and exhausting dark side, and the second, qualitative abundance line that there is a seductive alternative, "an altered conception of what it is to flourish and to enjoy a 'high' standard of living" (Soper, 2008, p. 571). Like Elgin and Mitchell, Soper also intermingles these lines by combining environmental and personal critiques of consumerism: "Consumerism is today for many people both compromised by the pollution, congestion, stress, noise, ill health, loss of community and personal forms of contact it entails, and viewed as pre-emptive of a distinct range of pleasures" (ibid, p. 571).

Soper holds that both lines are complementary, and this is reflected in the ways alternative hedonists behave. This behavior is partly explained by altruistic motivations, but not entirely. "It is, for example, a decision to cycle or walk whenever possible in order not to add to the pollution, noise and congestion of car use. The hedonist aspect, however, of this shift in consumption practice does not reside exclusively in the desire to avoid or limit the un-pleasurable by-products of collective affluence, but also in the sensual pleasures of consuming differently." (ibid, p. 572) Because these 'sensual pleasures' can only be had in a healthy environment that is not flooded with automobile traffic, the 'altruism' of not adding to congestion is really a form of "self-policing" (ibid, p. 572) or moral constraint to achieve a greater good.

It is important to notice that although the two lines of argument may be complementary, they do not coincide: they come from different perspectives and provide us with different boundaries. There are sensual pleasures to be had with walking, and Soper embraces those because walking is also sustainable, but the 'sensual non-sustainable' (of, for example, powerboat racing) still needs to be rejected with a negative argument. This illustrates that qualitative abundance by itself is not enough to guide us in energy transition; only in combination with concerns of climate change, resource depletion, etc., one can be sure that the resulting energy system will be both catering to the good life and sustainable. 
Three things need to be said about this. First, there is reason to believe that it no coincidence that many practices that tailor to the good life are also eco-frugal. This was mentioned above, and will be discussed in more detail in the next chapter. Second, in cases of conflict, it may be possible and desirable to 'self-police' at a higher level, and change our ideas of the good life. Many of us started something (a running habit, a change of diet) because we believed it was healthy, and at a later point started enjoying it and understanding it as increasing our well-being for its own sake, and not only because of its health effects. Along the same lines, we could develop low-energy habits and learn to love them. Third, the problem of incompleteness is true for eco-frugality as well: the negative line of argument will by itself also fail to guide us in conflict situations. If we have a variety of options available to reduce our environmental impact, but a limited amount of time and effort to put into it, what are we to choose? Qualitative abundance suggests choosing the option that increases our well-being whilst reducing its environmental footprint.

The idea that simplicity is fundamentally a 'balancing act' is described most explicitly by Gambrel and Cafaro (2009), who argue that (voluntary) simplicity ought to be understood as a virtue. Virtues are always conceptualized as the mean between two vices. Gambrel and Cafaro describe several axes of vices along which simplicity should be understood as the prudent mean: between underconsumption and overconsumption; unthinking consumption (carelessness) and overthinking consumption (obsession); none or crude consumption (asceticism) and luxurious consumption; inefficient or pointless consumption (wastefulness) and hyper-efficient consumption (Penny-pinching), for example (Gambrel and Cafaro, 2009, p. 91). Although these distinctions are useful, they do not coincide with the distinction between negative and positive (or eco-frugal and boundless consumerist) approaches to simplicity mentioned above. These are all related to finding a balance that leads to a good (virtuous) life, and not to the balance between living a good life and minimizing one's environmental footprint to do so.

The balanced virtue that Gambrel and Cafaro refer to finds itself in between the vices that can be recognized in boundless consumerism (overconsumption; unthinking, luxurious, inefficient consumption) and in eco-frugality (underconsumption; overthinking, none or crude, hyper-efficient consumption). Therefore, their use of the concept of voluntary simplicity seems to coincide with my concept of qualitative abundance, and not with the debate between qualitative abundance and eco-frugality, which I characterize with the concept of simplicity. Although this is a possible source of confusion, there may be a straightforward reason for it. Gambrel and Cafaro notice that their term of 'simplicity' seems to 


\section{Chapter 4}

contrast more strongly with the approach that is here called boundless consumerism than with what is called eco-frugality. They argue that this is acceptable because they hold that modern society has a clear tendency to err on the side of boundless consumerism, so they propose a strong pull in the other direction. In other words: their 'mean' is slightly overcompensated, and leaning beyond qualitative abundance towards eco-frugality - exactly where I place the concept of simplicity. Qualitative abundance may be understood as a more neutral, albeit admittedly also less 'simple', term for the true mean.

This description of qualitative abundance as forming a middle ground between boundless consumerism and eco-frugality hints at the final feature of the schematic description of discourse on energy transition in figure 1. Qualitative abundance does not just draw attention away from scarcity, but offers a new route to compare the other two positions: between for example overconsumption and underconsumption. This comparison is impossible without the 'detour' of this extra position, because none of the positions can be related to the issue opposite of them. Similar to qualitative abundance being unfit to discuss scarcity, boundless consumerism is incompatible with simplicity, and eco-frugality does not have anything to say about prosperity. Referring to either of these concerns therefore automatically precludes arguments from the positions opposite to them. So if we believe that a discussion on energy transition must go beyond scarcity, we must learn to discuss the ends to the means of boundless consumerism, and the balance to the minimalism of ecofrugality. In other words, we need to develop qualitative abundance. 


\title{
Chapter 5
}

\section{Towards a Qualitative Assessment of Energy Practices: Illich and Borgmann on Energy in Society}

\author{
Paper under review for publication ${ }^{1}$
}

${ }^{1}$ No co-authors. 


\begin{abstract}
Energy consumption is central to both a number of pressing environmental issues, and to people's attempts to improve their well-being. Although typically understood as essential for people to thrive, this chapter explores the possibility that the form and amount of energy consumption in modern society may inhibit rather than enable human flourishing. Through connecting and critically assessing the writings of Ivan Illich and Albert Borgmann, a number of concepts are introduced that enable a qualitative discussion on energy practices.
\end{abstract}

For different reasons, both authors are highly critical of the societal tendency to command ever increasing amounts of energy. Illich focuses on negative effects of high energy consumption at the societal level, whereas in my particular re-reading of Borgmann we find reasons why high energy consumption fails to realize intended positive effects.

If their positions have merit, debates on the path of energy transition need to be radically altered: not the development of 'clean' energy sources should be central to the discussion, but the question what we could consider good energy practices. 


\section{Chapter 5 - Towards a Qualitative Assessment of Energy Practices: Illich and Borgmann on Energy in Society}

\subsection{Introduction}

Energy consumption is central to both a number of environmental issues, and to people's attempts to improve their well-being. The use of fossil energy sources is leading to climate change and resource exhaustion. People travel, purchase goods, consume foodstuffs, heat their houses and use all kinds of electric equipment in the name of living their lives. All these activities and practices consume energy, and the received view is that if current (fossil fuel based) energy production schemes are problematic, they need to be replaced by sustainable alternatives in order to allow people to continue their consumption practices. Understanding it this way, energy transition may be mostly a technical endeavor: we simply need novel technologies to reliably harvest and distribute energy from a sustainable source like the sun, preferably in a form that fits current practices (electricity and liquid hydrocarbon fuels).

However, this leaves the connection between energy consumption and well-being unexamined. Is it really true that consuming increasing amounts of energy improves our lives? According to Vaclav Smil (2010), this is not the case anymore in much of the western world: beyond around $110 \mathrm{GJ}$ of energy consumption per person per year, relevant indicators for quality of life, such as infant mortality, life expectancy at birth, and malnourishment, do not improve any further. Smil's conclusion is that the US average (330 GJ) indicates overconsumption, and that even if it were possible to continue on this level or to grow further, the costs would most certainly outweigh the benefits. Instead, wealthy societies must learn to embrace lower energy consumption. Smil suggests that with moderate efficiency improvements, it must be possible to live decently on $80 \mathrm{GJ}$ per person per year in the near future, only slightly more than the current world average (75 GJ).

The indicators Smil provides can be argued to measure a 'decent' life, but not necessarily a good life. Sure, we all want to live in good health, but that is not all there is to it: we would like to flourish, thrive, to do things that excite us, travel the 


\section{Chapter 5}

world or own a large house and a car. Do such desires explain energy expenditure beyond the decent minimum? I am not aware of hard figures on this, but I believe this is likely the case. We may call this approach to improving the quality of life the luxurious life. Is this approach successful? Research in green economics suggests otherwise. While GDP, which is closely correlated to energy consumption, steadily increased in the US over the last 60 years, the amount of Americans considering themselves very happy with their lives did not increase (Speth, 2009). Whether this is because material consumption ultimately does not lead to happiness, or because the costs (environmental degradation, harried lifestyles) outweigh the benefits, is not obvious from empirical data ${ }^{1}$. But this situation does suggest that the relation between (energy) consumption and quality of life is more complex than is typically assumed.

Why do we consume so much energy, even when it is environmentally problematic, and it does not appear to make us happier? And what paths are available if we are to drastically reduce our consumption, whether to improve the quality of life or to reach a more sustainable society? This chapter sheds light on these questions by looking closely at how people in modern society expend energy. The ways in which energy is consumed I approach as energy practices. I hold that practices (generally: the ways in which we do things) are embedded in and largely shaped by our surroundings, which in our industrial society are tailored towards the consumption of high amounts of energy. The question then becomes why the energy practices that are typical of modern life are so wide-spread, and whether we can imagine and develop better energy practices.

Energy practice is a bit of a curious term, because when expending energy, we are not typically interested in the energy itself, but in the things we get done by expending it. Energy practices thus remain implicit behind a myriad of actual practices. This chapter is aimed at making this background explicit and showing there is actually something significant at stake. It does so by moralizing energy

${ }^{1}$ Of course, there are rationales available for this increased material consumption. Tim Jackson (2011) suggests issues such as status anxiety (the need for consumption to signal success in life) and increasing amount of energy needed to reach the same goals (e.g. because visiting family now involves traveling further). He shows that even though all this may be the case empirically, there seems to be no explanation for why this is, and whether it is the only route available. Cannot 'keeping up with the Joneses' happen in terms of time spent with your loved ones? 
practices, in the literal sense of the word: I make energy practices a matter of moral concern.

This is not an easy or unproblematic thing to do. To point at problematic aspects of people's behavior is never a way to make oneself popular, and readers may feel I am moralizing in the negative sense of the word: that I am making unwarranted claims of right and wrong. I would like to emphasize that my intention first and foremost is to put energy practices up for debate, because this may offer new routes towards a sustainable future. To do this, I try to build a strong case for a different and more modest energy practice. The reader is invited to question whether these arguments are convincing, and whether any particular energy expenditure is justified. If they do, no matter the outcome, this chapter has been successful in its main goal: to instigate reflection on energy practices.

The work of two thinkers is central to my approach: Ivan Illich and Albert Borgmann. Both have been critical of the effectiveness of industrial society to provide for our human needs. Energy consumption is central in Illich' critique, but his work often lacks detail. Borgmann on the other hand speaks little of energy, but does provide a clear analysis of some problems of industrial society. I approach my main questions by first exploring whether and how the work of Illich and Borgmann is compatible with and complementary to each other in relation to energy practices. Then I use the resulting synthesis to describe how current energy practices are problematic if we are concerned with the good life, and how we may be able to move forward.

Neither Illich nor Borgmann has received the attention that their work warrants, it appears to me. Some 25 years after the publication of Illich' Tools for Conviviality, Carl Mitcham noted that "as argument, it remains young" (Mitcham, 1991), and not much has changed since that publication. Borgmann's work has been more visible within philosophy of technology, but his pleas for a holistic appreciation of the effects of technology on society have largely been ignored in favor of more analytic and more artifact-oriented approaches (Verbeek, 2005). However, the silence around their work has not made it any less pregnant. Especially for problems like energy transition, which relate to complex systems of technologies on various scales, a broader critique of technology is more valuable than a tight focus on particular artifacts. Both Illich and Borgmann offer radical critiques to the most central ways that modern society is organized. If there is truth to their respective positions, this has large consequences for how we should be consuming energy. It is high time to give their ideas the place in the discussion that they deserve. 


\subsection{Illich and the issues of high-energy society}

Ivan Illich wrote extensively about many facets of modern society, criticizing its blind faith in narrow goals from education and healthcare to transportation. Tools for Conviviality (1973) most broadly develops his theory; the short book Energy and Equity (1974) and the essay The Social Construction of Energy (2013) deal more specifically with energy practices. In Tools for Conviviality, a critique of industrial society, Illich develops a history of tool usage. Tools are important for him because they are not neutral; they afford (Gibson, 1977) or suggest certain kinds of uses over others. Not all tools can be appropriated in a way that agrees with what Illich considers a good life.

\section{The high-energy society}

I am interested in tool usage because it is through tools that humanity has changed its energy practices: any energy transition coincides with a transition of tools, and a transition of thinking. But which of these three is dominant? Against popular understanding, Illich holds that the steam engine was the result rather than the cause of the industrial revolution. The real revolution, that of the dominance of efficiency thinking and the emergence of 'work', resulted in the appropriation of a new form of energy via fossil fueled machinery.

The ideology of an industrial organization of tools and a capitalist organization of the economy preceded by many centuries what is usually called the Industrial Revolution. On Baconian premises Europeans began, according to Mumford, to save time, shrink space, augment power, multiply goods, overthrow organic norms and displace real organisms with mechanisms that stimulated them or vastly magnified some single function they performed. All these imperatives, which have become the groundwork of science as technology in our present society, seem axiomatic and absolute only because they remain unexamined (TfC, p. 30).

Thinking in mechanisms thus enabled humanity to replace human power with machine power, but not before humans were treated like machines first: "Up to the early nineteenth century men in English prisons actually labored on the treadmills to make machines work" (TfC, p. 31). When fossil-fueled power developed and grew more efficient, slavery and human power became uneconomical, which freed many humans from menial labor. But this was not just good news; something valuable was already lost: 
The individual's autonomy is intolerably reduced by a society that defines the maximum satisfaction of the maximum number as the largest consumption of industrial goods. Alternate political arrangements would have the purpose of permitting all people to define the images of their own future. New politics would aim principally to exclude the design of artifacts and rules that are obstacles to the exercise of this personal freedom. Such politics would limit the scope of tools as demanded by the protection of three values: survival, justice, and self-defined work (TfC, p. 13).

Illich here criticizes the utility of economic growth by an appeal to autonomy. Whereas the current economic system obligates (or at least strongly encourages) people to participate in the 'rat race', he envisions a 'good' society in which people could decide for themselves how to design their lives. In order to make this happen, we must be sensitive to how our 'artifacts and rules' inhibit such freedom, and learn to move away from such technologies. Only then, "[a] postindustrial society must and can be so constructed that no one person's ability to express him- or herself in work will require as a condition the enforced labor or the enforced learning or the enforced consumption of another" (TfC, p. 13).

It is doubtful whether Illich' ideal situation is at all possible. As for example Thaler and Sunstein (2008) have argued, humans are not the rational, autonomous creatures we often believe we are. Our choices and behavior are always influenced by the context, and a purely neutral context is simply not possible. Choices are always presented in a specific order, and often include a default option. In many cases, like when designing the infrastructure of a new area to be developed, only one layout of options (roads and paths) can be implemented. How can this be squared with the aim of "permitting all people to define the images of their own future"? It is impossible to principally exclude all artifacts and rules that obstruct personal freedom, as Illich would like. This is not to say that it cannot be a worthy ideal to aspire to, but we must be aware of its utopian character.

A postindustrial revolution as envisioned by Illich would also entail a significant energy transition. Illich suggests that it would radically reduce energy consumption, because "[p]eople will rediscover the value of joyful sobriety and liberating austerity only if they relearn to depend on each other rather than on energy slaves" (TfC, p. 14).

The structure of the problem according to Illich is thus as follows: industrial society is based on mechanistic thinking, which has expanded affluence via exosomatic 


\section{Chapter 5}

energy usage, but also reduced autonomy. If we are to regain autonomy, we must go beyond the mechanistic thinking of the industrial society, and this would lead to our letting go of our 'energy slaves'. The new energy regime must come out of a new understanding of life and society, so we cannot design a new energy system before we are thinking in the way that this new energy system is built on. A 'modest' transition from fossil to renewable sources will perpetuate all our societal ills as long as we simply aim to replace electricity from coal and gas to electricity from solar and wind, as this does not address the underlying problem. But why are these energy slaves so much of a problem?

\section{Energy slaves and the good society}

How exactly does an industrial society reduce the autonomy of its inhabitants? Illich goes into more detail in Energy and Equity (1974), a short book on the problems of motorized traffic, which can be understood as an example of energy practices in general. He here distinguishes between transit (self powered, autonomous travel) and transport (motorized carriage of passengers). As soon as transport starts dominating traffic, it creates a number of problems.

As soon as people become tributaries of transport ... the contradictions between social justice and motorized power, between effective movement and higher speed, between personal freedom and engineered routing, become poignantly clear. Enforced dependence on auto-mobile machines then denies a community of self-propelled people just those values supposedly procured by improved transportation (E\&E, p. 15-16).

One problem is that of equality. When speeds increase, it turns out that the costs of the speediest transportation is carried by the people who cannot afford its use. The elite that benefits from it, bypassing city traffic on elevated highways, or traffic jams in jet airplanes, does so at the cost of the rest of society, which spends more time getting from $\mathrm{A}$ to $\mathrm{B}$ because the highway blocks the direct route, pays more taxes to build the infrastructure, and finds the built environment expanding because of all the space demanded by vehicles.

But even if a society manages to circumvent this inequality by organizing speedy transportation for all, by offering a well-organized and classless public transport system, it still runs into trouble: "High speeds for all mean that everybody has less time for himself as the whole society spends a growing slice of its time budget on moving people. Vehicles running over the critical speed not only tend to impose 
inequality, they also inevitably establish a self-serving industry that hides an inefficient system of locomotion under apparent technological sophistication" (E\&E, p. 37).

Illich gives the example of the time the average American in his time spent on their car: 1600 hours a year. "He sits in it while it goes and while it stands idling. He parks it and searches for it. He earns the money to put down on it and to meet the monthly installments. He works to pay for gasoline, tolls, insurance, taxes, and tickets" (E\&E, p. 18). With an average mileage of 7500, this translates into an average speed of 5 miles an hour. "In countries deprived of a transportation industry, people manage to do the same, walking wherever they want to go, and they allocate only 3 to 8 per cent of their society's time budget to traffic instead of 28 per cent. What distinguishes the traffic in rich countries from the traffic in poor countries is not more mileage per hour of life-time for the majority, but more hours of compulsory consumption of high doses of energy, packaged and unequally distributed by the transportation industry" (E\&E, p. 19). Jean-Pierre Dupuy repeated this exercise in France and found a similar result (Dupuy, 2002).

Transportation develops into what Illich calls a radical monopoly, which is not the monopoly of a specific automobile producer, or even the monopoly of automobiles over trains, but of transport over transit. It is called radical because of its "hidden, entrenched, and structuring nature" (E\&E, p. 45), successful "by virtue of its acquired ability to create and shape the needs which it alone can satisfy" (E\&E, p. 47).

So not the specific organization of transport (public or privately owned; automobiles or trains; increased efficiency or just increased power) is the problem, but the very idea of speedy transportation. Beyond roughly the speed of the bicycle, there are only disutilities: we spend more time and physical resources on travel, change our environment in a way that discourages transit, feel disheartened while being stuck in traffic jams, and increase inequality.

Transportation stands model for industry in general. Illich formulates the general case as follows: "Any industrial product that coms in per capita quanta beyond a given intensity exercises a radical monopoly over the satisfaction of a need" (E\&E, p. 46). Wherever industry colonizes a practice, it creates counterintuitive inefficiencies. Illich also mentions education (which allegedly destroys an environment fit for learning) and medicine (which creates new illness). To remain on the topic of energy, I can think of examples like air conditioning, which heats city streets, 


\section{Chapter 5}

creating 'heat islands' in already warm regions; and industrial agriculture, which demands higher caloric inputs (by means of power tools, artificial fertilizers, and transportation) than their food output.

In its most general form, Illich holds that the problem of industry is overefficiency. Overefficiency, or the counter-productivity of narrow goals, refers to the problem that sustained efforts towards a certain goal will at some point actually undermine it. Illich describes the development of this effect via two 'watersheds'. The first watershed refers to the moment that a technological system represents a net gain compared to the traditional method: the moment that going to a doctor instead of just waiting increased your chance of getting better, or the moment mechanized transport became faster than walking. The second watershed refers to the moment at which further development of the system does more harm than good: when a medical treatment is more likely than not to create new (iatrogenic) diseases, or when faster vehicles or bigger roads lead to more rather than less time spent travelling (or working to fund traffic). Given enough time, every technological system will pass both watersheds. The trick, obviously, is to recognize these watersheds, and inhibit development past the second.

\section{A program for transformation}

In both Tools for Conviviality and Energy and Equity, Illich provides ideas for a better society. The task is threefold: "First, the need for limits on the per capita use of energy must be theoretically recognized as a social imperative. Then, the range must be located wherein the critical magnitude might be found. Finally, each community has to identify the levels of inequity, harrying, and operant conditioning that its members are willing to accept in exchanged for the satisfaction that comes of idolizing powerful devices and joining in rituals directed by the professionals who control their operation" (E\&E, p. 10-11).

Although that third step is described rather cynically, it should be noted that Illich does not completely reject those tools that would, if left unchecked, lead to radical monopoly. The important thing is that these technologies are accepted for what they are, and carefully monitored in order to guard society for falling into their trap. With this having been said, we can take a closer look at the positive program behind the critique.

Good tools, for Illich, are convivial, literally those tools that 'live together' with their users. "Tools foster conviviality to the extent to which they can be easily used, by 
anybody, as often or as seldom as desired, for the accomplishment of a purpose chosen by the user. The use of such tools by one person does not restrain another from using them equally. They do not require previous certification of the user. Their existence does not impose any obligation to use them. They allow the user to express his meaning in action" (TfC, p. 22).

Once again we notice that these goals are probably not completely achievable in each and every case because of the inescapability of choice contexts and default options. Although any strict 'obligation' may be prevented, tools will always suggest a certain use, or inspire one kind of behavior rather than another. Illich seems to argue that convivial tools are strictly instrumental in their use, and that their availability does not change our actions and desires at all. Although possibly strive worthy, this ideal is impossible to achieve.

Illich believed that "[t]ools for a convivial and yet efficient society could not have been designed at an earlier stage of history. We can now design the machinery for eliminating slavery without enslaving man to the machine. Science and technology are not bound to the peculiar notion, seemingly characteristic of the last 150 years of their application to production, that new knowledge of nature's laws has to be locked into increasingly more specialized and highly capitalized preparation of men to use them." (TfC, p. 33) Unfortunately, Illich does not give any concrete details about an 'alternative' science and technology ${ }^{2}$.

Although Illich holds that life in a reformed society will be objectively better, he is not confident that this knowledge is enough to initiate the transformation.

To invert politics, it will not be enough to show that a convivial life style is possible, or even to demonstrate that it is more attractive than life in a society ruled by industrial productivity. We cannot rest with the claim that this inversion would bring society closer to meeting the goals now stated as those of our major institutions. It is not even enough to show that a just or socially equal order can become a reality only through a convivial reconstruction of tools and the consequent redefinition of ownership and power. We need a way to recognize that the inversion of present political purpose is necessary for the survival of all people (TfC, p. 43-44).

\footnotetext{
${ }^{2}$ Arguments can be made that e.g. open source software, modern organic and permaculture farming, and off-grid passive solar houses could fit the bill.
} 


\section{Chapter 5}

But here a problem emerges. In some cases, 'the survival of all people' and better life of those people coincides, but in other cases they do not. "The barriers beyond which destruction looms are of a different nature from the boundaries within which a society freely constrains its tools. The former establish the realm of possible survival; the latter determine the shape of a culturally preferred environment" (TfC, p. 78). The culturally preferred environment will always be a subset of the realm of the possible: if it is not possible, a certain situation will not be preferable either (so there are no preferable non-possible situations); but we can imagine possible nonpreferable situations. If the transformation can only take place by an appeal to the possible (i.e. a situation in which the survival of all people is not threatened), this will not help with making sure that the situation will also end up being preferable.

The seriousness of this problem becomes clear when Illich states that "[e]ven clean and equally distributed electricity could lead to intolerable radical monopoly of power tools over man's personal energy" (TfC, p.76-77), or "[e]ven if planes and buses could run as nonpolluting, nondepleting public services, their inhuman velocities would degrade man's innate mobility and force him to spend more time for the sake of travel" (TfC, p. 52). Many current efforts towards a sustainable energy system (efficiency improvements, sustainable sources) are aimed at developing exactly the kind of energy system that Illich argues to be part of the possible non-preferable. It is therefore not clear whether his project is really helped by the recognition that we need a change 'for the survival of all people'.

Illich thus adds a dimension to our understanding of excessive energy consumption. It is not simply the infinite climbing of a ladder of a positional good, but also the result of radical monopoly and overefficiency. But how to move beyond this? Illich' pleas for reforms are radical, and he even acknowledges that it will not happen except when we realize survival is at stake, but as we have seen this 'ally' is problematic, too. In the next section I turn to Albert Borgmann, because as it turns out, his work enables me to imagine a more clear and nuanced reform.

\subsection{Borgmann: beyond commodification and the device paradigm}

Writing a decade after Illich, Albert Borgmann explores many of the same topics in Technology and the Character of Contemporary Life (1987). A close look at his argument will allow me to gain understanding in Illich' argument, and begin a critique. 
For Borgmann, the defining characteristic of modern technology is its tendency to commodify things of value: making them available instantly, while hiding the machinery that brings forth these commodities. The resulting structure of technological societies he calls the device paradigm. A common example is the way we heat our homes: where people used to have a central fireplace which needed maintenance and the chopping of wood before winter, modern houses are heated by central heating systems, often tucked away in a closet and fed by an underground natural gas pipeline. A thermostat allows the inhabitants to easily adjust the heat, and in many cases to program the system so that it is already heated up by the time they return from work. So far so good, as there seems to be little to object to getting rid of chores. The problem for Borgmann is that the fireplace used to be more than a source of heat. A fireplace was a focus, the center of the house, a place where the family gathered to interact with each other. Chopping wood was not just a way to make sure one did not freeze to death in the winter, it connected people with their surroundings, so they learned to appreciate the gifts of nature. By commodifying heat, these engaging practices were lost and a one-dimensional consumption remained. Disengaging technologies like a central heating system are called devices, as opposed to traditional things ${ }^{3}$. "Commodities, in comparison with focal things, are highly reduced entities and abstract in the sense that within the overall framework of technology they are free of local and historical ties" (TCCL, p. 81). The device paradigm leads people to focus more and more on the consumption of commodities, while engagement with one's surroundings becomes increasingly difficult.

Verbeek (2005) argues that this is a single-sided view of the effects of technologies on our lives: a technology like the telephone can connect people with distant friends and relatives, something impossible without telecommunication. Describing technologies in terms of the device paradigm appears to focus only on impoverishing effects of technology, ignoring the enriching ones. Borgmann agrees that engaging technologies exist, but his point is that disengaging technologies seem to be much more ubiquitous than engaging ones (Borgmann, 2002).

Engaging technologies Borgmann calls instruments. These are tools that enable people to engage in focal practices, activities that are valuable in themselves and that

\footnotetext{
${ }^{3}$ The word 'thing' is used in two distinct ways in the work of Borgmann. First, there is the (pre-modern) thing as opposed to the device, a technological object that can be used in a number of ways, and not necessarily in the context of a focal practice (e.g. a hammer). Second, there is the 'focal thing', the object towards which focal practices are aimed. These can be either natural (wilderness) or human-made (a musical piece), and physical (a mountain) or psychological (a shared meal).
} 


\section{Chapter 5}

revolve around focal things. Examples are running shoes and freeze-dried food which enable us to explore trails in the wilderness, musical instruments that allow us to make music with friends, or kitchen appliances that help us prepare our own meals. People do not engage with instruments, but through them: the engagement with the focal things (the trail, the musical piece, or the shared meal) is mediated by instruments. When Verbeek argues that the telephone can be used to connect with distant friends, he argues that it can be used as an instrument. Although Borgmann does not explore this, there is no sharp divide between instruments and devices, as technologies can be used for different purposes. Even the dreaded television, the cause of the 'couch potato', can be used in an engaging manner, for example when one watches a debate program which ignites a discussion with other viewers of the program. On the other side, running shoes can be used to run on a treadmill for the sole purpose of staying fit; a practice that commodifies health. But treadmills too can be used in focal practices, for example when they facilitate meaningful connections with companions in the gym.

The point is not to strictly divide the world into devices and instruments, but to understand that there are different ways of using technologies. Counterexamples do not diminish the potency of Borgmann's insight. Different technologies do afford or inspire different uses, and will encourage one practice over another. Furthermore, we should notice that indeed, contemporary society seems to be built mostly around devices rather than things and instruments. And this is where Borgmann focuses his critique on modern society: we tend to develop practices that are not contributing to an engaged life. Because Borgmann holds that commodities are ultimately empty, he argues that instead of comfortable, attention-scattering commodious consumption, we should partake in focal practices.

What are practices? "A practice is a regular way of doing things" (Borgmann, 2006). They form and evolve over time, influenced by our environment, values, and dedication. Focal practices give direction and meaning in one's life. They are "centering and orienting" (TCCL, p. 207). Borgmann describes them starting from focal practices in 'mythic times', when a 'divine power or mythic ancestor' was founded and consecrated. "A sacred practice, then, consisted in the regular reenactment of the founding act, and so it renewed and sustained the order of the world" (TCCL, p. 207). Part of the force of such practices came from their opposition; the alternative of the order defined by the myth was chaos and disorder. Modern focal practices do not benefit from such direct opposition, but they do benefit from a deeper, more subtle one. Technology, understood as the device paradigm, must be understood as a practice as well, but importantly not a focal one. 
It has not arisen out of a founding event that had a focal character, and it has "a debilitating tendency to scatter our attention and to clutter our surroundings" (TCCL, p. 208). Once one has appreciated this tendency and has realized the "pervasiveness and consistency of its pattern" (TCCL, p. 208), one comes to understand that it "must be countered by an equally patterned and social commitment, i.e., by a practice" (TCCL, p. 208). That is to say: a few 'focal things' here and there dispersed in our lives are not enough to break the pattern. We need to arrange our lives in ways that are structurally centering and orienting. Only through such an enduring commitment can the device paradigm be broken, because "focal things can prosper in human practices only" (TCCL, p. 200).

Like Illich, Borgmann hopes that this insight will have a transformative effect. People should be made aware of the device paradigm, so they can develop a critical stance towards devices. This awareness would lead to a (better) balance between the use of instruments on the one hand and devices on the other. Discussions about such topics can only occur as 'deictic discourse' according to Borgmann: appeals to certain understandings of the world as participant, rooted in specificities of one's life ${ }^{4}$.

\section{Borgmann on Illich}

Borgmann mentions Tools for Conviviality in TCCL, and is rather critical about it:

$$
\begin{aligned}
& \text { At one place Illich defines "ideally convivial" techniques this way: "Almost } \\
& \text { anybody can learn to use them, and for his own purpose. They use cheap } \\
& \text { materials. People can take them or leave them as they wish. They are not } \\
& \text { easily controlled by third parties." To require that tools, whenever possible, }
\end{aligned}
$$

\footnotetext{
${ }^{4}$ Readers may take issue with this argument. Borgmann appears to paint himself into a corner by first pointing at the moral significance of our (technological) surroundings, and then arguing that the only way to discuss these things is to write from our own experience. This appears to make him susceptible to be accused of moralizing, in the negative sense of the word: baseless judging of actions in terms of right and wrong. If we can only use our own experience and nothing more objective, how can we possibly make claims about behavior beyond stating that it is up to us as individuals? Without sketching a full defense of his position here, we remark that he may simply be right that 1) our environment is morally relevant (Verbeek, 2011) and that 2) morality is ultimately based in personal experience, and general rules are only general because we happen to share them across a society (and beyond). Analogous to my intentions in this chapter, Borgmann does not tell anybody what to do, except to reflect upon and discuss their practices and habits.
} 


\section{Chapter 5}

meet these conditions seems like a reasonable demand, and they will certainly serve Illich well in his slashing attacks on the powers that be. Yet we may lead the disengaged and distracted life that is typical of advanced technology in the midst of conviviality as defined by Illich. The electronic and video marvels that we are being promised meet his definition of conviviality. Illich tries to secure the good life by establishing boundaries that would keep dehumanizing technology outside and allow the good life to flourish within. But such limits are always drawn too narrowly and too broadly at once. Illich, to give another example, would restore a more buman scale to our dwelling and traveling by restricting all speeds to that of a bicycle, 15mph, I suppose. But what if technology gives us humanpowered vehicles that allow us to move at $50 \mathrm{mph}$ ? Would not conviviality have to accept the present patterns of commuting and population distribution? Technology will be appropriated, it seems to me, not when it is enclosed in boundaries but when it is related to a center (TCCL, p. 167168).

Borgmann states that 'limits are always drawn too narrowly and too broadly at once'. He gives examples of both. Too narrowly, because there may be convivial transportation that goes faster than the typical bicycle. Too broadly, because 'electronic and video marvels' may be convivial, but not part of the good life according to Borgmann. Let us take a closer look at these examples.

There are in fact bicycles that go that fast, the world hour-record for aerodynamic recumbents is more than $90 \mathrm{~km}$ (International Human Powered Vehicle Association, n.d.), and many of us can experience similar speeds on steep downhills. This counter example indeed seems to undermine Illich's position that going (much) faster than the bicycle is theoretically not possible (E\&E, p. 61). But those are exceptional situations, and indeed fall into the trap of overeffiency - these record setting contraptions are not at all practical to move around, and when riding in the mountains one's average speed up and down is typically lower than on the flat. My own experience of living in a bicycle-dense environment makes me believe that despite all kinds of 'innovations', the typical cyclist has not increased their speed in the last few decades. There certainly seems to be a ceiling to human-powered speed in practical situations. However, this empirical claim does not at all proof any theoretical limit. Perhaps Illich overstates his case here, but as long as we have not seen the possibility of retaining conviviality in high speed transportation, it may not hurt to err on the safe side and draw the limits too narrowly. 
Whether 'electronic and video marvels' are convivial is interesting for Borgmann because this enables him to claim that Illich draws his limits too broadly (in combination with his own claim that they disperse attention and do not disclose the richness of reality, and therefore cannot be part of the good life). It may not be a very strong example - we would be hard-pressed to believe that Illich would consider contemporary media 'convivial'. But this example does lead to a key difference between the two thinkers. Illich is looking at negative design rules: these guidelines inhibit practices that obstruct our abilities to live good lives. Borgmann finds a more positive approach: this is what we need to actually live the good life. This is a narrower solution space, but one that is likely to overlap to a very large extent with the one that Illich envisions; hence Borgmann's qualification that conviviality "seems like a reasonable demand". If we are interested in the good life as Borgmann envisions it, Illich's work is valuable to recognize a broad variety of practices in industrial society that demand reform, so that we are already moving in on a situation that Borgmann could accept.

An important question then becomes whether Borgmann's good society is a subset of Illich's, or simply a largely overlapping set. Can we imagine a 'focal' society that is not also convivial (to a very large extent, remember Illich allows for some 'industrial' practices)? Whatever the answer to that question, which will remain for another day, it is clear that the two thinkers' aims are not mutually exclusive.

One more thing: Borgmann also suggests that "conviviality [has] to accept the present patterns of commuting and population distribution", a puzzling statement in both Borgmann's and Illich's work. If Borgmann is talking about the fact that many people live solitary lives in impersonal suburbs and spend hours in their cars to get to work, it appears to me that neither would accept the status quo for obvious reasons: Illich understands this as the result (and further cause) of the radical monopoly of transport, and therefore part of the problem; Borgmann would understand these patterns to inhibit community life, and therefore up for discussion. Neither of them should accept these patterns.

\subsection{Synthesizing Illich and Borgmann for better energy practices}

If we combine Illich' and Borgmann's terminology, we find powerful connections between the two thinkers. Here I discuss a number of such connections between Borgmann's concepts of instruments, devices, and the device paradigm and Illich' concepts of overefficiency, watersheds, conviviality, and radical monopoly; as well as their respective positions on the level of technology and world views. 


\section{Chapter 5}

Borgmann's concept of commodification is a practice that can only occur in a society that values efficiency: a commodity is successful exactly because it appears to deliver a good in a more efficient way than was otherwise possible. Do devices also tend to overefficiency? This seems not the case in the most obvious sense. A central heating system does not, in the end, fail to deliver warmth. But in a broader understanding of its function, when we appreciate what other functions a hearth fulfilled, it seems that the efficiency of the central heating system is a false one: by optimizing heat throughout the house, it has actually, according to Borgmann, reduced the quality of life within it. And was not the aim of the central heating system to create a home that was better to live in? If so, a central heating system is overefficient: by narrowly optimizing the provision of heat, we may end up losing more than we gain. Because devices work exactly by narrowing and one-dimensionally re-interpreting the functioning of instruments, they tend towards overefficiency. Borgmann's theory of the device paradigm can thus be used to extend and refine Illich' concerns with overefficiency: it allows for a broader application of the term in cases where the functions of a tool cannot be reduced to a single dimension. Although a central heating system does not leave us cold like 'fast' transportation slows us down, it still is a form of over-optimization of the narrow goal of heating to the detriment of the auxiliary functions of its predecessor, the hearth ${ }^{5}$.

If devices tend towards overefficiency, it may make sense to talk about instruments and devices in terms of two watersheds. I already argued that the line between instruments and devices is not always clear-cut - technologies may be used in different ways. If the good life revolves around focal activities, a specific technology will pass the first watershed and function as an instrument when it enables one to (better) indulge in such an activity, and it passes the second and becomes a device when it becomes counter-effective. For example, the bicycle passes the first watershed when it allows one to appreciate the landscape better than while walking perhaps because it increases the radius that one can explore within a day. It is an instrument that enables one to partake in the focal practice of exploring one's environment. But when the technology develops, when skinnier tires inhibit exploration of gravel roads, or the more aerodynamic pose becomes uncomfortable

\footnotetext{
${ }^{5}$ A problem with Illich' overefficiency argument is the subjectivity of time accounting. There is no objective way to decide exactly which activities are part of the means towards a specific goal and which are not. Is for example the price people are willing to pay for a certain style of car over a car with the same functionality part of the costs for automobile traffic? This problem is amplified in the case of Borgmann's broader understanding of the functions of devices and instruments - depending on one's intentions, it would be easy to manipulate the calculus.
} 
after an hour or two, it passes the second watershed and starts inhibiting the focal aims of the ride in exchange for 'performance': it becomes a device for a 'workout' or swift transportation. However, further development of the bicycle can also go in other directions, for example by adding suspension and extra low gears, enabling the cyclist to ride single tracks as well as regular roads, leading to a whole new experience of the mountain. Both when designing technologies and when choosing which ones to use in our daily lives, the concept of the two watersheds is helpful in guiding our assessment of a particular tool: in which ways does this help me with what? Will it allow me to do one thing very efficiently, or does it help me with certain focal practices?

The example of different bicycles also suggests that the level of technology is not necessarily related to its usability as instrument or device. This leads back to Illich' remark that the level of technology is not related to its conviviality. Neither Borgmann nor Illich can be accused of being traditionalist or Luddite when it comes to their preference for what seem to be 'old' technologies, but perhaps they can be considered conservative when it comes to their understanding of quality of life. Their tendency towards older technologies results from the fact that many more recent technological developments have been used to come up with (over)efficient rather than convivial tools, and devices rather than instruments. But this is not necessary. Ultralight hiking gear for example is high-tech, yet clearly instrumental to the focal activity of spending time in the outdoors. Online communities can be very convivial.

This apparent symmetry makes us wonder whether instruments are always convivial. Let us recall Illich' guidelines for convivial tools: "Almost anybody can learn to use them, and for his own purpose. They use cheap materials. People can take them or leave them as they wish. They are not easily controlled by third parties" (TfC, p 64). Instruments can be difficult to master (e.g. the violin), and may use expensive materials, but they seem to allow (or even encourage) people to use them for their own purpose. Convivial tools are not always instruments; they can be used for other than focal activities. The hammer ticks all the boxes for conviviality, but is a 'thing' rather than an instrument. Here we once more find a key difference between the two thinkers that is closely related to the difference between a positive and negative approach mentioned above: Borgmann is not interested in those activities that are needed for survival, but have little to do with focal activities. Convivial tools may be used for such purposes, but they may also be used for focal activities. Instruments are therefore a subset of convivial tools. Devices are never convivial: they are tailored to 


\section{Chapter 5}

produce a specific commodity, and can therefore not be used 'for one's own purpose'. In the device paradigm, it is awfully hard to 'take them or leave them as one wishes'.

This final remark suggests that the device paradigm, the situation in which we are surrounded with devices and life becomes the consumption of commodities, is the situation in which devices enjoy a radical monopoly over things and instruments: devices have created needs (of speedy transportation, material opulence, etc.) that only they can fulfil.

A more complex parallel can be found with regards to world views. Borgmann argues that next to the allegedly wrong use of the time saved, the very notion that time is saved when not having to spend time on all kinds of chores anymore is only possible from the perspective of the device paradigm, because within this perspective labor is seen as 'mere means'. The thorough separation of means and ends makes us "exaggerate the liberating character of the transformation of work and thus cover up the concomitant cultural and social losses" (TCCL, p. 119). Borgmann thus claims that in a pre-technological society, people did not see cutting wood as a mere means to stay warm in winter, but as an integral part of their lives. Another factor contributing to our disdain for labor such as cutting wood is tied to the fact we understand it as 'unskilled': the tools used are not as complex as modern devices, and our lengthy education is not aimed at such manual work. Implicitly we assume that complex devices are more difficult to operate than simple things, even though devices tend to not require much skill from their users, while a thing like an axe demands a certain amount of dexterity to use it.

Both these points can also be found in the work of Illich: radical monopoly of education pushes away traditional practices that become 'chores'; in The social construction of energy he mentions that the pilgrim and the modern traveler do not traverse the same world. Motorized transport transforms space: "By transforming commons into resources for the production of passenger miles, vehicles take the use value out of feet" (Illich, 2013, p. 120). By transforming the very nature of what we are looking at, we make quantitative comparison impossible. Our perception of gains and losses is world-view related.

The key is to become aware of this world-view, and develop a critical stance towards it. Borgmann states: "As long as we overlook the tightly patterned character of technology and believe that we live in a world of endlessly open and rich opportunities, as long as we ignore the definite ways in which we are, acting technologically, have worked out the promise of technology and remain vaguely 
enthralled by that promise, so long simple things and practices will seem burdensome, confining, and drab. But if we recognize the central vacuity of advanced technology, that emptiness can become the opening for focal things" (TCCL, p. 199).

This is to break through radical monopoly.

\title{
5.5 A renewed look at energy transition
}

With this critique of industrial consumption in mind, the aims of the energy transition now become bigger than ever. If exosomatic energy consumption is central to the industrial way of life, and this can only be countered by 'an equally patterned and social commitment', then a radical re-appreciation of energy consumption is necessary. But in order to defend such large claims, we must move carefully.

Even though Borgmann seems to hold a position that is largely compatible with Illich' energy-critical approach, he does not explicitly mention energy consumption himself. What, if there is any, is the problem for exosomatic energy use for Borgmann? Are focal practices always (or likely to be) low-energy? Borgmann provides us with a useful clue to build on:

\begin{abstract}
Running is simply to move through time and space, step-by-step. But there is splendor in that simplicity. In a car we move of course much faster, farther, and more comfortably. But we are not moving on our own power and in our own right. We cash in prior labor for present motion. What I am doing now, driving, requires no effort, and little or no skill or discipline. I am a divided person; my achievement lies in the past, my enjoyment in the present. But in the runner, effort and joy are one; the split between means and ends, labor and leisure is healed (TCCL, p. 202).
\end{abstract}

Borgmann here argues that the split between production and consumption is the key reason why driving automobiles does not fit the centered life: by first having done the work and later appreciating its benefits, one is not 'focused' in the present activity. This, I hold, is problematic. I claim that the internal combustion engine and its commodified power are more central to the issue Borgmann tries to get at than the temporal split between means and ends. Consider, next to the runner and the motorist, a cyclist who, after sweating up a mountain pass, enjoys a high-speed descent on the other side. Their high speed is not a direct result from their own power, but rather an indirect one: the cyclist has gained potential energy on the way 


\section{Chapter 5}

up, and is now cashing this in with gravity's downward push. There is a clear temporal division between mean and end, but still there is an undeniable engagement and focus in the activity. The practice is much closer to that of the runner than that of the motorist, because of, I would argue, the bodily source of the effort.

But does this argument hold up closer scrutiny? Going a little further, we may imagine a stationary bicycle used to charge batteries for an electric car, which, after a week of relentless pedaling, is taken out for a drive. Does this result in an exhilaration similar to the descent from the mountain pass? Probably not, even though the original energy source is the same. Perhaps the example of the bike ride is misleading because of poor demarcation. Without the way up, the descent becomes meaningless: it is because we directly worked our way up, that we can enjoy the way down. The bike ride should therefore be approached in its whole, and when ascent and descent become one, means and ends do too.

But this raises further questions. If we can combine different parts of a bike ride, why would we not say that the year of work in a cubicle and the two-week holiday that it pays for are both part of the whole of the practice of 'modern life'? Is this at most a difference of degree, rather than of kind? No. The key here, I believe, is that there is a clear symmetry or reciprocity between the two parts of the bike ride, where there is none in the case of a year's work paying for a holiday.

As long as we are embodied beings, any focal activity will revolve around bodily engagement, and therefore, bodily energy expenditure. Exosomatic energy use to fuel an activity intrinsically leads to an asymmetry between (exosomatic) means and (endosomatic) ends. Like the telephone, as Borgmann himself argues, such technologies may "support, but could not be at the center of, a life worth living" (Borgmann, 2000). Rather than temporality, the asymmetry between means and ends should be understood as the key difference between running and driving for Borgmann.

This does not condemn exosomatic energy use in general, but it significantly narrows its appropriate application. It suggests that any attempt to make focal activities easier with power tools, be it kitchen robots to prepare meals quicker or airplanes to travel faster, are bound to fail reaching their goal. The well-lived life according to Borgmann avoids many modern technologies not because of an alleged romanticism (source), but because of the anthropological position that we are embodied beings. 
But this is likely to ring all kinds of bells with the field of philosophical anthropology. Were we not, according to e.g. Gehlen (1980) and Plessner (1975), the animal that needed technology to be in the world? Do we not, with Latour (1993), become part of all kinds of networks, without which we would not be fully human? This may be the case, but using this to argue for exosomatic energy use will only defend its supporting function, and this is not under debate. We may use exosomatic energy to sustain life, perhaps even to support us in our focal practices (e.g. to drive a car to a trailhead to start hiking). But focal practices themselves do not at all benefit from exosomatic energy use, because it is incompatible with endosomatic experience. Technology may mediate our experience in the world (Ihde, 1990), but the experience itself still occurs in our bodies (at least until we become transhumans).

We must be careful however not to equate focal activities with bodily experience. Endosomatic energy consumption may be necessary, but it is not sufficient for a practice to be focal. Running on a treadmill for example is but a weak, commodified version of running in the wilderness or through town. Although the running still happens with our own body, the practice is taken out of its context, the disclosure of one's environment in all its richness. One may still be able to cultivate a healthy body or experience a runner's high, but one cannot engage with a technical trail, the wind and the sun, the fresh air, and chance encounters anymore. Borgmann's good life revolves around low-energy practices, but not all low-energy practices lead to good lives.

One issue remains: what about the hearth, Borgmann's paradigmatic focal thing, burning wood and centering lives? The hearth clearly functions via exosomatic energy; it creates an environment that allows our bodies to keep their temperature steady in cold climates. It has allowed humanity to spread over the earth. It seems to me that although the hearth works very well as an example to explain the centering effects of focal things, its warming function is not central to its functioning as a focus. In its design of supporting life the hearth simply happened to gather the family, the members of which then proceeded to have a centered life. In warmer climates, where heat is not in demand, the shade under a big tree may have a similar function, or people still congregate around the fire where the food is being made. The hearth (or the fire in the kitchen) feeds the body with food and sometimes warmth, and feeds the soul with company. It is not a tool to do exosomatically what used to be done endosomatically, but a source that feeds us in multiple ways. 


\subsection{Conclusion}

Where do we go with all these pieces? Borgmann and Illich suggest that an ever increasing access to exosomatic energy does not improve our lives, and in some ways deteriorates it. Building on statistical evidence, this has been argued before by e.g. Vaclav Smil (2007, 2010). The idea that (exosomatic) energy consumption has little to do with well-being goes against traditional understandings of progress, and indeed economic policy in most countries. However, it does square with findings in positive psychology and arguments made in favor of an energy ethics that discusses the appropriate level of energy consumption, rather than only a debate on which sources are best (Mitcham and Rolston, 2013).

Both Illich and Borgmann provide us with a number of plausible theoretical explanations of why this is the case. With Borgmann, we have come to understand how it is impossible for exosomatic energy consumption to directly improve our quality of life. Energy transition should therefore involve a re-appreciation of its function: to support, rather than to be central to life. This support should not get in the way of focal practices, and Illich has shown how easy it is for industrial society to get bogged down, become counterproductive, and consume more and more time and resources without delivering anything valuable at all.

This knowledge can help us envision the route to better low-energy lives. As we have seen, it is not simply a limit on the amount of energy per capita, as for example the 2000W society (Hänggi, 2011) would have it, but rather a qualitatively different approach to energy consumption that makes for good living. Understanding what kind of energy consumption does and does not actually improve well-being enables both individuals to make informed choices when designing their lives, and societies to put in place prerequisites to make low-energy choices like an infrastructure tailored towards transit rather than transport and a level playing field for local food production.

I am aware that discussions on well-being are complex, and that we are unlikely to settle on a particular position any time soon. Borgmann's position is not universal: there are people who do not at all enjoy running, as well as those who take great pleasure in the comfort of commodities. But this diversity should not be seen as a signal that we should be silent about this and everybody should figure it out for themselves; it should be the starting point of a substantive debate about it. It is neither feasible nor desirable for our society to simply get rid of anything resembling 
devices. But considering their ubiquity and lack of support for alternative practices, there is much to be done.

First and foremost, Borgmann offers a vocabulary in which it becomes possible to see these matters. To make people more conscious of the differences between commodified entertainment and focal activities is the first stage for them to act on these matters. Awareness may lead more people to lead a rich, low-energy lifestyle simply because it makes them realize they prefer it. Next to this possibility for individuals, it enables a political sensitivity to the ubiquity of devices in society. Individuals can only do so much; all our choices are partly preordained by the context in which they take place. A society aware of the problems of devices can choose to change this context in order to make it possible for people to choose differently.

Second and more contentiously, Borgmann starts a debate simply by taking a position. With his plea for focal practices, he makes a first move in a discussion that typically does not happen at all in our liberal society: the good life is something for everyone personally to figure out. This may make people uncomfortable, but there are good reasons for actually discussing this. Firstly because in its structure our society is far from neutral on the matter, and secondly, at least when one does not hold the position that well-being is completely subjective, because people probably benefit from reflecting on their own practices in order to improve them.

We believe that those who object to Borgmann's position on the good life because they prefer the life of the commodious individual face at least three challenges. First, there is the question whether or not their preferences are caused by the pattern of modern technology and the logic of the growth economy. How do people become commodious individuals? It seems to me that at least some of them may have been lured into appreciating this lifestyle through ceaseless marketing and the decreasing possibility to choose otherwise. When Illich speaks of industry creating and shaping needs that only it can satisfy (E\&E, p. 47), he suggests that exactly this is happening. If this is the case, then there is no reason continuing in this direction other than the fact that we are already on our way.

Second, Illich makes a strong case around the counter-productivity of optimizing narrow goals. To what extent do commodious individualists manage to avoid this trap? If their big cars and comfortable suburban dwellings demand working longer hours and spending more time in traffic jams, they may be simply fooling themselves. It may be that different choices (e.g. living in slightly smaller houses 


\section{Chapter 5}

with shorter commutes) would lead to better lives as conceived by commodious individuals themselves.

Finally, adherents to commodious individualism need to come to terms with the environmental consequences of their behavior. If it is true that excessive consumption of all sorts of resources leads to ecological degradation, climate change, etc., and commodious individualism embraces patterns of ever increasing consumption, how do they plan to balance the good with the bad? This is a complicated problem in the short term, but becomes steadily more complicated as continuous growth increases pressures on many fronts. Are mechanisms of restraint possible when these would suggest behavior exactly opposite of one's understanding on how to improve well-being?

These points lead us to wonder what reasons there may be to not put our energy practices up for debate. Is there really no more to it than habit and misunderstanding? If so, this seems like an awfully weak case against a proper conversation on the matter. We better get started. 
Chapter 6

Discussion and conclusions 



\section{Chapter 6 - Discussion and conclusions}

It is time to reflect on where the previous chapters have taken us. What insights are to be found in this dissertation? How can philosophy of technology guide the emerging energy transition? This main research question has been answered by demonstration: this is how philosophy of technology can guide the emerging energy transition. It has provided perspective, nuance, new questions, and suggestions for answers. In this concluding chapter, I will briefly summarize these findings, place them in the broader discussions on both energy transition and philosophy of technology, and discuss some limitations and suggestions for further research.

\subsection{Summary of findings}

In the introduction (p.22) it is mentioned that my aims are not so much related to finding truth, but to providing insight in the problem of energy transition. The subquestions are therefore designed to guide the project towards relevant rather than merely possible ways to philosophize about energy transition. Where have these questions led us?

Sub-question 1: What philosophical basis allows for constructive thinking about energy transition?

Chapter 2 introduces the reader to three twentieth century philosophical perspectives on energy. Lewis Mumford understands energy production as the first of four stages towards society's goal of producing something lasting; Georges Bataille sees it as life's way to deal with the excess that the sun gifts us; and for Heidegger it is the ultimate form of having nature as a standing reserve, ready at our command. It turns out that there is a complexity behind the concept of energy that usually remains unexamined in discussions on energy transition. Energy can be interpreted in many ways, and these interpretations allow us to see different issues when approaching energy transition. But it also becomes clear that these ('classic') perspectives lack a certain refinement when it comes to particular energy technologies and practices. Whereas for Heidegger any form of energy in modern society is to be understood as a 'standing reserve', I claim that there are important 


\section{Chapter 6}

differences between for example solar power and electricity from coal-fired power plants. Analogous to the empirical turn in philosophy of technology, focusing on artifacts rather than 'capital T-technology', a constructive philosophical perspective on energy needs to look at particular elements in and arrangements of energy systems, rather than 'capital E-energy'.

Examples of this focus on particularities, while still remaining connected to the overall functioning of energy in society, can be found throughout this dissertation. Section 2.4 on flux and potentiality uncovers the challenge of intermittent sources as the problematizing of continuous availability of power, itself a relatively novel and unique aspect of twentieth-century energy systems. Chapter 3 emphasizes the invisibility of electricity in our daily practices as both tremendously useful because it enables us to focus on the tasks at hand, and at the same time problematic as soon as one tries to reflect on their energy practices. Chapter 4 and 5 focus on the question what energy is for, and chapter 5 in particular emphasizes that depending on its function, particular energy systems may be more or less appropriate. Questions on energy transition should therefore not focus on how much energy a society needs, but what kind of energy is needed: the particularities become central to the question of energy transition, rather than merely related to it.

Sub-question 2: How do contemporary energy systems discourage reflection on energy practices by users?

In chapter 3 it is argued that the invisibility of electricity during its consumption holds an important key to the question why people fail to reflect on their energy consumption. The chapter explores the phenomenology of electricity consumption in relation to the ability of the consumer to develop an ethical position on the matter. An 'experiential gap' makes a large part of the electric system invisible, and according to Foucault's work on self practices, this invisibility makes it impossible to morally relate to the practice: ethical behavior can only be built from the relation with the morally relevant environment. The complex and opaque electrical network thus makes 'ethical consumption' particularly difficult. This insight provides a robust reason for the poor results of efforts that aim at moralizing energy consumption, despite the fact there are plenty of arguments for reducing energy consumption from any theoretical ethical perspective.

The chapter also explores the consequences of this situation. Simpler and more transparent energy systems could enable ethical engagement, but at the cost of decreased usability: ethical behavior demands that the problem 'gets in the way', but 
when using technology the user needs the medium to dissolve in the practice. It makes sense to then suggest that through re-design of both the hidden parts of the system and end-user artifacts, the desired morality may be embedded in the energy system. However, with users still not being engaged, the democratic foundation to justify such actions is not easily obtained. If not through energy practices themselves, perhaps consumers can be made sensitive to these issues via discussions that are already taking place: the debates around energy transition at the systemic level. A space for constructive reflection can be created by showing how those debates need a more refined understanding of energy practices to go forward. This is one of the aims of sub-questions 3 and 4 .

Sub-question 3: In what way does the centrality of scarcity in discussions on energy transition obscure alternative approaches?

In many discussions on energy transition, energy is approached as a scarce commodity. Chapter 4 argues that the dominant lines of reasoning I call 'boundless consumerism' and 'eco-frugality' both hold that the principles of scarcity govern the energy available to us, and that in focusing on this scarcity they emphasize that in essence, energy transition is a management problem. The difference between the two lines lies merely in the question whether growth remains possible in the face of this scarcity. Boundless consumerism argues that growth will remain possible via efficiency improvements and novel energy technologies; eco-frugality argues that instead, consumption should decrease radically by making energy conservation a central aspect of our lives. This focus on scarcity and how to manage it obscures the deeper reason why society is interested in energy at all: the ways in which energy is supposed to cater to society's needs and enable people to flourish as human beings.

By looking at the understandings of the good life that are implicit in the lines of reasoning focused on this scarcity, it becomes clear that both miss the mark. Boundless consumerism has already proven to be ineffective: over the last half century, growing energy consumption has not led to greater subjective well-being in the western world. Eco-frugality meanwhile focuses our attention on everything we cannot do: a protestant ethic without the appeal of a good afterlife. The way forward, it is proposed, is by introducing a third line of reasoning in the debate: qualitative abundance. This line focuses first on good energy practices rather than efficiency and savings, because there are valid reasons to believe that good energy practices will also tend to be low-energy practices. By introducing and theorizing this third line of argument, two concerns beyond scarcity become central to the debate. Between qualitative abundance and boundless consumerism, a discourse on 


\section{Chapter 6}

the notion of prosperity emerges, inviting discussion on what exactly makes a particular practice of energy consumption contribute to well-being. Between qualitative abundance and eco-frugality, questions concerning simplicity emerge: where and how do we find a balance between simplifying for our own good, and for the endless concern of environmental impact? Both issues are important expansions of the discussion on energy transition if we are concerned not just with a sustainable energy system, but also with one that caters to our well-being.

Sub-question 4: How can we construct critiques on specific energy practices and guide improvement?

Chapter 5 takes up the challenge to further develop the idea of low-energy good living in a constructive way: why does increased energy consumption fail to improve well-being, and what kind of energy practice would increase quality of life? It does so by exploring the work of Ivan Illich and Albert Borgmann, who have developed different but complementary critiques of the effectiveness of industrial society to provide for human needs. Illich looks at society in general and provides a compelling narrative on how a narrow focus on efficiency becomes counterproductive. Borgmann starts with the individual, and argues that embodied engagement with our environment is crucial for our well-being.

Borgmann's analysis is here extended with the insight that such embodied engagement is always low-energy: we experience the world through our body, and not through our 'extended body' of machinery. If one accepts the premise that engagement is central to the good life, it becomes clear that energy consuming technology can only be used to support the good life, and not be central to it. Because our expanding energy consumption is precisely through these tools and machines we surround ourselves with, we must conclude that much of our energy consumption is misguided and superfluous. Combined with Illich' cautionary remarks on counterproductivity, this misguided consumption is not merely wasteful, but actually detrimental to the good life.

In tandem, Borgmann and Illich provide a strong case for a substantial reconsideration of many energy practices. They invite us to look at consumption in the larger context in which it takes place, and to distinguish between different forms of consumption as qualitatively (rather than only quantitatively) different. Although certainly not indisputable when it comes to the particular conception of the good life, this line of argumentation shows that it is at least possible to discuss the relative merits of various kinds of energy practices. Because the main concern is with having 
a discussion in the first place, rather than to promote a particular vision, this possibility for dispute may be seen as a benefit, as it invites responses. Engaging in such discussions cannot but lead to more nuanced statements than the 'more is better' or 'energy savings are holy' rhetorics that so often dominate the conversation.

\section{How can philosophy of technology guide the emerging energy transition?}

To sum up, we have seen that philosophy of technology is able to guide the emerging energy transition in a number of ways. It provides new, broader perspectives to look at energy in society, thus opening up the solution space in which newly designed and emerging energy practices may be found. It provides concepts that enable a better understanding of particular issues within energy transition, such as the problem of intermittency. It clarifies misconceptions and confusions, such as the idea that users are well-equipped to develop ethical behavior in energy consumption, and the idea that energy transition must be discussed in terms of how to deal with scarcity. Finally, it provides a more nuanced understanding of the relation between energy consumption and quality of life, such that it enables the discussion to move from purely quantitative discussions towards more qualitative concerns.

Obviously, this is not an exhaustive answer. It is likely there are more ways in which philosophy of technology can guide the emerging energy transition. But at least it is an answer, a demonstration that there is indeed something that philosophy of technology can bring to the table. Two questions then present themselves: are these insights new? And are they useful? These two questions will be tackled in turn.

Novelty is complicated. Everything may have been said before, but discussions do not take place with the totality of all knowledge in mind. A reminder of wisdom can be understood as a novel insight in a new context. Reframing the work of others makes insights accessible to new audiences and in new situations. With this in mind, I am not the first to identify intermittency as an issue for energy transition, or to notice the difficulties the people run into when they try to be more aware of their consumption, or to point out the apparent misguidedness of many energy practices. But as far as I am aware, there is some novelty to the diagnosis of what causes these problems (e.g. self practices and the experiential gap, chapter 3), and to the conceptual proposals to move forward (e.g. 'qualitative abundance' as counter to scarcity-based discussions, chapter 4). Throughout this dissertation, I have argued that these are novel insights in this debate, rather than the same old insights packaged in new concepts. 


\section{Chapter 6}

Usefulness is probably even more difficult to assess than novelty. From the beginning I made clear my ambitions to deliver useful and insightful philosophical writings on energy transition. Not truth, but benefit to the debates is my ultimate aim. Although I still stand by these lofty ambitions, I must admit that besides some anecdotal evidence, at this point it is still mostly a promise. In personal conversations I have learned that people find these perspectives refreshing and stimulating, but it remains to be seen whether those involved with energy transition will find this work as useful as I have tried to make it. At least two elements are at play here: dissemination and quality.

Dissemination, or whether my concepts and proposals will be found by those who may be able to use them, is only partly in my hands. For this project to actually have impact it needs to find its audience, and this is something that still needs effort. This does not just involve writing papers and making them available in journals and on the internet, but also showing rather than telling. I can participate in existing debates on energy transitions and weave the concerns and concepts explored here into them. When others appeal to the same or related issues I can connect and support these efforts with broader frameworks. And I can practice what I preach, and develop my own energy practices in accordance with these reflections. But no matter these efforts, successful dissemination is also contingent on random events (or luck, if you will). Therefore, I would like to suggest that 'usefulness' of a dissertation should be understood as having the quality of potentially being of use, rather than having actual impact. It is, after all, an intellectual endeavor. I can only aim to be relevant, and whether I have the impact I aspire to, is up to larger forces than just me.

This leaves us with 'quality'. I have argued for the potential usefulness, or practical quality, throughout this dissertation. When proposing the distinction of flux and potentiality, I showed that this allows for a broader appreciation of intermittency, and therefore the possibility to think beyond the technical difficulties of energy storage. When discussing the limitations of the perspective of scarcity in discussions, I proposed a new route that invites reflection on the actual use of energy in society, enabling a more nuanced appreciation for energy practices, and therefore novel ways to improve the current situation.

Still, these examples are perhaps abstractions of actual debates that people interested in energy transition may be involved in. They are stylized situations that may not quite represent the real world. What do I have to add in the actual contexts in which deliberation on energy transition is taking place? 


\subsection{Practical implications}

Let me here offer two wildly different contexts in which one may attempt to use some of the insights of this dissertation: the design and implementation of research programs aimed at aiding the energy transition, and choices an individual may make when deliberating some kind of energy consumption.

\section{Energy-focused research programs: BioSolarCells}

This project has been funded within the BioSolar Cells research program, a Dutch public-private collaboration between 10 knowledge institutions and some 45 companies revolving around photosynthesis research. The main objectives of this program are "the development of optimized photosynthetic systems in plants, microorganisms and artificial leaves for the durable production of energy, chemicals, food, and feed" (Reek et al., 2013). Although here tucked away between other goals, one could say that energy production is indeed the central concern for much of the program. The website ${ }^{1}$ argues for the importance of the program in terms of fossil fuel depletion and climate change. Two of the three technological clusters focus on novel pathways for renewable energy production: one on algae and cyanobacteria as source for 'solar fuels' such as biodiesel and ethanol (Wijffels and Barbosa, 2010), and one on artificial leaves (engineered photosynthesizing systems) as source of electricity, hydrogen, or possibly more complex synthesized solar fuels (Purchase and Groot, 2015). The third cluster, focusing on plants, may benefit more traditional biomass production, although that particular use of plant research is less central to the cluster.

Next to these technical clusters, a fourth cluster focuses on education and societal debate. Here too, energy production is front and center. Aside from this philosophical project, there is one developing lifecycle analyses of biosolar technologies as compared to conventional and other renewable pathways to transport fuels, one using bioart to instigate societal debate on particular genetic procedures that may be used in biosolar technologies, and one building scenarios around different implementations of production systems in society.

What we see then, is that for the entire project it is energy production that is imagined as up for transition. Society is consulted regarding whether it would accept

\footnotetext{
${ }^{1}$ www.biosolarcells.nl; the main page is titled "BioSolar Cells - The sun as a sustainable source of energy" (translation RJG).
} 


\section{Chapter 6}

a particular route towards energy production (or more concretely: whether it has issues with genetic modification for bio-fuel), but there is no similar consultation on what access to energy society finds most important, or where society finds it most challenging to change practices, even if such change would be beneficial. The scenario study gets closest to truly connecting production and consumption in its distinction between an 'energy port' and 'energy farm' scenarios: the first building on current power dynamics and infrastructures prioritizing large-scale industrial production and a largely business-as-usual passive role for consumers; and the second imagining a fine network of small- and medium-scale production facilities connected to a 'smart' infrastructure that would make energy highly visible to the consumer (Hanssen et al., 2014). This paper clearly shows that different designs of the energy system would need and/or illicit a different amount of societal engagement with energy. It also mentions that in the 'energy farm' scenario, thanks to their role as co-producers, "consumers have a higher sense of urgency concerning energy efficiency" (Hanssen et al., 2014). Still, it stops short of raising questions of what exactly society could be interested in doing 'efficiently'; whether and how we are indeed using this 'co-produced' electricity in ways that improve our lives.

In general, there are good reasons for a research program to bracket such questions and make some assumptions that allow engineers to develop technologies according to some boundary conditions. This is how puzzles can be split into more manageable chunks, and hopefully all those partial solutions add up to a solution to the big puzzle. But as became clear in this dissertation, even basic assumptions such as that society is interested in electricity and liquid fuels, are not trivial and may be up for debate. Society will of course be most accepting to such 'drop-in' technologies that do not challenge the current system, but this does not mean that these are therefore the best solutions for the societal interests. As I have explored in chapter 5, some theorists suggest that highly concentrated liquid fuels that make fast transportation possible are in fact part of the problem, rather than part of the solution. If this is indeed the case, that would mean that for example the research on artificial leaves should focus on different kinds of output. When discussing biosolar technologies in society, we should (also) talk about the qualitative aspects of the outputs: what kinds of energy would be best? A fluent transition thanks to 'drop-in' technologies may be seen as a benefit, but if a more demanding transition would lead to a much better result, then convenience may be trumped by ambition. Also, discussions on the shape of the energy system, such as when talking about energy port and energy farm scenarios, should be expanded to questions concerning the appreciation of particular consumption practices, rather than only focusing on efficiency and concerns of costs. 
The possibility of the prosumer (Ellsworth-Krebs and Reid, 2016; Schick and Gad, 2015) plays an important role here. There is no more clear-cut case to point out how production and consumption influence each other than when both happen in the same actor. Such people benefit from insights on both sides of the story, including the phenomenology of the practice. They may be the first to understand that the dichotomy between production and use is a false one, not just because prosumers do both, but because the one informs the other: depending on how you produce, you'll use differently. Many prosumers use electricity differently after installing PV-panels on their roofs (Ellsworth-Krebs and Reid, 2016). Depending on use practices, other characteristics and outputs are demanded from production. When such insights begin to settle in rather obvious situations such as those of prosumers, it becomes easier to appreciate the fact that this is also the case in an energy system like the current one, which in its structure gives the inaccurate impression to the uninformed user that production and consumption are strictly separated.

\section{Personal deliberations on energy: a cold evening}

Say, you are at home in the evening, you are cold, and you are contemplating what to do about it. Your first idea may be to either turn up the thermostat or light the wood stove. If you're aware of pleas for energy conservation, you may think about the efficiencies of the central heating system as compared to the wood stove, benefits and drawbacks of natural gas and wood for fuel, the fact the wood stove will only heat a small part of your house, and other technical considerations. You may also make a mental note to look into improving the insulation of your house at some point in the future. These are the most common topics of discussion when talking about energy transition.

But most owners of wood stoves would also think of something else: that the heat from the wood stove is very different from the heat of the central heating system. Next to heating the air, the hot surface of the stove radiates warmth to the surrounding area, which is appreciated by many. (And may also be appreciated by those who never realized, but do recognize the difference now it has been pointed out to them.) To a lesser extent, hot water radiators in central heating systems do this as well; heat pumps that are used in many modern low-energy housing systems do not. Although the air temperature may be the same in such buildings, they are perceived as less comfortable by the inhabitants. (Moe, 2010; Anonymous, 2016) Although such considerations on the quality of heat may influence the action of choice when you are cold at night, they are not yet part of discussions on energy 


\section{Chapter 6}

transition. Chapter 4 and 5 defend the claim that indeed, they should be central to such discussions.

Beyond choosing between either this or that system to provide you with heat, you may also consider the option to insulate your body a little better with an extra piece of clothing or a blanket. Depending on your activities (Were you reading on the couch? Organizing some stuff? Moving around?) you may prefer the flexibility of a sweater or the coziness of a blanket. In discussions on energy consumption such solutions are often dismissively described as the austere or stingy options, but it seems to me that (perhaps down to some lower limit) being comfortable in appropriate clothing in lower air temperatures is a matter of habituation and personal taste, more so than some objective measure of comfort. In other words, this solution is not just for poor people and extreme eco-frugalists (chapter 4), it is simply a different approach with different drawbacks and benefits. If you happen to have a loved one to join you under your blanket, or you can trick a pet into sleeping on your lap, you may even enjoy the experience of giving warmth while receiving it a type of 'prosumer practice' that would also be heartwarming in the figurative sense...

Broader still, when taking into consideration the long history of human energy consumption (chapter 1) and classic philosophical understandings of energy (chapter 2), you may also consider drinking something warm (tea) or something that makes you feel warm (whisky), or burning some internal fuel (working out, going for a walk) as ways to warm yourself up. Indeed, these strategies may be as effective to keep you warm as any technical system that society has devised specifically to do so. And again, they all have different drawbacks and benefits. The message to be taken away from this dissertation in this context is not that there is a 'best' option that should be promoted, but that all of these options are legitimate, and that when discussing energy consumption, it is such options and their particularities that you should be thinking about. As I have here merely scratched the surface, I would like to invite the reader to keep exploring and discovering new ways to do so. 


\subsection{Broader insights}

\section{On energy dependence}

A focus on energy as key to understanding society and our choices within it also brings to the fore the deep reliance society has on nature. Understanding the industrial revolution not just as a tale of ingenuity of novel machinery, but also as the unlocking of a wealth of energy previously inaccessible to society, helps us to be a little more restrained in our expectations of novel energy technologies. Disregarding nuclear energy for a moment because of its societal and practical problems, fossil fuels are by far the most energy-dense sources we have ever encountered. Nature, understood as the physical characteristics of the world we live in, enables us to make choices strictly within the rules and opportunities that it allows us. Solar technology, no matter its efficiency, will always be marred by the limited intensity of solar income. Our engineers may be excellent locksmiths, but we have no choice in the treasures we are offered. The jackpot of abundant and convenient fossil liquid fuels may not come a second time.

But even if it does, if solar power or some other kind of energy source becomes 'too cheap to meter', like nuclear power was promised to become in the 1960s (Weinberg, 2006), this reliance of society on nature will continue. It may become invisible to large parts of society, just as it was during much of the fossil fuel era, but its reliance will still be there. If the invisibility of this reliance leads to ignorance and/or carelessness with those influencing the physical and virtual architecture of this society, we can expect nothing but another leap of growth until new boundaries are found. And with every intensification of energy reliance, the stakes increase. Already, modern agriculture is able to feed the 7 billion people on the earth only because of considerable fossil energy inputs (Smil, 2004). Increasingly globalized trade has led to a critical reliance on cheap and fast transport of all kinds of goods. Should anything go wrong with this system, we are, as they say, 'nine meals away from anarchy' (Steel, 2013). Such sensitivities are likely to further increase when, for example, we start synthesizing our food or depend more and more heavily on airconditioning due to run-away climate change.

If future energy systems continue to be globally oriented, they remain sensitive to a range of perturbations, such as disruptions of (local) supply, market fluctuations, technical failures, blockages, and embargos. But even a localized energy system of solar micro-grids could get seriously disrupted by, for example, a catastrophic volcanic eruption such as the 1815 eruption of Mount Tambora, resulting in a 'year 


\section{Chapter 6}

without a summer' across the world. The only defense strategy would be to live safely within our means, and develop buffers and resiliencies that would (hopefully) allow society to recover from such uncertain events. But 'living safely within our means' may be understood as the choice to not invest in urgent societal issues such as poverty reduction. How to balance choices between real but manageable and potential but catastrophic concerns? This certainly is a complex question, and this dissertation does not offer any solution to it. But what it does do, is suggest that this may not be the question we should be asking ourselves. Instead, the question is whether we can develop a different path for society with a much lighter energy footprint that has a different, but not necessarily worse, quality of life. Indeed, many of the greatest societal concerns (obesity, stress, the gap between the rich and the poor) have at least some root in our energy practices. Physical inactivity is caused by the proliferation of transport over transit; harried lifestyles as well as income gaps come with globalized economic systems that thrive on growth and substantial energy inputs, while only marginally fulfilling human needs. More responsible long-term energy targets may even benefit rather than hurt short-term societal goals. Although connections between self-powered transit and health are sometimes identified as 'cobenefits' when comparing energy pathways, I claim that they are intrinsically connected, rather than simply lucky side-effects.

The 'solution' I offer, of a conscious relating to and critique of energy practices, will come across as utopian to many. How could we inspire people to think more deeply on energy? People are just not going to reflect on everything they do. Why would they suddenly grow an interest in energy? I share this concern, but believe there are at least two reasons why we should not disregard this route just yet.

First, a thorough overhaul of energy practices does not need to happen overnight, and on many fronts it is already underway. It is true that many elements of energy practices (like city layout and choice of transportation) are interrelated, but this does not mean that at once, everybody needs to move to a place close to their job and start riding their bike. Instead, when (re)designing our cities, we could integrate living, working, and consuming in smaller areas, and continue to develop from there. In fact, this is what is happening in many European cities already. A generation of globetrotters will not suddenly stop flying, but a proper reflection on travel (Botton, 2002; Welten, 2013) could guide people to radically decrease the energy footprint of travel while maintaining or improving the kind of experiences we look for in our travels. The convenience of the seasonless supermarket will not be given up from one day to the next, but a re-appreciation of seasonal and local foodstuffs will decrease our dependence on it (Pollan, 2009). Energy neutral buildings will not 
replace all our homes right away, but at least they are being built in increasing amounts.

All these examples have in common that they will have an influence on aspects of our energy practices. A more focused attention to this effect of these developments could improve this connection and thus its impact. In other words, these are often implicit efforts to change energy practices, but making them explicit could make them more successful. When nudging people to move away from eating too much meat, perhaps the cashew nut is not the most appropriate alternative, considering its similarly high environmental footprint; try tempeh or tofu? (Blonk et al., 2008). The electric car may not be as good a solution for transportation as often imagined, because it still discourages transit - what about cycling or working closer to home (chapter 5)? A conscious attention to energy practices while trying to ameliorate pressing societal needs thus does not imply starting to do something radically new and unheard of, but rather pointing to what is already happening and improving upon it. Understanding it this way, it seems much less utopian.

Second, what is the alternative? The obvious alternative to reflecting on energy practices is not reflecting on energy practices. The sanity of this (non-)approach depends on the larger context in which it takes place: there may be situations in which lack of reflection on energy practices is less problematic than otherwise. Some useful distinctions in this context are made by Richard Heinberg. In Powerdown (2004), he suggests that there are four ways to prepare for what he holds to be the impending oil crisis. Without necessarily subscribing to his possibly alarmist 'peak oil' narrative, and expanding its focus to climate change next to fossil fuel depletion, his framework is still insightful. The four lines of action he names last one standing, powerdown, waiting for a magic elixir, and building lifeboats. Heinberg's strategies are not mutually exclusive: one may combine two or three to spread their chances.

Last one standing is the strategy of business as usual, which Heinberg holds will lead to increasing conflicts over steadily depleting deposits of fossil fuels. This is likely to illicit militarism and increasing tensions between nations. With a focus on climate change rather than on finite fossil fuels, this may be understood as the strategy to face climate change with national adaptation efforts only, rather than a combination of mitigation and adaptation, and global cooperation. One may imagine Northern countries closing their borders to climate refugees from other parts of the world, the hoarding of foodstuffs at national levels, etc. This strategy would combine well with a lack of reflection on energy practices: there is no need for reflection when society attempt to keep everything the same. 


\section{Chapter 6}

Powerdown is the attempt to radically reduce our energy needs in order to make it possible to abandon finite fossil sources. Heinberg argues that renewable sources are available, but not at the levels needed to sustain current energy usage, let alone the steady increase of energy use that is implicit in our growth-based economies. For climate change, the equivalent action would be a strong effort for climate change mitigation: drastically reducing greenhouse gas emissions by changing practices. This strategy asks for a radical change of the energy system, and therefore would also most likely change our energy practices, whether we like it or not. A lack of reflection on what would be good energy practices could result in sub-optimal sustainable energy systems, leading to a greater reduction in well-being than necessary at a particular level of 'powerdown'. Although not absolutely essential to the success of this strategy, reflection on energy transition could help winning over those people who are skeptical about the quality of life after the transition.

Waiting for a magic elixir is the techno-fix solution of hoping for the perfect renewable energy source, be it cheap and convenient solar power, nuclear fusion, or something else. This is not exactly waiting; the chance of finding a solution would rise by increasing investment in $\mathrm{R} \& \mathrm{D}$, but most importantly it is a strategy of hoping that a solution will become available. In terms of climate change, the magic elixir may be imagined as carbon capture and storage, or an unproblematic form of geoengineering. Not reflecting on energy practices would work well with this strategy, as a properly 'magic' elixir would fit so well that it would not need a change in practice. This, of course, assumes that the practices we have now are the best we can imagine; an assumption contested in chapter 5.

Building lifeboats finally, Heinberg's fourth strategy, is to save what is valuable for society until after the storm of dwindling fossil fuel supplies has settled. It essentially accepts catastrophes as possible or likely to happen, and aims at making sure the survivors do not have to start from scratch. Climate lifeboats are to be understood as databanks for helping both humans and nature deal with a radically different climate. An example is Svalbard Global Seed Vault that stores hundreds of thousands of different seeds to battle the reduction of (agro-)biodiversity (Fowler, 2008). Such a strategy would be hard to imagine without reflection on energy practices: if the goal is to save valuable knowledge and technology for after the storm has settled, it is unlikely that those future people will experience the same abundance of energy we currently enjoy. A test for anything to be added to the lifeboat would be whether it would entail an energy-effective means to achieve some human end. To properly make such an assessment, reflection on energy practices is essential. 
This is not the place to discuss the wisdom of particular strategies, but in general, we may say that the more optimistic the strategy, the less important reflection on energy practices would be. Waiting for a magic elixir supposes nothing needs to change, last one standing assumes the consequences can be managed. For these strategies, reflection on energy practices is not urgently needed. However, such reflection could still benefit our quality of life, as mentioned above. Powerdown and building lifeboats raise the stakes and put effort into changing society for lower impact and dealing with impacts, respectively. These strategies require larger changes and therefore broader reflection on society. It seems that ignoring energy practices may be theoretically possible, but also a lost opportunity or possibly a reason for reduced success of these strategies.

\section{On related fields of research}

\section{Philosophy of Technology}

In recent years, philosophy of technology has increasingly focused on the ethics of artifacts. Examples are Value Sensitive Design (Friedman et al., 2002), providing designers with a method to systematically include moral considerations in their designs, and Mediation Theory (Verbeek, 2015), understanding technologies as shaping the relationship between humans and the world. Parts of this dissertation could be understood as being inspired by either of these frameworks: designing artifacts in ways that enable the experience of energy consumption caters to the 'value' of engaged life (VSD), and at the same time allows the user to question the mediating effects that energy consuming technologies enact between them and the world (mediation theory).

Yet at the same time, I have attempted to put up for debate the larger context in which all of this takes place. Not just the artifacts at hand, but the hidden machinery and organization of the energy system are what shape both our relationship with, and our experience of the world. This larger context comes to the fore through embracing the classic 'grand narratives' of for example Heidegger and Mumford (chapter 2) as 'orienting perspectives', rather than as monolithic theories. In this way, they enable empirically informed reflection to go beyond narrow statements on particular artifacts, while still allowing for nuance and dissent. In other words: through these perspectives we can once more see the big picture and talk about it. After all, the design and use of particular artifacts always takes place within a larger context that is constantly changing - sometimes slowly, sometimes more abruptly. 


\section{Chapter 6}

The 'empirical turn' in philosophy of technology is thus modified from being a 'reorientation' of the field (from 'capital-T Technology' to the study of particular artifacts) to an additional dimension that increases the richness of the analysis. From a one-dimensional line to a two-dimensional surface, if you will. The energy system indeed makes the world present itself as 'Bestand' or stored potentiality, as Heidegger would have it, but only because of the particular configuration of the electric system as it developed in the twentieth century. By re-arranging and reforming this network, different perceptions of energy can and will come to the surface.

Value-sensitive design is similarly encouraged to broaden its scope to go beyond the design of particular artifacts and consider the design of the energy system, as well as the values that are promoted through both new and existing particularities of this system. If this recommendation has any merit, it also expands the relevant audience for the VSD procedures: not just engineers and designers 'design' the energy system, but so do city developers, law-makers, and humans living their lives and choosing the particular artifacts they engage with.

\section{Research in energy technology}

By its nature, research in energy technology is highly fragmented: the big questions are cut up into more or less manageable engineering puzzles, in the hope that their solutions somehow add up to answers to the large questions. The larger context is investigated by fields like industrial ecology, which use methods such as Life Cycle Assessments (LCAs) to make comparisons between alternative solutions while considering the big picture of their production, use, and disposal (Singh et al., 2013).

LCAs are great tools when it is possible to properly compare alternatives 'all else being equal', but this is often not the case. LCAs can compare the fuel efficiency of electric vehicles compared to gasoline powered vehicles, but comparing this to the efficiency of a bicycle does not work very well, because the use of a bicycle will lead to different practices (most notably, in this comparison, lower travel mileage). It gets even more problematic when trying to compare vehicle use to having a local social life, rather than friends dispersed through the country. Yet, when we talk about energy practices, this dissertation makes the claim that we need to compare such dissimilar solution paths. If such discussions are to be complemented with quantitative information, more flexible and dynamic LCAs would be much appreciated. 
In addition to this improved informing of the debates by technical information, the debate should inform technological development. This dissertation has shown that a broader perspective tends to allow for a larger solution space: when thinking more broadly of being cold, one can think of different ways to do something about it beyond turning up the heat. It is good to remember that any translation of grand societal problems to engineering puzzles is based on assumptions, many of which can be contested if we approach energy transition as broadly as is proposed here.

Such contestations are not mere limitations that ethicists like to posit in order to frustrate technological development, to the contrary: they are invitations to come up with different formulations of the problem that may result in more appealing solutions. This means that a quest for a new appreciation of energy (this we may call a broad energy transition) can go hand in hand with a technological (narrow) energy transition. Society will need renewable sources no matter what, but it may need less of them in a broad transition. It needs some kind of storage to cover for intermittency, but in a broad transition there are other (perhaps technologically or environmentally less challenging) solutions possible, like periodic production of preservable goods and slower or less transportation in periods of lower energy availability. By listening more closely to the debate on energy transition, in this case the challenges for engineers may get smaller rather than larger. At the very least, they will be different.

\section{Transition studies}

Research in transition studies and transition management emphasizes the commonalities between various transitions, their consecutive stages, and the challenges and pitfalls at each stage (Grin et al., 2010). When it comes to energy transition, according to Rotmans (2012) The Netherlands currently finds itself in the 'acceleration stage'. This means that the multitude of initiatives that emerged during the start-up phase are now challenged to prove their worth, so that the truly good initiatives will be copied and implemented at a broader scale. In this context, Rotmans speaks exclusively about energy cooperations in "regions, big cities, small municipalities, neighborhoods, districts, and streets" (Rotmans, 2012), focusing on wind, solar, heat, and smart grids. Whether these initiatives actually address the challenges that energy transition is supposed to tackle is not being questioned - there is not even a mention of intermittency in a 28 page chapter on energy transition.

This is understandable from the perspective of transition studies - it makes sense to assume that whenever an issue is not being addressed, an initiative will pop up to fill 


\section{Chapter 6}

in the gap. Perhaps dealing with intermittency is implicitly expected to be one of the factors which will play a role in the selection process of the accelleration stage. More generally, this would mean the technicalities are taken care of within the transition, and do not need any external management. But this is problematic. In studying energy transition dynamics, the boundaries of the study area are uncritically borrowed from the dominant conceptualization of energy transition as a transition of energy production. In this dissertation, it has been argued that when discussing energy practices in a broad sense, we end up speaking about matters that do not appear to relate to energy at first. Is rearranging your house to inspire retreating to a comfortable corner part of energy transition? Promoting bicycle tourism? Increasing comfort at lower temperatures through regular exercise?

Some of these may actually have an impact on energy transition, which would warrant the study of these initiatives. Then again, they may not. But this raises a problem for transition studies. If this field of research were only interested in describing transitions, one could, with the benefit of 20-20 hindsight, include such left-field initiatives after they have proven themselves. But transition studies aims also at managing or at least facilitating transitions. Tools such as strategic niche management, subsidies, incubators, and networking events are used to make the transition process a little less chaotic and uncertain. If such strategies are actually effective, the demarcations of 'relevant' and 'irrelevant' developments become a selffulfilling prophecy: those solutions that fit the dominant framing of the problem will be pushed forward and have the highest chance of survival. For the kind of reflection and experimentation with energy practices that I propose here to have any chance of impact, it needs to get a place at the table. But without a reflective attitude towards the question what is at stake in the energy transition, those who are able to offer that place are in no position to appreciate this broader perspective. And with substantial amounts of funding to distribute, the gate-keepers have ample reason to be critical of those claiming to be eligible for help for their wild ideas.

In other words, transition studies seems to be missing a procedure for defining the solution space of particular transitions that is capable of dealing with the variety of conceptualizations of the issues at stake that is typical of transitions. Transitions are pre-eminently situations in which it is unclear what is at stake, so this lack is highly problematic. The reason it is unable to provide such a procedure may be that transition studies is agnostic towards the particularities of the transition at hand: it assumes that no specific knowledge of the issue is needed to understand the development of the transition. At least in the case of energy transition this is 
problematic, and transition studies would benefit from developing a way to deal with this issue.

\subsection{Omissions and limitations}

\section{History and politics of energy}

Although I have emphasized the importance of considering the historical origins of the current energy system and practices when exploring possible alternatives, I have not been able to do justice to the complexities of the forces behind this. The business of energy production has created a number of very powerful players fighting over enormous stakes. Any pretention of a level playing field in which equal, rational actors can have a civilized conversation about energy transition would be a naive delusion. The extraction of fossil fuels and twentieth-century politics are deeply intertwined: the hegemony of western nation states has been enabled by oil, and the particular form of scarcity of fossil fuels has been the result of political, rather than technical, strategies and limitations (Mitchell, 2013). The lobbies that ensured the decommissioning of elegant public transport systems in US cities in the 1920s (Yago, 1984) have not since disappeared; their heirs now actively block taxing of aviation fuel, for example. Discussions on energy transition should be based on a proper understanding of such forces for at least three reasons.

First, although it may be appealing to scapegoat these businesses and lobbies and to uncover their tactics in order to ignite public outrage, these forces are, in fact, part of society. As Bill McKibben (2012) points out: through our savings, stocks, and pension funds, we are all heavily invested in these businesses that will try to do everything to keep extracting and selling fossil fuels no matter what. Recently there seems to be something of a turning point, with banks moving away from investments in (the dirtiest) fossil fuel projects (Milman, 2015), but we are still a long way from disentangling from these corporations. Whenever we see them obstructing developments towards energy transition, what we really see is part of ourselves being uncooperative.

Second, even if society would manage to shake off the particular power blocks that dominated energy policy in the fossil fuel era, it would only be reasonable to assume that new industries and lobbies would emerge. Whether these would revolve around scarce materials for solar panels, control over land mass and water for biomass production, management of electricity allocation in periods of scarcity, or something 


\section{Chapter 6}

else altogether, is hard to say. Still, it is most likely that providing society with the energy it needs to flourish will never be the only interest at play for the actors who do so; providing energy will also be a business, a political project, and a strategic goal.

Third, as Ruivenkamp (2015) points out, much like the intentions of designers are reflected in the designs of particular technological artifacts, the lop-sided power dynamics in society are also reflected in technological artifacts and systems. The energy technologies we have, and the energy practices we have developed around these technologies, are scripted with the society that created them. If society is to move forward towards more equity and inclusivity, for example, these scripts need to be recognized and challenged.

This broader context cannot be ignored, and indeed, the ultimate aims of this project would be helped by a further critical examination of these dynamics. A central question is how the forces outlined above could be effectively countered: how can those concerned with sustainability, climate change, and 'good' energy practices form an effective opposition to them? Perhaps an equivalent to the labor movements that emerged during the industrial revolution can be found in a coalition of environmental agencies, energy cooperatives, bicycling representatives, and various other groups that may find themselves united against a common opponent. Strong coalitions can achieve big things: recently a coalition of environmental agencies successfully filed a lawsuit against the Dutch government for not doing enough against climate change (Cox, 2016).

Some attention to groups and coalitions would thus have been interesting to include in this dissertation. However, this would have significantly increased its breadth, and therefore weakened its particular focus on energy practices and its relation to quality of life, a line of reasoning that I claim to be seriously underdeveloped and in need of broader appraisal. The focus on the individual (rather than social groups) is essential to this argument. After all, it is the individual who experiences their (well-)being in the world, and it is this individual experience that can be said to have a certain quality. The individual is of course situated within a society, just as they are situated within a particular technological context. An interesting parallel research project could focus on societal energy practices and how the health of societies may improve or deteriorate due to particular energy system arrangements. However, this would have been beyond the scope of this particular project. 
This is not to say that the insights in this dissertation are of no value to groups and actors concerned with the politics of energy transition. First, by broadening the scope of the discussion on energy transition, the potential range of coalition partners is broadened as well. Advocates for safety of pedestrians and cyclists do not usually frame their work in terms of low-energy traffic, but they do make these alternative practices of moving around possible (or more attractive). Second, the shift to practices and quality of life may be of particular value for debates on who is to decide on the available options. For example, in The Netherlands, building regulations make it difficult if not impossible to live 'off the grid' (Ministerie van Binnenlandse Zaken en Koninkrijksrelaties, 2011). If this was traditionally argued for in terms of a particular business arrangement in which the commitment of utility services to offer service to anyone is exchanged for the commitment of all citizens to chip in, one may now argue that more than business, having the choice to live off-grid means having the choice to live a particular way of life, with particular energy practices. Disallowing people to develop an alternative (and benevolent) lifestyle is a much bigger deal than disallowing them to make an alternative business arrangement. Third and finally, any political movement ultimately consists of individuals who are passionate about a particular cause. By inviting individuals to reflect on their own energy practices, this dissertation may start a fire that ignites these passions.

\section{Global and developmental concerns}

The focus in this dissertation has been rather single-mindedly on the West, the 'developed' world, North-America and Europe, the life-world of the author. There are a number of reasons for this. First, any strategy for mitigating climate change, dealing with decreasing fossil fuel reserves, or securing energy security, would need to deal with the specific situation in this part of the world: the region that has the largest energy consumption per capita, the largest historic emissions, and likely the largest financial and intellectual opportunities to develop alternatives - one simply cannot ignore this region. Second, focusing on energy practices, I have repeatedly explored phenomenological and more subjective elements in energy consumption, seducing the reader to play along and reflect on their own energy practices. This approach only works in contexts that are familiar to both the author and the audience. Considering myself a product of western society, writing at a western university for a western audience, this choice of focus also has a pragmatic grounding.

But that does not mean that other regions and other perspectives are of no importance. Energy transition is a global challenge, and any region or particular 


\section{Chapter 6}

society impacts and is impacted by others. Therefore, any feasible strategy for energy transition should consider its impact on other parts of the world. In addition, the particular situations and cultures make it impossible to develop one standard 'cookie-cutter' approach that fits everyone. Industrializing and growing nations such as China raise different concerns, African countries with (very) low access to energy need yet different approaches. This means that it is best to refrain from making any generalizing claims on sensible energy practices for all of humanity.

Still, there is a general quality to the philosophical approach of exploring the relationships between energy systems and particular artifacts on the one hand and practices and quality of life on the other. Not just in western society, but for humanity in general, the main goal of energy consumption is to achieve particular human goals. Anyone could benefit from asking whether their particular practices are contributing to these goals, and whether the structure of the energy system keeps users sufficiently free to develop their own goals, whatever they may be. Just like me and you, Chinese factory workers and Malawian subsistence farmers have their own energy practices. These will change when the Chinese government decides that rolling blackouts are necessary when network loads are too high, or when local entrepreneurs bring solar cookers or LED-lighting to a village.

The insights that such explorations lead to may well be very different depending on the context. Whereas chapter 5 has made the claim that good energy practices are likely to be low-energy practices, much research has shown that at the bottom of the list, an increase in energy consumption has direct and substantial positive effects to the quality of life (Mitcham and Rolston, 2013; Smil, 2010). Clearly, not everybody should reduce their energy consumption. But there is a further point to make: it is also likely that even for the very (energy-)poor, not every increase in energy consumption will improve their lives, or at least, not to the same extent. What changes can make the biggest impact? Which 'innovations' should not be pushed? Much like here in the West, deliberating energy practices elsewhere can have a positive impact on both quality of life, and the environment. I can only hope that people with the required expertise would pick up this challenge and develop work on 'global energy practices'.

Further, despite my concerns about specificities and the impossibility to directly copy insights in one context to another, there is another reason why 'global energy practices' may be important. Low- to medium-energy societies are successful in fulfilling all kinds of human goals with a lower energy input than high-energy societies. A qualitative appreciation of these energy-efficient practices may 
encourage 'reverse innovation' (Govindarajan et al., 2012) and adaptation of these practices to western contexts.

\section{Energy literacy beyond direct consumption}

Only a fraction of the energy used by society is consumed directly by end-users. Energy consumption is visible when we pay our energy bill or fill up the tank of our cars, but everything else we do also involves (indirect) energy consumption. Energy is expended on our behalf when we purchase food or electronics, when we use the built environment, when we watch a video on the internet or have a phone conversation, when we enjoy the weather forecast or protection from terrorism. The energy system and this indirect consumption are related as well: efforts to reduce energy consumption need to take indirect consumption into consideration; different energy systems will lead to different indirect energy consumption practices. Therefore, analogous to the arguments in this dissertation, it would make sense to have a discussion about the relative value of such practices as well.

However, this is a daunting task. In many cases, the particular ways in which energy is consumed in the making of a product or a service has little to do with our perception of those goods as end-users. Whether we stream a YouTube video through a mobile $4 \mathrm{G}$ network or through $\mathrm{WiFi}$ will matter little with regards to our enjoyment of the content, but the $4 \mathrm{G}$ network consumes on average 23 times more energy (Huang et al., 2012). The appeal to bodily experience in chapter 5 is irrelevant when the energy consumption takes place away from the user anyway.

There are some takeaways from this dissertation for such a discussion, though. The experiential gap, as described in chapter 3, seems appropriate to explain why consumers fail to choose energy-efficient alternatives to the goods they are looking for, even when they are interested in doing so. Chapter 4 may be illuminating to people contemplating consumer society in general: is the choice between finding ways to keep the industrial production machinery going and learning to do with as little stuff as possible, or can we go beyond this scarcity paradigm and question what kind of goods make our life better? Whether this analogy could in fact hold, is something for another project.

\section{A true integration of production and consumption}

In the introduction I mentioned that discussions on energy revolve too much around the production side: many of us talk about whether we rather have solar panels or 


\section{Chapter 6}

windmills, but not about how we want to consume our energy. I have aimed to show how production and consumption are intertwined; how particular energy systems invite or inhibit particular practices. In chapter 3 it is mentioned how some people become 'prosumers', producers and consumers at the same time, and that this may result in different practices because of the increased involvement in the energy system by its user.

However, the focus on energy practices in this dissertation has been almost exclusively on the consumption side: there has been talk on how particular ways of energy production lead to changing energy consumption practices, but there has been no consideration of practices of energy production. One could defend this asymmetry by arguing that it is the consumption that is of final importance, and the production is simply a means to an end, much like some jobs are just means to make money, and cutting an onion is just a means to make a tasteful dish. Nobody cuts onions as an end in itself. Likewise, energy production may be argued to be nothing but a means to provide society with the energy it needs. Indeed, I have done so numerous times in this dissertation.

But it would be good to at least consider the idea that there is more to it. Instrumentally, we could look into what kind of practices of energy production would promote societal deliberation on and involvement in the energy system and related energy (consumption) practices. If we take the relationships between the two seriously, it makes sense to explore the idea that not just the outcome of energy production matters (in terms of the quality and quantity of energy that becomes available for consumption), but also the way it came into being. For consumers of 'green' electricity, this indeed seems to be a concern: the electricity and its resulting practice of consumption is the same, but the origin is perceived to be different enough to change between providers of electricity.

Next to this instrumental reason, there may be some final quality to energy production. The long history of human energy use revolves around fire, cooking, agriculture, sailing ships, wind- and watermills, etc. These stages in human history have changed humanity, both biologically and culturally. Also, in all of this energy use, 'production' is part of the practice. We became both cooks and eaters of cooked food; both farmers and consumers of domesticated crops. Both sailors and beneficiaries of global trade. In this sense, we have now become both producers of oil as well as consumers of fossil fuels, except for the fact that we have subcontracted the drilling to a tiny fraction of humanity. As such, most of us have been cut off from the source of our energy-dense practices, and the kind of society and particular 
way of being human that is connected to it. Is it intrinsically valuable for a human to be knowledgeable about the fundamental processes that make their existence possible? Perhaps. Could it be that integrated energy practices (combining production and consumption) increase one's quality of life, in the same way that eating out of one's own garden is appreciated in itself? Maybe. Answering such questions may take an entire new $\mathrm{PhD}$ project, but this may then start by exploring various practices of energy production.

\subsection{Conclusion}

How to conclude something that is meant as a beginning? This project has never been about 'concluding' anything, but rather the focus has been on discovering new trails to explore and novel spaces to deliberate. The aim has been to reinvigorate and expand discussions on energy transition. To conclude, then, means to put our faith in the previous chapters, and to let them do their work. It is to stop talking and to become silent. To find out whether anyone is still listening, and to learn what kind of responses these arguments elicit. I must admit I have mixed feelings about ending this monologue and finding out what comes after.

Progress towards a renewable energy regime so far has been slow at best. In this dissertation, we have seen a number of reasons for this: current practices are tangled up with the forms and sources of energy that have helped create them, available alternatives are different from fossil fuels in important respects such as intermittency and concentration, and the shape of the energy network makes it particularly difficult for users to reflect on their impact. This is to say there is a large amount of inertia in the system, and actors are unlikely to excite it to jump into another mode.

However, we have also seen that the current mode of readily available, highly concentrated, large amounts of energy is not the only way to provide good lives for society. In fact it is likely there are better ways, using radically less energy and gaining a certain engagement with our surroundings. Because these ways remain hard to imagine for people living within the current dominant energy practices, the task is to find ways to start talking about energy practices in a variety of contexts. Only when we learn to discuss the nuances of energy consumption, we will be able to develop a system and practice that caters to human needs while respecting planetary boundaries. 


\section{Chapter 6}

The central message is thus a procedural one: a discussion on energy transition needs to be broader than is currently the case. The substantive points that have been made throughout this dissertation, on the importance of engagement, or the pleasures of riding bicycles, for example, are points I am willing to defend. But at the same time, they are ancillary to the procedural point. I welcome any rebuttal to my substantive ideas of 'good' energy practices, as that would mean we are already engaged in the broader discussion on energy transition.

So the arguments are there, and there are plenty of opportunities for taking up these arguments where I leave them. This is not the problem. My mixed feelings stem from the fact that despite a broad consensus among scientists that climate change is real and requires a radical response from society, climate negotiations have made only minor progress. That despite clear signs that much of the world does not benefit from further economic growth, the growth rhethoric in politics remains as strong as ever. That geoengineering, the practice of deliberately influencing climate (for example by emitting stratospheric aerosols to reflect sunlight), is slowly but surely being normalized as a viable 'Plan B' for when we find ourselves in a climate catastrophe. And that it seems unlikely that we would resist the temptation to actually deploy it when the time is there and it appears to be the lesser of two evils. If it ever comes to that, the risks are tremendous. The actual reaction of the climate system to such interventions is unknown, and probably unknowable (Shepherd, 2009).

My mixed feelings stem from the fact that while all of this is widely known, society still seems to be hell-bent on a business-as-usual approach, risks and uncertainties be damned. In light of all this, how can a sane person write a dissertation to add yet another voice to the energy debate, adding footnotes, nuance, and complexity that is only relevant after all that is currently being ignored is taken seriously? Why would it matter? What makes me believe I could make the difference?

I don't know. But if we are to ever make the difference, it will be because we have written and acted as if it were not too late, as if we could still make that difference. I like to pretend I still have that hope, and in the meantime at least I am learning how to properly spend the energy until it runs out. 




\section{Bibliography}

Anonymous (1998). Tapping into Fog. (June 15). Retrieved October 23, 2011, from http://archive.idrc.ca/Nayudamma/fogcatc_72e.html.

Anonymous (2016). Bewoners mopperen op hun Nul-op-de-Meter huurwoning. (January 25). Retrieved July 19, 2016, from https://www.energiekaart.net/bewoners-mopperen-op-hun-nom-huurwoning/.

Anonymous (n.d.). desertec | THE CONCEPT. Retrieved January 15, 2015, from http://www.desertec.org/\#!the-concept/bdnhj.

Asafu-Adjaye, J., Blomqvist, L., Brand, S., Brook, B., Defries, R., Ellis, E., Keith, D., Foreman, C., Lewis, M., Lynas, M., et al. (2015). An ECOMODERNIST Manifesto (Oakland: The Breakthrough Institute).

Barker, T., Bashmakov, I., Bernstein, L., Bogner, J.E., Bosch, P.R., Dave, R., Metz, B., and Nabuurs, G.J. (2009). Contribution of Working Group III to the Fourth Assessment Report of the IPCC: Technical Summary. In Climate Change 2007: Mitigation Contribution of Working Group III to the Fourth Assessment Report of the Intergovernmental Panel on Climate Change, Intergovernmental Panel on Climate Change, (Cambridge University Press), pp. 27-93.

Barrett, J., Peters, G., Wiedmann, T., Scott, K., Lenzen, M., Roelich, K., and Quéré, C.L. (2013). Consumption-based GHG emission accounting: a UK case study. Clim. Policy 13, 451-470.

Barton, J.P., and Infield, D.G. (2004). Energy storage and its use with intermittent renewable energy. IEEE Trans. Energy Convers. 19, 441-448.

Bataille, G. (1988). The Accursed Share: An Essay on General Economy (New York: Zone Books).

Bergh, J.C.J.M. van den, and Bruinsma, F.R. (2008). Managing the Transition to Renewable Energy: Theory and Practice from Local, Regional and Macro Perspectives (Edward Elgar Publishing). 


\section{Bibliography}

Blonk, H., Kool, A., Luske, B., and de Waart, S. (2008). Environmental effects of protein-rich food products in the Netherlands - Consequences of animal protein substitutes (Gouda: Blonk Milieuadvies).

Borgmann, A. (1987). Technology and the character of contemporary life: a philosophical inquiry (Chicago: University Of Chicago Press).

Borgmann, A. (2000). Reply to my critics. In Technology and the Good Life?, E. Higgs, A. Light, and D. Strong, eds. (Chicago: University Of Chicago Press), pp. 341-370.

Borgmann, A. (2002). Response to My Readers. Techné J. Soc. Philos. Technol. 6.

Borgmann, A. (2006). Real American Ethics: Taking Responsibility for Our Country (Chicago: University Of Chicago Press).

Botton, A. de (2002). The Art of Travel (New York: Pantheon).

Boyle, G. (2012). Renewable Electricity and the Grid: The Challenge of Variability (Earthscan).

Brey, P. (2010). Philosophy of Technology after the Empirical Turn. Techné Res. Philos. Technol. 14, 36-48.

Brey, P. (2016). Constructive Philosophy of Technology and Responsible Innovation. In Philosophy of Technology after the Empirical Turn, M. Franssen, P.E. Vermaas, P. Kroes, and A.W.M. Meijers, eds. (Springer International Publishing), pp. 127-143.

Briggle, A. (2008). Real friends: how the Internet can foster friendship. Ethics Inf. Technol. 10, 71-79.

Briggle, A., and Mitcham, C. (2009). Embedding and networking: conceptualizing experience in a technosociety. Technol. Soc. 31, 374-383.

Clastres, C. (2011). Smart grids: Another step towards competition, energy security and climate change objectives. Energy Policy 39, 5399-5408.

Club of Rome (1972). The Limits to Growth. N. Y. Universe.

Correljé, A., and van der Linde, C. (2006). Energy supply security and geopolitics: A European perspective. Energy Policy 34, 532-543. 
Cox, R. (2016). A climate change litigation precedent: Urgenda Foundation v The State of the Netherlands. J. Energy Nat. Resour. Law 34, 143-163.

Crisp, R. (2016). Well-Being. In The Stanford Encyclopedia of Philosophy, E.N. Zalta, ed.

De Decker, K. (2008). Information damages the environment.

De Decker, K. (2011). Informatie: een energievreter in opkomst. In Energie in 2030: maatschappelijke keuzes van nu, J. Ganzevles, R. van Est, and E. de Bakker, eds. (Boxtel: Æneas), pp. 67-82.

Dongen, H. van (2013). De lotgevallen van de energie. Filosofie 23, 34-39.

Dupuy, J.-P. (2002). Energy and the Mystery of Iniquity. In The Challenges of Ivan Illich: A Collective Reflection, L. Hoinacky, and C. Mitcham, eds. (New York: State University of New York Press), pp. 189-204.

Elgin, D.S., and Mitchell, A. (1977). Voluntary Simplicity: Life-Style of the Future? The Futurist 11, 254-261.

Ellsworth-Krebs, K., and Reid, L. (2016). Conceptualising energy prosumption: Exploring energy production, consumption and microgeneration in Scotland, UK. Environ. Plan. A 0308518X16649182.

Ellul, J. (1964). The Technological Society (New York: Vintage Books).

Foucault, M. (1984a). Histoire de la sexualité, vol. 3: Le souci de soi (Paris: Gallimard).

Foucault, M. (1984b). Histoire de la sexualité, vol. 2: L’usage Des Plaisirs (Paris: Gallimard).

Fowler, C. (2008). The Svalbard Seed Vault and Crop Security. BioScience 58, 190191.

Friedman, B., Kahn, P., and Borning, A. (2002). Value sensitive design: Theory and methods. Univ. Wash. Tech. Rep. 02-12.

Gambrel, J.C., and Cafaro, P. (2009). The Virtue of Simplicity. J. Agric. Environ. Ethics 23, 85-108. 


\section{Bibliography}

Geerts, R.-J. (2012). Self-Practices and the Experiential Gap: An Analysis of Moral Behavior around Electricity Consumption. Techné Res. Philos. Technol. 16, 94104.

Gehlen, A. (1980). Man in the Age of Technology (New York: Columbia University Press).

Gibson, J. (1977). The theory of affordances. In Perceiving, Acting, and Knowing, R. Shaw, and J. Bransford, eds. (Hoboken, NJ: John Wiley \& Sons Inc.), pp. 127143.

Govindarajan, V., Trimble, C., and Nooyi, I.K. (2012). Reverse Innovation: Create Far From Home, Win Everywhere (Boston: Harvard Business Review Press).

Greening, L.A., Greene, D.L., and Difiglio, C. (2000). Energy efficiency and consumption - the rebound effect - a survey. Energy Policy 28, 389-401.

Greer, J.M. (n.d.). The Archdruid Report. Retrieved April 22, 2016, from http://thearchdruidreport.blogspot.com/.

Grin, J., Rotmans, J., and Schot, J. (2010). Transitions to Sustainable Development: New Directions in the Study of Long Term Transformative Change (Routledge).

Hänggi, M. (2011). On the way to the 2000-watt society - Zurich's path to sustainble energy use (Zurich: City of Zurich, Office for Environmental and Health Protection Zurich (UGZ)).

Hanssen, L., de Vriend, H., and Gremmen, B. (2014). The role of biosolar technologies in future energy supply making scenarios for the Netherlands: Energy port and energy farm. Futures 63, 112-122.

Hardin, G. (1968). The Tragedy of the Commons. Science 162, 1243-1248.

Heidegger, M. (1977). Question Concerning Technology, and Other Essays, The (New York: Harper Torchbooks).

Heinberg, R. (2004). Powerdown: Options and Actions for a Post-Carbon World (Gabriola Island, BC: New Society Publishers).

Huang, J., Qian, F., Gerber, A., Mao, Z.M., Sen, S., and Spatscheck, O. (2012). A close examination of performance and power characteristics of $4 \mathrm{G}$ LTE networks. 
In Proceedings of the 10th International Conference on Mobile Systems, Applications, and Services, (ACM), pp. 225-238.

Hughes, T.P. (1993). Networks of Power: Electrification in Western Society, 18801930 (JHU Press).

Ihde, D. (1990). Technology and the Lifeworld: From Garden to Earth (Indiana Series in the Philosophy of Technology) (Indiana University Press).

Illich, I. (1973). Tools for Conviviality (London: Marion Boyars Publishers).

Illich, I. (1974). Energy and Equity (New York: Harper and Row).

Illich, I. (2013). The Social Construction of Energy. In Beyond Economics and Ecology: The Radical Thought of Ivan Illich, (London: Marion Boyars Publishers), pp. 105-123.

International Energy Agency (2015). 2015 Key World Energy Statistics (France: OECD/IEA).

International Human Powered Vehicle Association (n.d.). IHPCA Official Speed Records. $\quad$ Retrieved March 3, 2016, from http://www.ihpva.org/hpvarec3.htm\#nom27.

Ipakchi, A., and Albuyeh, F. (2009). Grid of the future. IEEE Power Energy Mag. 7, 52-62.

Jackson, T. (2011). Prosperity without Growth: Economics for a Finite Planet (London; Washington, DC: Routledge).

Jacobsson, S., and Lauber, V. (2006). The politics and policy of energy system transformation-explaining the German diffusion of renewable energy technology. Energy Policy 34, 256-276.

Jaffe, A.B., Newell, R.G., and Stavins, R.N. (1999). Energy-Efficient Technologies and Climate Change Policies: Issues and Evidence (Rochester, NY: Social Science Research Network).

Jevons, W.S. (2013). The Coal Question; An Inquiry Concerning the Progress of the Nation, and the Probable Exhaustion of Our Coal-Mines (HardPress Publishing). 


\section{Bibliography}

Kempton, W., and Tomić, J. (2005). Vehicle-to-grid power implementation: From stabilizing the grid to supporting large-scale renewable energy. J. Power Sources 144, 280-294.

Kern, F., and Smith, A. (2008). Restructuring energy systems for sustainability? Energy transition policy in the Netherlands. Energy Policy 36, 4093-4103.

Klein, N. (2014). This Changes Everything: Capitalism vs. the Climate (Allen Lane).

Latour, B. (1992). Where Are the Missing Masses? The Sociology of a Few Mundane Artifacts. In Shaping Technology/Building Society: Studies in Sociotechnical Change, W. Bijker, and J. Law, eds. (Cambridge, Mass.: MIT Press), pp. 225258.

Latour, B. (1993). We Have Never Been Modern (Cambridge, Mass: Harvard University Press).

Lilliestam, J., and Hanger, S. (2016). Shades of green: Centralisation, decentralisation and controversy among European renewable electricity visions. Energy Res. Soc. Sci. 17, 20-29.

Lindsay, R.B. (1971). The concept of energy and its early historical development. Found. Phys. 1, 383-393.

Lund, H., and Mathiesen, B.V. (2009). Energy system analysis of 100\% renewable energy systems-The case of Denmark in years 2030 and 2050. Energy 34, 524531.

MacKay, D.J. (2009). Sustainable Energy — without the hot air (Cambridge: UIT Cambridge Ltd.).

Malthus, T. (1999). An Essay on the Principle of Population (New York: Oxford University Press).

Matthijssen, E. (2014). Eco-kindjes | Green Evelien.

McKibben, B. (2012). Global Warming's Terrifying New Math. Roll. Stone.

Meijer, M., Adriaens, F., van der Linden, O., and Schik, W. (2011). A next step for sustainable urban design in the Netherlands. Cities 28, 536-544. 
Milman, O. (2015). ANZ “will not finance" dirty coal plants and pledges $\$ 10 \mathrm{bn}$ for clean energy. The Guardian.

Ministerie van Binnenlandse Zaken en Koninkrijksrelaties (2011). Bouwbesluit 2012.

Mitcham, C. (1991). Tools For Conviviality: Argument, Insight, Influence. In Europe, America, and Technology: Philosophical Perspectives, P.T. Durbin, ed. (Springer Netherlands), pp. 17-56.

Mitcham, C., and Rolston, J.S. (2013). Energy Constraints. Sci. Eng. Ethics 19, 313319.

Mitchell, T. (2013). Carbon Democracy: Political Power in the Age of Oil (London: Verso).

Moe, K. (2010). Thermally Active Surfaces in Architecture (New York: Princeton Architectural Press).

Mohd, A., Ortjohann, E., Schmelter, A., Hamsic, N., and Morton, D. (2008). Challenges in integrating distributed Energy storage systems into future smart grid. In 2008 IEEE International Symposium on Industrial Electronics, pp. 1627-1632.

Mumford, L. (2010). Technics and Civilization (Chicago; London: University Of Chicago Press).

Mwasilu, F., Justo, J.J., Kim, E.-K., Do, T.D., and Jung, J.-W. (2014). Electric vehicles and smart grid interaction: A review on vehicle to grid and renewable energy sources integration. Renew. Sustain. Energy Rev. 34, 501-516.

Pacala, S., and Socolow, R. (2004). Stabilization Wedges: Solving the Climate Problem for the Next 50 Years with Current Technologies. Science 305, 968-972.

Peters, G.P., Minx, J.C., Weber, C.L., and Edenhofer, O. (2011). Growth in emission transfers via international trade from 1990 to 2008. Proc. Natl. Acad. Sci. 108, 8903-8908.

Plessner, H. (1975). Die Stufen des Organischen und der Mensch: Einleitung in die philosophische Anthropologie (Berlin: de Gruyter).

Pollan, M. (2009). In Defense of Food: An Eater's Manifesto (Penguin Books). 


\section{Bibliography}

Postma, R. (2012). Doe het groen - Maar doe het dan wel slim. Interview Lex Hartman. NRC Handelsbl.

Purchase, R.L., and Groot, H.J.M. de (2015). Biosolar cells: global artificial photosynthesis needs responsive matrices with quantum coherent kinetic control for high yield. Interface Focus 5, 20150014.

Raupach, M.R., Marland, G., Ciais, P., Le Quere, C., Canadell, J.G., Klepper, G., and Field, C.B. (2007). Global and regional drivers of accelerating $\mathrm{CO}_{2}$ emissions. Proc. Natl. Acad. Sci. 104, 10288-10293.

Reek, J., Hellingwerf, K.J., Klein Lankhorst, R., and Harbinson, J. (2013). Bio solar solutions. Int. Innov. 66-69.

Richardson, D.B. (2013). Electric vehicles and the electric grid: A review of modeling approaches, Impacts, and renewable energy integration. Renew. Sustain. Energy Rev. 19, 247-254.

Rotmans, J. (2012). In het oog van de orkaan: Nederland in transitie (Æneas).

Ruivenkamp, G. (2015). Humanisering van technologie en de productie van het gemeenschappelijke (Amsterdam-Duivendrecht: Humanistics University Press).

Rupp, S. (2013). Considering energy: $E=m^{\wedge} 2=(\text { magic } x \text { culture })^{\wedge} 2$. In Cultures of Energy: Power, Practices, Technologies, S. Strauss, S. Rupp, and T. Love, eds. (Walnut Creek: Left Coast Press), pp. 79-95.

Sarewitz, D. (2004). How science makes environmental controversies worse. Environ. Sci. Policy 7, 385-403.

Saunders, H.D. (1992). The Khazzoom-Brookes Postulate and Neoclassical Growth. Energy J. 13, 131-148.

Schick, L., and Gad, C. (2015). Flexible and inflexible energy engagements-A study of the Danish Smart Grid Strategy. Energy Res. Soc. Sci. 9, 51-59.

Shah, S. (2006). Crude: The Story of Oil (New York: Seven Stories Press).

Shepherd, J.G. (2009). Geoengineering the climate: science, governance and uncertainty (London: The Royal Society).

Sieferle, R.P. (2010). The Subterranean Forest (Cambridge: White Horse Press). 
Simon, J.L. (1981). The Ultimate Resource (Princeton, NJ: Princeton University Press).

Simondon, G. (2012). Die Existenzweise technischer Objekte (Zürich: Diaphanes).

Singh, A., Pant, D., and Olsen, S.I. (2013). Life cycle assessment of renewable energy sources (Springer).

Skolimowski, D. (2005). Philosophy for a New Civilisation (New Delhi: Gyan Publishing House).

Smil, V. (2004). Enriching the Earth: Fritz Haber, Carl Bosch, and the Transformation of World Food Production (Cambridge, Mass.: The MIT Press).

Smil, V. (2007). Energy in Nature and Society: General Energetics of Complex Systems (Cambridge, Mass: The MIT Press).

Smil, V. (2010). Science, energy, ethics, and civilization. In Visions of Discovery New Light on Physics, Cosmology, and Consciousness, M.L. Cohen, A.J. Leggett, W.D. Phillips, and C.L. Harper, eds. (Cambridge: Cambridge University Press), pp. 709-729.

Soper, K. (2008). Alternative Hedonism, Cultural Theory and the Role of Aesthetic Revisioning. Cult. Stud. 22, 567-587.

Speth, J.G. (2009). The Bridge at the Edge of the World: Capitalism, the Environment, and Crossing from Crisis to Sustainability (New Haven: Yale University Press).

Steel, C. (2013). Hungry City: How Food Shapes Our Lives (Random House UK).

Steg, L. (1999). Verspilde energie?: wat doen en laten Nederlanders voor het milieu (Den Haag: Sociaal en Cultureel Planbureau).

Stern, N. (2007). Stern Review: The Economics of Climate Change - Introduction.

Stiegler, B. (1998). Technics and time: The fault of epimetheus (Stanford University Press).

Stoekl, A. (2007). Bataille's peak: energy, religion, and postsustainability (Minneapolis: University of Minnesota Press). 


\section{Bibliography}

Strauss, S., and Reeser, D. (2013). Siting, scale, and social capital: wind energy development in Wyoming. In Cultures of Energy: Power, Practices, Technologies, S. Strauss, S. Rupp, and T. Love, eds. (Left Coast Press), pp. 110-125.

al-sumaiti, A.S., Ahmed, M.H., and Salama, M.M.A. (2014). Smart Home Activities: A Literature Review. Electr. Power Compon. Syst. 42, 294-305.

Tatum, J.S. (1994). Technology and Values: Getting beyond the "Device Paradigm" Impasse. Sci. Technol. Hum. Values 19, 70-87.

Thaler, R., and Sunstein, C. (2008). Nudge: Improving decisions about health, wealth and happiness (Penguin).

Thompson, P.B. (2007). The Agricultural Ethics of Biofuels: A First Look. J. Agric. Environ. Ethics 21, 183-198.

Unruh, G.C. (2000). Understanding carbon lock-in. Energy Policy 28, 817-830.

Unruh, G.C. (2002). Escaping carbon lock-in. Energy Policy 30, 317-325.

Unruh, G.C., and Carrillo-Hermosilla, J. (2006). Globalizing carbon lock-in. Energy Policy 34, 1185-1197.

Verbeek, P.-P. (2005). What Things Do: Philosophical Reflections on Technology, Agency, and Design (University Park, PA: Penn State University Press).

Verbeek, P.-P. (2008). Obstetric Ultrasound and the Technological Mediation of Morality: A Postphenomenological Analysis. Hum. Stud. 31, 11-26.

Verbeek, P.-P. (2011). Moralizing Technology: Understanding and Designing the Morality of Things (Chicago ; London: University Of Chicago Press).

Verbeek, P.-P. (2015). Toward a Theory of Technological Mediation: A Program for Postphenomenological Research. In Technoscience and Postphenomenology: The Manhattan Papers, J.K.B.O. Friis, and R.P. Crease, eds. (London: Lexington Books), pp. 189-204.

Verbong, G., and Loorbach, D. (2012). Governing the Energy Transition: Reality, Illusion or Necessity? (Routledge).

Viardot, E. (2013). The role of cooperatives in overcoming the barriers to adoption of renewable energy. Energy Policy 63, 756-764. 
Weinberg, A.M. (2006). Can Technology Replace Social Engineering? In Technology and the Future, A.H. Teich, ed. (Belmont, CA: Thomson Wadsworth), pp. 2734.

Welten, R. (2013). Het ware leven is elders (Klement, Uitgeverij).

Wiedmann, T.O., Schandl, H., Lenzen, M., Moran, D., Suh, S., West, J., and Kanemoto, K. (2015). The material footprint of nations. Proc. Natl. Acad. Sci. 112, 6271-6276.

Wijffels, R.H., and Barbosa, M.J. (2010). An Outlook on Microalgal Biofuels. Science 329, 796-799.

Wrangham, R. (2010). Catching Fire: How Cooking Made Us Human (New York: Basic Books).

Wrigley, E.A. (2010). Energy and the English Industrial Revolution (Cambridge University Press).

Yago, G. (1984). The Decline of Transit: Urban Transportation in German and U.S. Cities, 1900-1970 (Cambridge University Press). 



\section{Summary}

How can philosophy of technology guide the emerging energy transition? This is the question I have tried to answer in this dissertation. The question is pertinent because in response to climate change, resource scarcity, local environmental issues, and concerns of national security, many initiatives are emerging aimed at changing in one way or another the system that powers our society. However, these initiatives often make slow progress, have conflicting visions of the required direction, and tend to focus on technological developments, rather than techno-social change. A philosophical perspective in general can point at possibly problematic implicit assumptions, aid discussions by introducing concepts and distinctions, and broaden the debate by embedding the issue in a broader context. In the case of energy transition, it can point out how the current energy system inhibits the rise of the 'ethical consumer', why and how to move beyond the dominance of scarcity in discussions on energy transition, and how we may learn to appreciate energy consumption not just in terms of quantity, but also and especially in terms of quality and experience. Or so I claim in this dissertation.

In the introduction, it is pointed out that exosomatic (outside of the body) energy use started with the use of fire and the cooking of food, and enabled humanity to enroll a much larger range of energy sources to achieve their goals than was otherwise possible. The 'energy system' must therefore not be understood as limited to the oil-, gas-, and electricity-industry, but as involving the entire network of technologies and organizations that enables energy use, from power plants and grids to kitchen appliances and from oil fields to highways and the tendency to commute to work. This broad range of relevant elements, shifting between the levels of artifacts, technical systems, and societal arrangements, causes me to borrow from a range of approaches in philosophy and history of technology, as well as energy research and transition studies. The result is a first exploration of promising routes into what may in the future become the field of philosophy of energy.

But before embarking on this explorative journey, chapter 2 looks backward and connects the current aims to some earlier work on energy, energy in society, and energy transition. A philosophical approach can fill the gap between the 'greenwashing police' of empirical critique on energy transition initiatives and the 
social science critique of 'soft impacts' of technological developments, by connecting particularities of the energy system with its functioning in society. Three twentieth century philosophers provide us with valuable perspectives here. Lewis Mumford describes energy use in four stages towards society's goal of producing something lasting: conversion, production, consumption, and creation. He suggests that efficiency in one of these stages is not worth much on its own - the whole process is what counts if we are to assess and improve upon society's energy system. Georges Bataille is not at all interested in efficiencies, and sees energy simply as life's way to deal with the excess that the sun gifts us. For him, the point is not to ever increase the flow of energy in society, but to embrace its squandering in the most satisfying way possible. Martin Heidegger, finally, may have seen modern energy systems as the ultimate form of having nature as a standing reserve, ready at our command.

Together, functioning as 'orienting perspectives', these thinkers show that there is a complexity behind the concept of energy that usually remains unexamined in discussions on energy transition. Energy can be interpreted in many ways, and these interpretations allow us to see different issues when approaching energy transition. But it also becomes clear that these ('classic') perspectives lack a certain refinement when it comes to particular energy technologies and practices. Whereas for Heidegger any form of energy in modern society is to be understood as a 'standing reserve', I claim that there are important differences between for example solar power and electricity from coal-fired power plants. Analogous to the empirical turn in philosophy of technology, focusing on artifacts rather than 'capital T-technology', a constructive philosophical perspective on energy needs to look at particular elements in and arrangements of energy systems, rather than 'capital E-energy'.

The chapter concludes with a first practical suggestion for an expansion of the discussion on energy transition. Via the work of Heidegger it is proposed that energy is currently conceptualized both as flux and as potentiality, and that there is a tension between the two that comes to the fore in the problem of intermittency of renewable energy sources. Energy is 'flux' when it is flowing, doing work, being used, effecting change. It is 'potentiality' when it is stored, waiting to be used, available. The problem of intermittency occurs because wind and solar power emerge as flux, unlike fossil fuels which emerge as potentiality. It is argued that Mumford's theory of four stages in energy use opens up a solution space for intermittency beyond the currently popular and technically complex attempts at energy storage: we can also 'store' part of our energy as produced goods or postponed consumption when continuous availability of electricity turns out to be difficult to maintain. 
Whereas the example in chapter 2 focuses on production, chapter 3 provides insights in the context of energy consumption. Specifically, it is argued that the invisibility of electricity during its consumption holds an important key to the question why people fail to reflect on their energy consumption. The chapter explores the phenomenology of electricity consumption in relation to the ability of the consumer to develop an ethical position on the matter. An 'experiential gap' makes a large part of the electric system invisible, and according to Foucault's work on self practices, this invisibility makes it impossible to morally relate to the practice: ethical behavior can only be built from the relation with the morally relevant environment. The complex and opaque electrical network thus makes 'ethical consumption' particularly difficult, because it is difficult to develop a 'relation' to it at all, ethical or otherwise. This insight provides a robust reason for the poor results of efforts that aim at moralizing energy consumption, despite the fact there are plenty of arguments for reducing energy consumption from any theoretical ethical perspective.

The chapter also explores the consequences of this situation. Simpler and more transparent energy systems could enable ethical engagement, but at the cost of decreased usability: ethical behavior demands that the problem 'gets in the way', but when using technology the user needs the medium to dissolve in the practice. It makes sense to then suggest that through re-design of both the hidden parts of the system and end-user artifacts, the desired morality may be embedded in the energy system. However, with users still not being engaged, the democratic foundation to justify such actions is not easily obtained. If not through energy practices themselves, perhaps consumers can be made sensitive to these issues via discussions that are already taking place: the debates around energy transition at the systemic level. A space for constructive reflection can be created by showing how those debates need a more refined understanding of energy practices to go forward. This is one of the aims of the next two chapters.

After the focus on the two poles of energy practices, chapter 4 revolves around debates on energy transition. It suggests that in many discussions on energy transition, energy is approached as a scarce commodity. Chapter 4 argues that the dominant lines of reasoning I call 'boundless consumerism' and 'eco-frugality' both hold that the principles of scarcity govern the energy available to us, and that in focusing on this scarcity they emphasize that in essence, energy transition is a management problem. The difference between the two lines lies merely in the question whether growth remains possible in the face of this scarcity. Boundless consumerism argues that growth will remain possible via efficiency improvements 
and novel energy technologies; eco-frugality argues that instead, consumption should decrease radically by making energy conservation a central aspect of our lives. This focus on scarcity and how to manage it obscures the deeper reason why society is interested in energy at all: the ways in which energy use is supposed to cater to society's needs and enable people to flourish as human beings.

By looking at the understandings of the good life that are implicit in the lines of reasoning focused on this scarcity, it becomes clear that both miss the mark. Boundless consumerism has already proven to be ineffective: over the last half century, growing energy consumption has not led to greater subjective well-being in the western world. Eco-frugality meanwhile focuses our attention on everything we cannot do: a protestant ethic without the appeal of a good afterlife. The way forward, it is proposed, is by introducing a third line of reasoning in the debate: qualitative abundance. This line focuses first on good energy practices rather than on efficiency and savings, in the expectation that good energy practices often also tend to be low-energy practices. By introducing and theorizing this third line of argument, two concerns beyond scarcity are added to the debate. Between qualitative abundance and boundless consumerism, a discourse on the notion of prosperity emerges, inviting discussion on what exactly makes a particular practice of energy consumption contribute to well-being. Between qualitative abundance and ecofrugality, questions concerning simplicity emerge: where and how do we find a balance between simplifying for our own good, and for the endless concern of environmental impact? Both prosperity and simplicity are valuable concepts to expand the discussion on energy transition if we are concerned not just with a sustainable energy system, but also with one that caters to our well-being.

Chapter 5 takes up the challenge to further develop the idea of low-energy good living in a constructive way: why does increased energy consumption often fail to improve well-being, and what kind of energy practice would increase quality of life? It does so by exploring the work of Ivan Illich and Albert Borgmann, who have developed different but complementary critiques of the effectiveness of industrial society to provide for human needs. Illich looks at society in general and provides a compelling narrative on how a narrow focus on efficiency becomes counterproductive. Borgmann starts with the individual, and argues that embodied engagement with our environment is crucial for our well-being.

Borgmann's analysis is here extended with the insight that such embodied engagement is always low-energy: we experience the world through our body, and not through our 'extended body' of machinery. If one accepts the premise that 
engagement is central to the good life, it becomes clear that energy consuming technology can only be used to support the good life, and not be central to it. Because our expanding energy consumption is precisely through these tools and machines we surround ourselves with, we must conclude that much of our energy consumption is misguided and superfluous. Combined with Illich' cautionary remarks on counterproductivity, this misguided consumption is not merely wasteful, but actually detrimental to the good life.

In tandem, Borgmann and Illich provide a strong case for a substantial reconsideration of many energy practices. They invite us to look at consumption in the larger context in which it takes place, and to distinguish between different forms of consumption as qualitatively (rather than only quantitatively) different. Although not indisputable when it comes to the particular conception of the good life, this line of argumentation shows that it is at least possible to discuss the relative merits of various kinds of energy practices. Because the main concern is with having a discussion in the first place, rather than with promoting a particular vision, this possibility for dispute may even be seen as a benefit, as it invites responses. Engaging in such discussions cannot but lead to more nuanced statements than the 'more is better' or 'energy savings are holy' rhetorics that so often dominate the conversation. It becomes clear that depending on the aims, particular energy systems may be more or less appropriate. Questions on energy transition should therefore not only focus on how much energy a society needs, but also on what kind of energy is needed: the particularities become central to the question of energy transition, rather than merely related to it.

Chapter 6 takes stock of the insights gained. After a summary of the main arguments and answers to the research questions, it is pointed out how such insights may be used. The insights that resulted from a philosophical reflection on energy transition enable a much broader vocabulary for discussion and an expanded 'solution space' for energy practices to develop. Programs on energy research could become more sensitive to the connections between energy production and consumption, and think beyond the easy adaptation of 'drop-in technologies' as neutral means and towards attention for final goals and the most appropriate energy system to reach them. Energy users are invited to become better aware of the many alternatives for conventional energy practices that may increase their well-being while reducing their environmental impact and resource usage.

Although these and other changes will not dissolve the energy dependence of society, they may increase its resilience in case of crisis, and in the meantime reduce 


\section{Summary}

air pollution, inequality, obesity, and other social concerns. There seems to be very little reason indeed not to start reflecting on the ways in which we are and should be using energy.

The central message is thus a procedural one: a discussion on energy transition needs to be broader than is currently the case. I am willing to defend the substantive points that are made throughout this dissertation (on the importance of engagement, or the pleasures of riding bicycles, for example), but they are ancillary to the procedural point. Any rebuttal to the substantive ideas of 'good' energy practices put forward here are welcomed, as that would mean we are already engaged in the expanded discussion on energy transition that this dissertation is aimed at initiating. 




\section{Acknowledgements}

It's impossible to properly express my gratitude to everyone who made this project possible and enjoyable, let alone to do so in a few pages of name-dropping. But this is the format that I'm offered, so I'll just have to make do and hope that the reader understands that this is most likely incomplete and inadequate to explain what you all meant to me. Before I begin with anyone in particular I should say that the most central thread throughout this process has been that wherever I looked, whether it was friends I'd known for years or people I'd just met, I was faced with an unending trust and confidence in me that has been so overwhelming that by now I almost start to believe in it myself. This has helped me tremendously, and has been the single most important thing to get me through this. Thank you, and please don't stop.

With that off my chest, I should thank my advisors, Bart, Josette, and Guido. Right from the beginning, they've offered me a safe environment in which I could grow and shape the project in a direction that fit me. They offered me lots of space while still lending a helping hand when I got stuck, and this was just the right thing for me. Bart, thank you for many valuable discussions and for knowing where to push to show the flex in my arguments so I could reinforce them. Josette, thanks for all your encouragements and advice on how to remain standing in the academic environment. Guido, thank you for keeping me sharp throughout the project, and for continuing to ask questions, even when I thought I'd had enough. I'm still learning because of them.

But this is not where the journey started. During my masters' in Twente I learned much to prepare me for working on a dissertation, and especially the insights and encouragement from Johnny Søraker, Pak Wong, Tsjalling Swierstra, Adam Briggle, and Peter-Paul Verbeek made me believe that this may be a thing I could do. Johnny, thanks for making me submit that first paper to Techné. Adam, thank you for making it possible to come to Denton for a bit and pretend to be a grad student before I was. Peter-Paul, thank you for leading me to Pieter Lemmens, which turned out to be a quicker route to a $\mathrm{PhD}$ project than I could have ever imagined. 
The shift to Wageningen was made easy thanks to some fantastic colleagues. I fondly remember both the 'old days' with META, thanks to Reginald, Paul, Lebeyesus, Douwe, and Karen, and the 'new era' in the Philosophy Chairgroup thanks to Henk, Leon, Cor, Bernice, Marcel, Tjidde, Beatrijs, Jacqueline, Stas, and Koen. From complaints about awful coffee machines to discussing each other's work, I got everything I could wish for in colleagues. Tjidde and Beatrijs, thank you for having been great roommates, and for willing to protect me from violent opponents during my defense. Also, I should thank Inge, Sylvia, Bea, Vera, Mirjam, Carlotte, and the rest of the secretariat - without whom we would all be lost.

Besides my home department in Wageningen, I really enjoyed hanging out with the neighbors as well. This is where the boundary between colleagues and friends quickly starts crumbling - the PhD life seems to lead to situations in which the emphasis continuously shifts between 'PhD' and 'life'. Downstairs at RSO it was always good to run into Simona, Femke, Esther, Gina, Pieter, and others, while around the corner at COM it was great to get to know Tim, Marie, Bob and (when she didn't feel like a philosopher) Stas. No thanks for never introducing me to Hanneke, though. Simona and Esther, thank you for organizing a wonderfully interesting and convivial seminar with me. Esther, Femke, and Muriel, thanks for being my go-to $\mathrm{PhD}$ support group right from the beginning, and Simona, thank you for having been my best Wageningen friend for a long time - I hope our paths will continue to cross each other every now and then.

Some of the most stimulating meetings in Wageningen were not really related to any particular department. The homeotechnology/biomimicry reading group has been so interesting exactly because the members came from different environments. I thank Vincent Blok, Pieter Lemmens (especially these two in opposition), Jochem Zwier, Mithun Bantwal Rao, Bart Gremmen, Guido Ruivenkamp, Clemens Driessen, and others for contributing to this valuable and enjoyable discussion environment. Jochem, Vincent, and Pieter, thank you also for allowing me to tag along to the first productive output from this group, writing together has been a valuable learning experience. Jochem, Pieter, and Mithun, thank you for the more modest but equally interesting reading-and-espresso group on Simondon in Nijmegen. I look forward to being able to return to these meetings at some point in the future.

With these reading groups, I'm starting to move in the direction of (geographically) more distant neighbors, who have been no less of a support during these years. Jochem, thanks for being a great friend, and for having joined me on a parallel 
journey. Our talks about writing struggles, journals, conferences, coffee makers and generally growing up have been indispensable. You're almost there too, I'm cheering for you at the finish line. Zoë Robaey, Jan Bergen, Cees Zweistra, and Tim Meijers, it was great to have met you in Barchem during the OZSW summer school, and even better to run into you later at various conferences or when we happened to visit each other's departments. In Eindhoven, I thank Gunter Bombaerts, Nick Verkade, Andreas Spahn, Auke Pols, Sven Diekmann, and others for their support in the final year of this project.

Next to the financial support, which is gratefully acknowledged, the BioSolarCells organization also provided me with some truly valuable meetings and discussions. I thank Huib de Vriend, Lucien Hanssen, Coen van der Giesen, David Louwrier, Jan Dekker, Huub de Groot, Rene Kleijn, Rob Zwijnenberg, and others for critical and always constructive meetings as well as good company during the annual conferences.

I should also thank the people at Breet Bikes here. Johan, Ivo, Vincent, Helmer, and Martin, thanks for awakening a deeper appreciation for cycling - and therefore intimate energy consumption - than I'd known before. Discussing material and adventures with you has been just as formative for this project as the time I spent reading books; never mind the insights that emerged from the long solitary bike rides that all this enabled.

A special period has been my time in Colorado - a time in which theory and practice proceeded to become an inextricable jumble, which enabled me for the first time to see where the project was heading. Carl Mitcham, thank you for your hospitality, your insights, your useful pointers towards interesting thinkers, our many discussions, and for allowing me to tag along for a while to see what the Colorado academic life is like. Brian Zaharatos, thanks for being a great friend and for showing me around the Denver area and beyond - I hope I can one day return the favor. Phil Cafaro and Albert Borgmann, thank you for carving out some time for me. Our conversations meant a lot to me, and to the development of chapters 4 and 5. Tom Hornbein and Norm Milleron, thank you for the brief time we got to spend together. Our chance encounter is one of the best things that happened to me in this already amazing period. Michael Moriarty, Brandon Johnson, David Fox, and the Golden Mountain Runners, thank you for showing me what trail-running is about. Kate Denninger, thank you for unforgettable mountain adventures, and Kevin, thank you for wonderful bike rides. I should also thank the crew and the regulars at Café 13 for consistently kick-starting my days with conviviality and caffeine. 
The home stretch has not been easy, partly because of the great but demanding job I was offered in Twente. I thank Ciano, Philip, Peter-Paul, Saskia, Brandt, and others, perhaps not for the work load, but at least for the spirit and the encouragement they provided to get me to the finish line. I look forward to finally being allowed officially to do what I was hired for.

Gratitude also goes out to mom and dad, who have always supported along the way. Even when my study choices were at times rather puzzling to you, or when things didn't progress as quickly as you would have liked, you've always been a solid fundament to whatever I've been building. Thank you for being my stable basis. Suzanne and Marco, Oma, uncles and aunts, and Henk and Sytske, thanks for your interest and support. A special word of gratitude should go out to Angela, who's been crucial for me to learn to follow my heart, first into philosophy and then during the first half of this project. Thank you for growing up together, I'm proud of the part of our journeys that we got to spend side-by-side. My heart also opened up through music. Casper, Roland, Friso, Wilbert, Ruben, and Robin, thank you for having been part of Captain. For a long time, summoning this beast every week was the perfect ritual to avoid getting stuck in my mind. Ruben, thank you for the similar effect of our 'vrijmiro's' lately, they're growing to be something to look forward to every week.

My dearest Hanneke, I started these acknowledgments with saying it's impossible to properly express my gratitude to all the people who helped me out along the way, and I saved the hardest bit for the end, because you truly mean the world to me. Thank you for being the love of my life. We started off as writing buddies, and because the writing went so well we thought it would be best to not let 'feelings' get in the way. The forces of nature found their way of course, but instead of making things complicated, you've been a better thesis buddy (or really, thesis co-pilot) than I could have hoped for. Thank you for supporting me through long writing sessions, encouraging me to keep things in motion, guiding me through the minefield of deadlines, milestones, and revisions, and taking the lead with the lay-out and printing. I'm super proud that my little book can now sit next to yours in our book cases. And with these projects out of the way, I look forward to the next one - it's time to start planning our wedding day, birtanem! 

Robert-Jan Geerts

Wageningen School of Social Sciences (WASS)

Completed Training and Supervision Plan

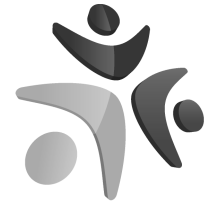

Wageningen School

of Social Sciences

\section{Name of the learning activity \\ Department/Institute \\ Year ECTS*}

A) Project related competences

Purefood - Contemporary

agrifood studies

Ethics of the Green Future

Summer School

Thesis Proposal writing
Wageningen School of Social 2011

6

Sciences (WASS)

Onderzoeksschool Ethiek 2012

6

(OZSE)

WASS

2012

5

B) General research related competences
WASS

2011

2014

2011-

2015

Radboud University,

2013-

2014

Nijmegen

2012-

2014

2012

European Society for

Agricultural and Food Ethics

(EurSAFE) Conference,

Tübingen, Germany

'Flux, potentiality, and energy neutrality - on energy conceptions and sustainability'

'Energy Transition for the Good Life'

'The eternally hungry extended human - on philosophical anthropology and environmental limits'
Society for Philosophy and

2013

1

Technology (SPT) conference, Lisbon, Portugal

16th International

2014

1

Conference on Ethics Across the Curriculum at ASU, Scottsdale, Arizona, USA

Society for Philosophy and

2015

1
Technology (SPT) conference at NEU, Shenyang, China 


\section{C) Career related competences/personal development}

\begin{tabular}{|c|c|c|}
\hline Workshop Presentation Skills & WUR Language Centre & 2012 \\
\hline $\begin{array}{l}\text { Process coach for Academic } \\
\text { Consultancy Training }\end{array}$ & WUR & 2012 \\
\hline $\begin{array}{l}\text { Teaching: Philosophy of Science } \\
\text { \& Technology and Ethics for } \\
\text { Landscape Architects and } \\
\text { Planners }\end{array}$ & WUR & $\begin{array}{l}2014- \\
2015\end{array}$ \\
\hline $\begin{array}{l}\text { Teaching: Ethics, Philosophy of } \\
\text { Science, and Philosophy of } \\
\text { Technology for Environmental } \\
\text { Scientists }\end{array}$ & WUR & 2014 \\
\hline $\begin{array}{l}\text { 'Voluntary Simplicity in Food } \\
\text { Choices. A Seminar to Navigate } \\
\text { Through Theory and Practices of } \\
\text { responsible food consumption' }\end{array}$ & $\begin{array}{l}\text { Organization WASS thematic } \\
\text { activity }\end{array}$ & 2013 \\
\hline
\end{tabular}

Total

* One credit according to ECTS is on average equivalent to 28 hours of study load 


\section{Colofon}

The research described in this thesis was funded by BioSolarCells.

Financial support from Wageningen University for printing this thesis is gratefully acknowledged.

Copyright (C) 2017, Robert-Jan Geerts, Enschede.

All rights reserved. No part of this publication may be reproduced, stored in a retrieval database or published in any form or by any means, electronic, mechanical or photocopying, recording or otherwise, without the prior written permission of the publisher.

Contact: robertjangeerts@gmail.com

Cover photo and design: Robert-Jan Geerts

Lay-out: Hanneke Nijland

Printed by Digiforce Vianen 